Prepared for the U.S. Department of Energy

Under Contract DE-AC05-76RL01830

\title{
T Tank Farm Interim Surface Barrier Demonstration - Vadose Zone Monitoring FY08 Report
}

\section{ZF Zhang CE Strickland}

Pacific Northwest National Laboratory

JG Field DL Parker

Washington River Protection Solutions, Inc.

January 2009 


\title{
DISCLAIMER
}

This report was prepared as an account of work sponsored by an agency of the United States Government. Neither the United States Government nor any agency thereof, nor Battelle Memorial Institute, nor any of their employees, makes any warranty, express or implied, or assumes any legal liability or responsibility for the accuracy, completeness, or usefulness of any information, apparatus, product, or process disclosed, or represents that its use would not infringe privately owned rights. Reference herein to any specific commercial product, process, or service by trade name, trademark, manufacturer, or otherwise does not necessarily constitute or imply its endorsement, recommendation, or favoring by the United States Government or any agency thereof, or Battelle Memorial Institute. The views and opinions of authors expressed herein do not necessarily state or reflect those of the United States Government or any agency thereof.

\author{
PACIFIC NORTHWEST NATIONAL LABORATORY \\ operated by \\ BATTELLE \\ for the \\ UNITED STATES DEPARTMENT OF ENERGY \\ under Contract DE-AC05-76RL01830
}

Printed in the United States of America

Available to DOE and DOE contractors from the

Office of Scientific and Technical Information,

P.O. Box 62, Oak Ridge, TN 37831-0062;

ph: (865) 576-8401

fax: (865) 576-5728

email: reports@adonis.osti.gov

Available to the public from the National Technical Information Service,

U.S. Department of Commerce, 5285 Port Royal Rd., Springfield, VA 22161

ph: (800) 553-6847

fax: (703) 605-6900

email: orders@ntis.fedworld.gov

online ordering: http://www.ntis.gov/ordering.htm 


\section{T Tank Farm Interim Surface Barrier Demonstration - Vadose Zone Monitoring FY08 Report}

ZF Zhang CE Strickland

Pacific Northwest National Laboratory

JG Field DL Parker

Washington River Protection Solutions, Inc.

January 2009

Prepared for

the U.S. Department of Energy

under Contract DE-AC05-76RL01830

Pacific Northwest National Laboratory

Richland, Washington 99352 



\section{Executive Summary}

DOE's Office of River Protection constructed a temporary surface barrier over a portion of the T Tank Farm as part of the T Farm Interim Surface Barrier Demonstration Project. The surface barrier is designed to minimize the infiltration of precipitation into the contaminated soil zone created by the Tank T-106 leak and minimize movement of the contamination. As part of the demonstration effort, vadose zone moisture is being monitored to assess the effectiveness of the barrier at reducing soil moisture. A solar-powered system was installed to continuously monitor soil water conditions at four locations (i.e., instrument Nests A, B, C, and D) beneath the barrier and outside the barrier footprint as well as site meteorological conditions. Nest A is placed in the area outside the barrier footprint and serves as a control, providing subsurface conditions outside the influence of the surface barrier. Nest B provides subsurface measurements to assess surface-barrier edge effects. Nests $C$ and D are used to assess changes in soil-moisture conditions beneath the interim surface barrier.

A timeline showing major events of monitoring system installation, data logging, and the surface barrier construction is given below:

- September 2006: Completed the installation of instruments in Nests A and B and the T Tank Farm meteorological station; started data logging from instruments in Nests A and B and the T Farm meteorological station

- June 2007: Completed the installation of instruments in Nests C and D

- April 2008: Completed the construction of the interim surface barrier

- May 2008: Instruments in Nests C and D were hooked up for data logging.

Each instrument nest is composed of a capacitance probe with multiple sensors, multiple heat-dissipation units (HDUs), and a neutron probe (NP) access tube. Nests A and B also each contained a drain gauge. The principal variables monitored for this purpose are soil-water content, soil-water pressure, and soilwater flux. Per the recommendations in the FY07 Report, the drain gauges were not used for soil water flux measurement. Soil temperature, precipitation, and air temperature are also measured. The following table summarizes the monitoring instruments and variables, instrument nests, measurement points, and monitoring frequencies:

\begin{tabular}{||c|c|c|c|c||}
\hline $\begin{array}{c}\text { Monitoring } \\
\text { Instrument }\end{array}$ & Monitoring Variable & $\begin{array}{c}\text { Instrument } \\
\text { Placement } \\
\text { (Nest) }\end{array}$ & $\begin{array}{c}\text { Actual } \\
\text { Depth of Sensors/ } \\
\text { Measurement Points }\end{array}$ & $\begin{array}{c}\text { Monitoring } \\
\text { Frequency }\end{array}$ \\
\hline Neutron Moisture Probe & Soil-water content & A, B, C, D & $\begin{array}{c}0.6,0.9,1.3,1.8, \text { and } \\
2.3 \mathrm{~m}\end{array}$ & Quarterly \\
\hline Capacitance Probe & Soil-water content & A, B, C, D & $\begin{array}{c}\text { From } 1 \text { to } 50 \mathrm{ft} \text { bgs at } \\
1-\mathrm{ft} \text { interval }\end{array}$ & Hourly \\
\hline Heat Dissipation Unit & Soil-Water Pressure & $\mathrm{A}, \mathrm{B}, \mathrm{C}, \mathrm{D}$ & $1,2,5$, and 9 or $10 \mathrm{~m}$ & Every 6 hours \\
\hline Heat Dissipation Unit & Soil Temperature & A, B, C, D & $1,2,5$, and 9 or $10 \mathrm{~m}$ & Every 6 hours \\
\hline Rain Gauge & Precipitation & Met Station & - & $\begin{array}{c}\text { Every } 15 \\
\text { minutes }\end{array}$ \\
\hline Thermistor & Air Temperature & Met Station & - & $\begin{array}{c}\text { Every } 15 \\
\text { minutes }\end{array}$ \\
\hline \hline
\end{tabular}

Each instrument nest is designed to have its own data logger, the data from which are transmitted remotely to the receiving computer. The neutron-probe access tube is used to perform quarterly manual measurements of soil-water content using a neutron probe. All equipment was functional except for the 
capacitance probe in Nest A after January 31, 2008. The monitoring results in FY08 are summarized below.

According to the data from Nest B, the soil-water content was increasing since late November 2007 and reached the maximum in late February 2008, followed by a slight decrease. At the 0.6-m depth, there were two fast increases in soil-water content in late November and mid-February, respectively. These increases were also observed at the $0.9-\mathrm{m}$ depth. At the $1.3-\mathrm{m}$ depth and deeper, the soil-water contents were relatively stable during FY08. For Nests C and D, the soil-water content at all depths showed a slight decreasing trend from May to September 2008.

The neutron-probe measurements show that the normalized neutron counts had relatively large temporal variation in the soil above $5 \mathrm{ft}(1.52 \mathrm{~m}) \mathrm{bgs}$ but smaller variation in the deeper soil. For all the instrument nests, the soil was wetting from October 2007 to April 2008 but was drying from April to July 2008.

Based on the results from Nests A and B, the heat-dissipation-unit sensors at the 1.0-m depth showed a significant increase in soil-water pressures in late November or early December 2007, which indicate increased water content. The sensors at the $2.0-\mathrm{m}$ depth showed increased soil-water pressures from January to late February or early March 2008 before they started decreasing. The soil-water pressures at 5- and 10-m (9-m for Nest C) depths were relatively stable.

Generally, the capacitance probes, neutron probes, and HDUs showed results that were consistent with the weather conditions and the water addition during barrier construction. The soil above $\sim 1$ meter $(\mathrm{m})$ bgs became wetter in the fall of 2007 (when water was sprinkled on ground surface) and winter of 2008 (under wet and cool weather conditions), and drier in the spring and summer of 2008 (under dry and hot weather conditions); the soil from $\sim 1$ to $\sim 2 \mathrm{~m}$ bgs showed similar seasonal variation but within a smaller range; and the soil-water conditions below $\sim 2 \mathrm{~m}$ bgs were relatively stable.

The construction of the surface barrier was completed in the April 2008. During the period from May to September 2008, the water content from the capacitance probes, neutron count ratio (as an indication of soil water content) from the neutron probe, and the soil-water-pressure head from the HDUs in Nests B, C and $\mathrm{D}$ showed that the soil beneath the barrier with the 0 to $2 \mathrm{~m}$ depth became drier. This confirms that the antecedent soil-water was draining out from the top soil. The soil outside of the barrier footprint (Nest A) was also drying during the same period of time due to drainage to deeper soil and evaporation to the atmosphere. 


\section{Acronyms and Abbreviations}

$\begin{array}{ll}\text { bgs } & \text { Below Ground Surface } \\ \text { CP } & \text { Capacitance Probe } \\ \text { DOE } & \text { Department of Energy } \\ \text { FY07 } & \text { Fiscal Year 2007 } \\ \text { FY08 } & \text { Fiscal Year 2008 } \\ \text { HDU } & \text { Heat-Dissipation Unit } \\ \text { HMS } & \text { Hanford Meteorological Station } \\ \text { NP } & \text { Neutron Probe } \\ \text { OD } & \text { Outside Diameter } \\ \text { ORP } & \text { Office of River Protection } \\ \text { PMP } & \text { Project Management Plan } \\ \text { PNNL } & \text { Pacific Northwest National Laboratory } \\ \text { PSC } & \text { Previous Standard Count } \\ \text { QAP } & \text { Quality Assurance Plan } \\ \text { SC } & \text { Standard Count } \\ \text { SDR } & \text { Standard Deviation Ratio of Neutron Count } \\ \text { SST } & \text { Single-Shell Tank } \\ \text { STD } & \text { Standard Deviation }\end{array}$




\begin{tabular}{|c|c|}
\hline$a, b, c$ & $\begin{array}{l}\text { Coefficients for the relationship between soil water content and } \\
\text { normalized frequency }\end{array}$ \\
\hline $\mathrm{b}$ & Coefficient for correcting temperature effects on $\mathrm{CP}$ measurements \\
\hline $\mathrm{A}, \mathrm{B}, \mathrm{C}$ & $\begin{array}{l}\text { Coefficients for the relationship between Model } 109 \text { thermistor } \\
\text { resistance and temperature }\end{array}$ \\
\hline $\mathrm{c}_{0}, \mathrm{c}_{1}, \mathrm{c}_{2}, \mathrm{c}_{3}, \mathrm{c}_{4}, \mathrm{c}_{5}$ & Coefficients for correcting temperature effects on HDU measurements \\
\hline $\mathrm{C}_{0}, \mathrm{C}_{1}, \mathrm{C}_{2}, \mathrm{C}_{3}, \mathrm{C}_{4}, \mathrm{C}_{5}$ & $\begin{array}{l}\text { Coefficients for the relationship between Model } 107 \text { thermistor } \\
\text { resistance and temperature }\end{array}$ \\
\hline $\mathrm{F}$ & Frequency reading \\
\hline $\mathrm{F}_{\mathrm{a}}$ & Frequency reading in air \\
\hline $\mathrm{F}_{\mathrm{w}}$ & Frequency reading in water \\
\hline $\mathrm{k}$ & Permeability \\
\hline $\mathrm{N}$ & Neutron counts per $16 \mathrm{sec}$ \\
\hline $\mathrm{N}_{\mathrm{n}}$ & Normalized neutron counts \\
\hline $\mathrm{N}_{\mathrm{s}}$ & Standard neutron counts per $16 \mathrm{sec}$ \\
\hline $\mathrm{P}$ & Precipitation \\
\hline q & Heat input \\
\hline r & Correlation coefficient \\
\hline $\mathrm{R}_{\mathrm{s}}$ & Resistance \\
\hline s & An intermediate variable \\
\hline $\mathrm{S}_{\mathrm{f}}$ & Normalized frequency \\
\hline $\mathrm{S}_{\Delta \mathrm{T}}$ & Normalized temperature change \\
\hline $\mathrm{S}_{\Delta \mathrm{T}}{ }^{*}$ & Normalized temperature change after temperature correction \\
\hline $\mathrm{t}$ & Time \\
\hline $\mathrm{t}_{0}$ & Start time \\
\hline $\mathrm{T}$ & Temperature \\
\hline $\mathrm{T}_{0}$ & Initial temperature \\
\hline $\mathrm{T}_{\text {air }}$ & Air temperature \\
\hline $\mathrm{T}_{\mathrm{avg}}$ & Average temperature \\
\hline $\mathrm{T}_{\max }$ & Maximum temperature \\
\hline $\mathrm{T}_{\min }$ & Minimum temperature \\
\hline $\mathrm{T}_{\text {soil }}$ & Soil temperature \\
\hline $\mathrm{T}_{\text {std }}$ & Standard deviation of soil temperature \\
\hline$\Delta \mathrm{T}$ & Temperature change \\
\hline$\Delta \mathrm{T}_{\mathrm{d}}$ & Temperature change in a dry ceramic matrix \\
\hline$\Delta \mathrm{T}_{\mathrm{w}}$ & Temperature change in a water-saturated ceramic matrix \\
\hline$\theta$ & Soil volumetric water content \\
\hline$\theta_{\text {avg }}$ & Average soil volumetric water content \\
\hline$\theta_{\max }$ & Maximum soil volumetric water content \\
\hline$\theta_{\min }$ & Minimum soil volumetric water content \\
\hline$\theta_{\text {std }}$ & Standard deviation of Soil volumetric water content \\
\hline$\theta_{\mathrm{v}}^{*}$ & Soil volumetric water content after temperature correction \\
\hline$\psi$ & Soil water pressure head \\
\hline$\psi_{\text {avg }}$ & Average soil water pressure head \\
\hline$\psi_{\max }$ & Maximum soil water pressure head \\
\hline$\psi_{\min }$ & Minimum soil water pressure head \\
\hline$\psi_{\text {std }}$ & Standard deviation of soil water pressure head \\
\hline
\end{tabular}

\section{Definition of Variables}

Coefficients for the relationship between soil water content and normalized frequency

Coefficient for correcting temperature effects on CP measurements

resistance and temperature

Coefficients for correcting temperature effects on HDU measurements

resistance and temperature

Frequency reading

Frequency reading in air

Frequency reading in water

Permeability

Neutron counts per $16 \mathrm{sec}$

Normalized neutron counts

Standard neutron counts per $16 \mathrm{sec}$

Precipitation

Heat input

Correlation coefficient

Resistance

An intermediate variable

Normalized frequency

Normalized temperature change

Normalized temperature change after temperature correction

Time

Start time

Temperature

Air temperature

Average temperature

Maximum temperature

Minimum temperature

Soil temperature

Standard deviation of soil temperature

Temperature change

Temperature change in a dry ceramic matrix

Temperature change in a water-saturated ceramic matrix

Soil volumetric water content

Average soil volumetric water content

Maximum soil volumetric water content

Standard deviation of Soil volumetric water content

Soil volumetric water content after temperature correction

Soil water pressure head

Average soil water pressure head

Minimum soil water pressure head

Standard deviation of soil water pressure head 


\section{Contents}

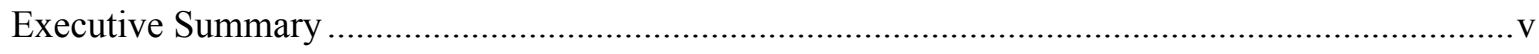

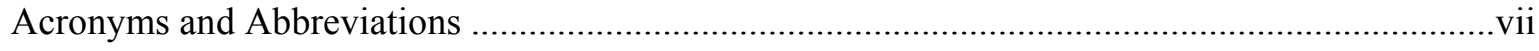

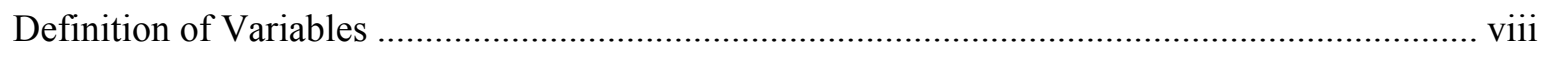

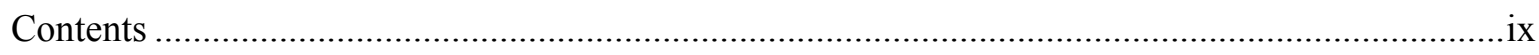

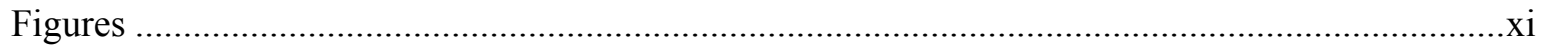

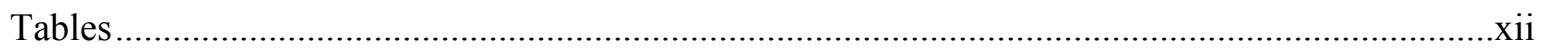

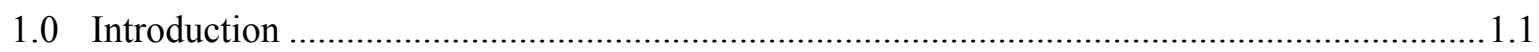

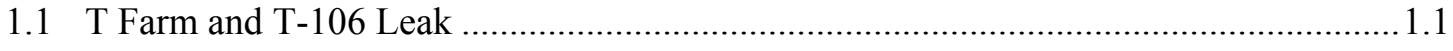

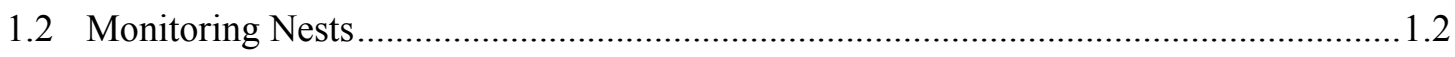

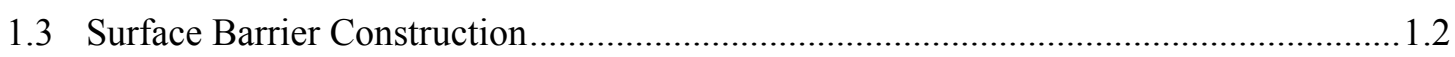

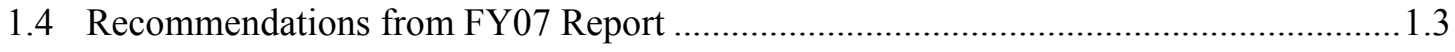

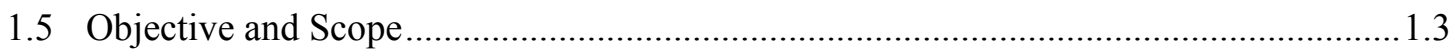

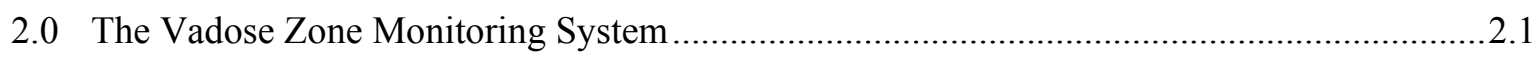

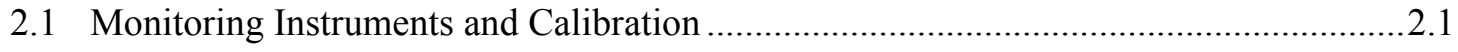

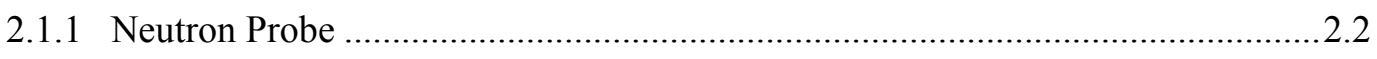

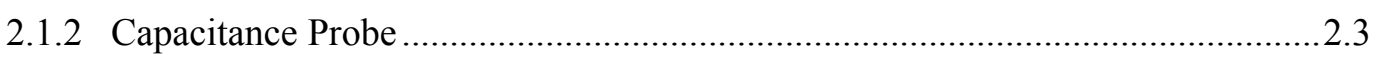

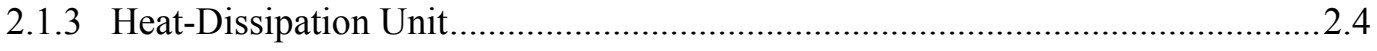

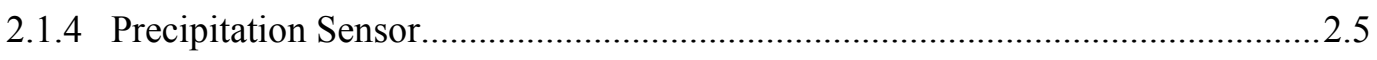

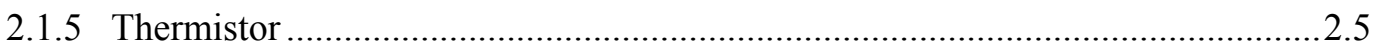

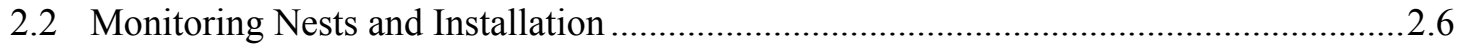

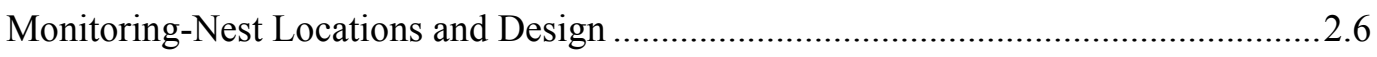

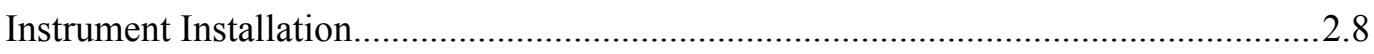

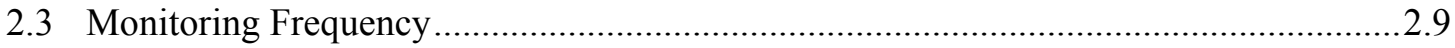

2.4 Water Use During Barrier Construction.................................................................. 2.10

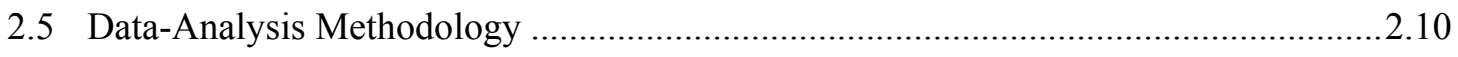

2.5.1 Removal and Correction of Anomalous Data ................................................2.10

2.5.2 Temperature-Correction on HDU Measurements ............................................2.11

2.5.3 Temperature-Correction on Capacitance-Probe Measurements.........................2.11

2.5.4 Normalized Neutron Counts........................................................................ 2.12

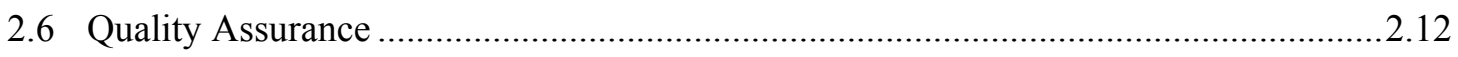

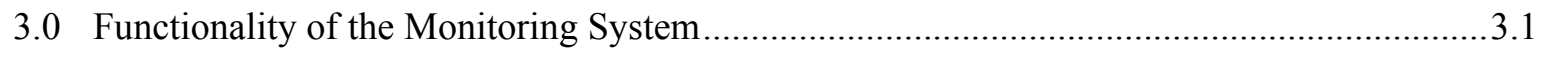

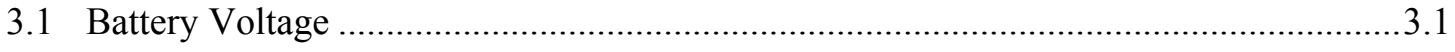

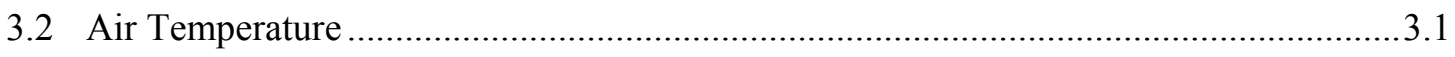

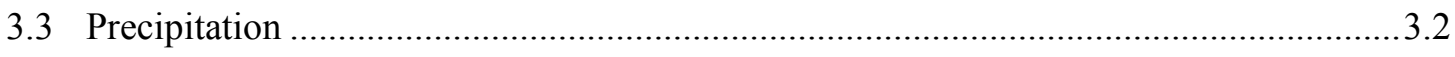

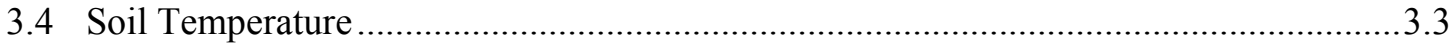

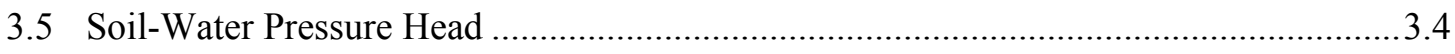

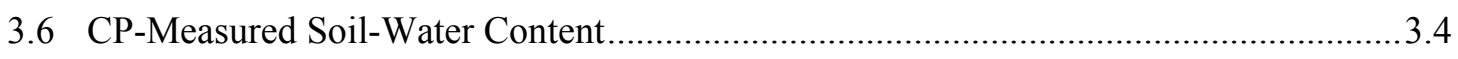




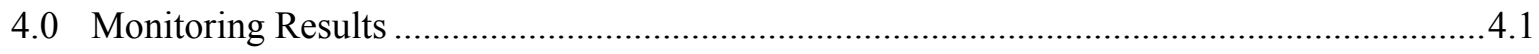

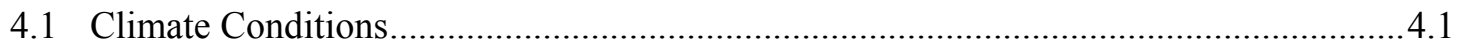

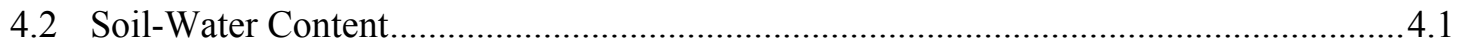

4.2.1 Capacitance-Probe Measurements................................................................ 4.1

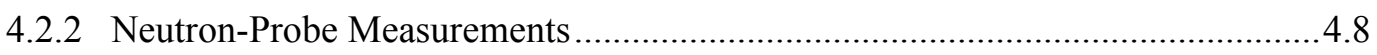

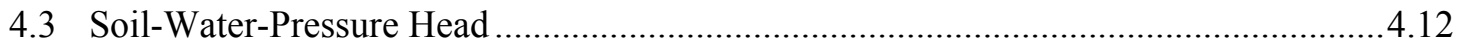

4.4 Effects of Surface Barrier on Soil Water Condition........................................................4.18

4.5 Instrument Performance ............................................................................................. 4.18

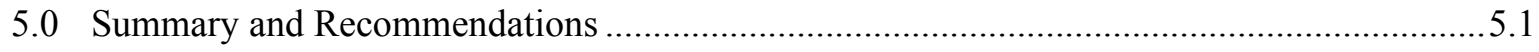

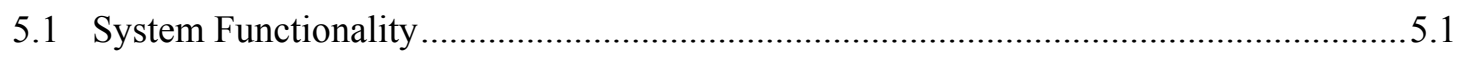

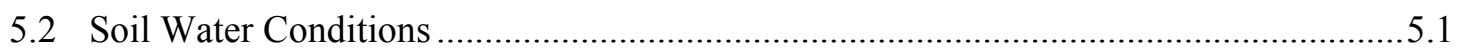

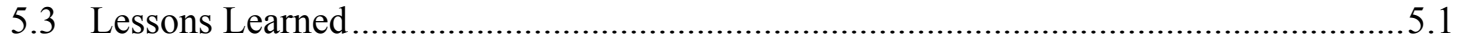

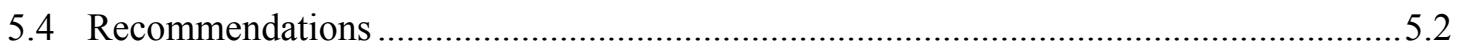

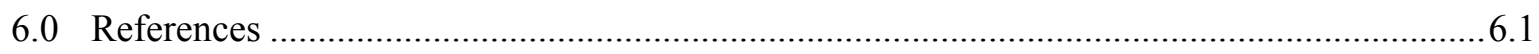

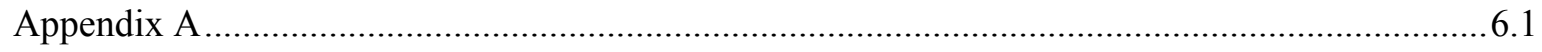




\section{Figures}

Figure 1.1. Plan View of T Tank Farm with the Approximate Locations of Monitoring Nests A, B, C, and D, Meteorological Station, and Approximate Interim Surface Barrier Boundary as Marked by the Octagon.

Figure 2.1. Vadose Zone Monitoring Components, Instrumentation, and Data-Collection and Management Flow Diagram for the T Farm Interim Surface Barrier Demonstration Project.2.2

Figure 2.2. Typical Instrument Surface Completion Showing Outer 24-In.-Diameter Corrugated Metal Pipe Sleeving and Inner Steel Casing (Nest A; photo taken in the winter 2008; snow can be seen on the ground).

Figure 2.3. Cone-Tipped Drive Shaft Used in Conjunction with a Hydraulic Hammer for Creating Boreholes (Photo taken in the summer of 2006).

Figure 2.4. Hydraulic Hammer Used to Install Instruments in the T Tank Farm (Photo taken in the summer of 2006).

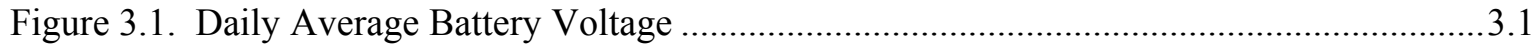

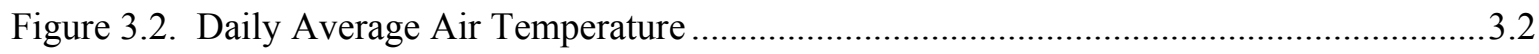

Figure 3.3. FY08 Cumulative Precipitation at the T Tank Farm and Hanford Meteorological Station a) before and b) after tipping volume correction.

Figure 3.4. Daily Average Soil Temperature at Different Depths Measured Using the HDUs (the HDUs in Nests C and D started logging on May 4, 2008)................................................... 3.5

Figure 3.5. Average Soil Temperature at Different Depths Measured Using the HDUs Since May 4, 2008, the time the HDUs in Nests C and D started logging. ............................................ 3.8

Figure 4.1. Monthly Precipitation (mm) in Hanford .........................................................................2

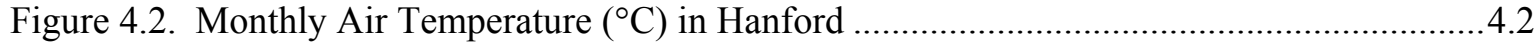

Figure 4.3. Daily Average Soil-Water Content at Five Depths Measured Using the CPs (the sensors in Nests C and D started logging on May 4, 2008; the data of the 0.9-m-depth sensor in Nest $\mathrm{D}$ were noisy and not shown)

Figure 4.4. Soil-Water Content Profiles on Selected Dates for CPs (The CP in Nest A was not functional after January 31, 2008; the sensors in Nests C and D started logging on May 4, 2008)

Figure 4.5. Normalized Neutron Counts Measured Using Neutron Probes at Different Depths (The depth bgs was relative to the ground surface before barrier construction. For Nest B, the logging in January could not be done due to the raised ground surface elevation during the surface barrier construction)

Figure 4.6. Daily Average Soil-Water Pressure at Different Depths Measured Using the HDUs (the sensors in Nests C and D started logging on May 4, 2008).

Figure 4.7. Soil-Water-Pressure Head Profiles on Selected Dates Using the HDUs (the sensors in Nests C and D started logging on May 4, 2008) 


\section{Tables}

Table 2.1. Instruments Selected for Interim Surface Barrier Monitoring and the Monitored Variables

Table 2.2. Capacitance Sensor Frequency Readings in Air and Water. Values are used to normalize capacitance sensor output using Eq. (2.1).

Table 2.3. Vadose Zone Monitoring Borehole Coordinates and Associated Installed Instruments 2.8

Table 2.4. Instrument Vertical Placement.

Table 2.5. Data-Collection Method ${ }^{(a)}$ and Approximate Frequency Under Normal Working Conditions

Table 3.1. The FY08 Annual HDU-Measured Average $\left(\mathrm{T}_{\text {avg }}\right)$, Minimum $\left(\mathrm{T}_{\min }\right)$, Maximum $\left(\mathrm{T}_{\max }\right)$, and Standard Deviation $\left(\mathrm{T}_{\text {std }}\right)$ of Soil Temperature for Nests A and B

Table 3.2. The HDU-Measured Average $\left(\mathrm{T}_{\mathrm{avg}}\right)$, Minimum $\left(\mathrm{T}_{\min }\right)$, Maximum $\left(\mathrm{T}_{\max }\right)$, and Standard Deviation $\left(\mathrm{T}_{\mathrm{std}}\right)$ of Soil Temperature for All Nests Since May 4, 2008 (the day Nests C and D started logging)

Table 4.1. The FY09 Average $\left(\theta_{\text {avg }}\right)$, Minimum $\left(\theta_{\min }\right)$ and Maximum $\left(\theta_{\max }\right)$ and Standard Deviation $\left(\theta_{\text {std }}\right)$ of Soil-Water Content for Nests A and B

Table 4.2. The Average $\left(\theta_{\text {avg }}\right)$, Minimum $\left(\theta_{\min }\right)$ and Maximum $\left(\theta_{\max }\right)$ and Standard Deviation $\left(\theta_{\text {std }}\right)$ of Soil-Water Content for All Nests After May 4, 2008.

Table 4.3. Water content changes from May 4 to September 30, 2008

Table 4.4. The Depth-Averaged Normalized Neutron Counts for Nest A

Table 4.5. The Depth-Averaged Normalized Neutron Counts for Nest B

Table 4.6. The Depth-Averaged Normalized Neutron Counts for Nest $\mathrm{C}$

Table 4.7. The Depth-Averaged Normalized Neutron Counts for Nest D

Table 4.8. The HDU-Measured Average ( $\psi_{\text {avg }}$ ), Minimum ( $\left.\psi_{\min }\right)$, Maximum ( $\left.\psi_{\max }\right)$, and Standard Deviation $\left(\psi_{\text {std }}\right)$ of Soil-Water-Pressure Head for Nests A and B

Table 4.9. The HDU-Measured Average ( $\left.\psi_{\text {avg }}\right)$, Minimum $\left(\psi_{\min }\right)$, Maximum $\left(\psi_{\max }\right)$, and Standard

Deviation ( $\left.\psi_{\text {std }}\right)$ of Soil-Water-Pressure Head for All Nests After May 4, 2008

Table 4.10. Soil-water-pressure head changes from May 4 to September 30, 2008 4.18

Table 4.11. Instrument Performance. 


\subsection{Introduction}

The Hanford Site in southeastern Washington State has 149 underground single-shell tanks (SSTs) that store hazardous radioactive waste. Many of these tanks and/or their associated infrastructure (e.g., pipelines, diversion boxes) have leaked. The largest known leak occurred from Tank T-106 in 1973. Many of the contaminants from that leak still reside within the vadose zone beneath the T Tank Farm. The U.S. Department of Energy (DOE), Office of River Protection (ORP) seeks to minimize movement of this residual contaminant plume by placing an interim barrier on the ground surface to minimize the infiltration of precipitation. The temporary surface barrier was constructed as part of the T Farm Interim Surface Barrier Demonstration Project. Vadose zone moisture has been monitored to assess the effectiveness of the surface barrier at reducing soil moisture beneath the barrier. The technology being used to create the impermeable barrier is a spray-polyurea liner material above a layer of compact soil. Construction of the surface barrier was completed in April 2008. This report presents soil-moisture data that were collected from October 2007 to September 2008 (FY08). Such data will provide information before and shortly after the surface barrier was emplaced and for comparison with the past and future data. The monitoring results in FY07 was summarized in the FY07 Report (Zhang et al. 2008), which will be referred to as the FY07 Report hereafter.

\subsection{T Farm and T-106 Leak}

According to Myers (2005), the T Tank Farm was built from 1943 to 1944. The T Tank farm contains 12 (SSTs with a diameter of 23 meter $(\mathrm{m})(75 \mathrm{ft})$ and a capacity of 2,006,050 L (530,000 gal), four SSTs

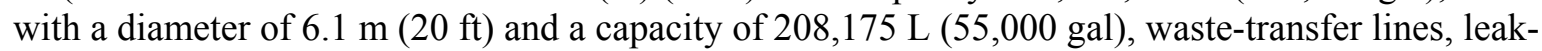
detection systems, and tank ancillary equipment. The soil cover from the apex of the tank domes to the ground surface is approximately $2.2 \mathrm{~m}(7.3 \mathrm{ft})$ thick. All the tanks have a dish-shaped bottom.

In general, the vadose zone in the T Tank farm consists of a portion of the thick, relatively coarse-grained sediments of the middle Ringold Formation overlain by the finer grained sediments of the upper Ringold Formation and the Plio-Pleistocene unit (also called the Cold Creek Unit). This, in turn is overlain by the coarser grained sands and gravels of the Hanford formation, which are exposed at the surface. The upper $12 \mathrm{~m}$ (40 ft) of the Hanford formation was locally excavated and redeposited as backfill material around the tanks.

A leak from Tank T-106 occurred in 1973; the details and chronology of the leak are well documented (ARHCO 1973; Routson et al. 1979). The leak was suspected to have started on April 20, 1973, during a routine filling operation. The leak stopped on June 10,1973, when the free liquid contents of the tank were removed. The total duration of the leak was estimated to be 51 days. Approximately 435,000 L (115,000 gal) of fluid leaked from Tank T-106. The fluid contained cesium-137, strontium-90, plutonium, and various fission products, including technetium-99. It is likely that the leak occurred in the southeast quadrant of the tank near the bottom of the tank side (Routson et al. 1979).

It is expected that the interim surface barrier will minimize the meteoric water entering into soil and consequently will reduce the rate of downward movement of antecedent water and transport of contaminants (McMahon 2007). At shallower depths, there will be no water supply from above to replace the draining antecedent pore water, and hence, in the shallow zone, the soil will dry more quickly. In deeper soil zones, the soil will continue to receive drainage from the soil above for some time and will then drain more slowly. Therefore, it may take years for drainage rates deep in the profile (e.g., $>10 \mathrm{~m}$ bgs) to reduce significantly. As the soil below the surface barrier becomes drier, the soil directly beneath the barrier edge will also become drier than would be the case were there no surface barrier. After the surface barrier is emplaced, there will be no water going through the barrier in either liquid or gas form, 
the soil water condition under the barrier will be more stable through the year than it would be under natural conditions.

\subsection{Monitoring Nests}

Four instrument nests have been installed in the T Tank Farm to monitor the vadose zone moisture and temperature conditions and a meteorological station has been installed to measure the weather conditions. During August and September 2006, Nests A and B (Figure 1.1) were installed within the T Tank Farm, and the meteorological station was installed outside of the tank farm. In September 2007, Nests C and D (Figure 1.1) were installed, but had not been hooked up to dataloggers and/or batteries until May 3, 2008. Each of the four instrument nests is designed to include its own datalogger as is the meteorological station outside the farm.

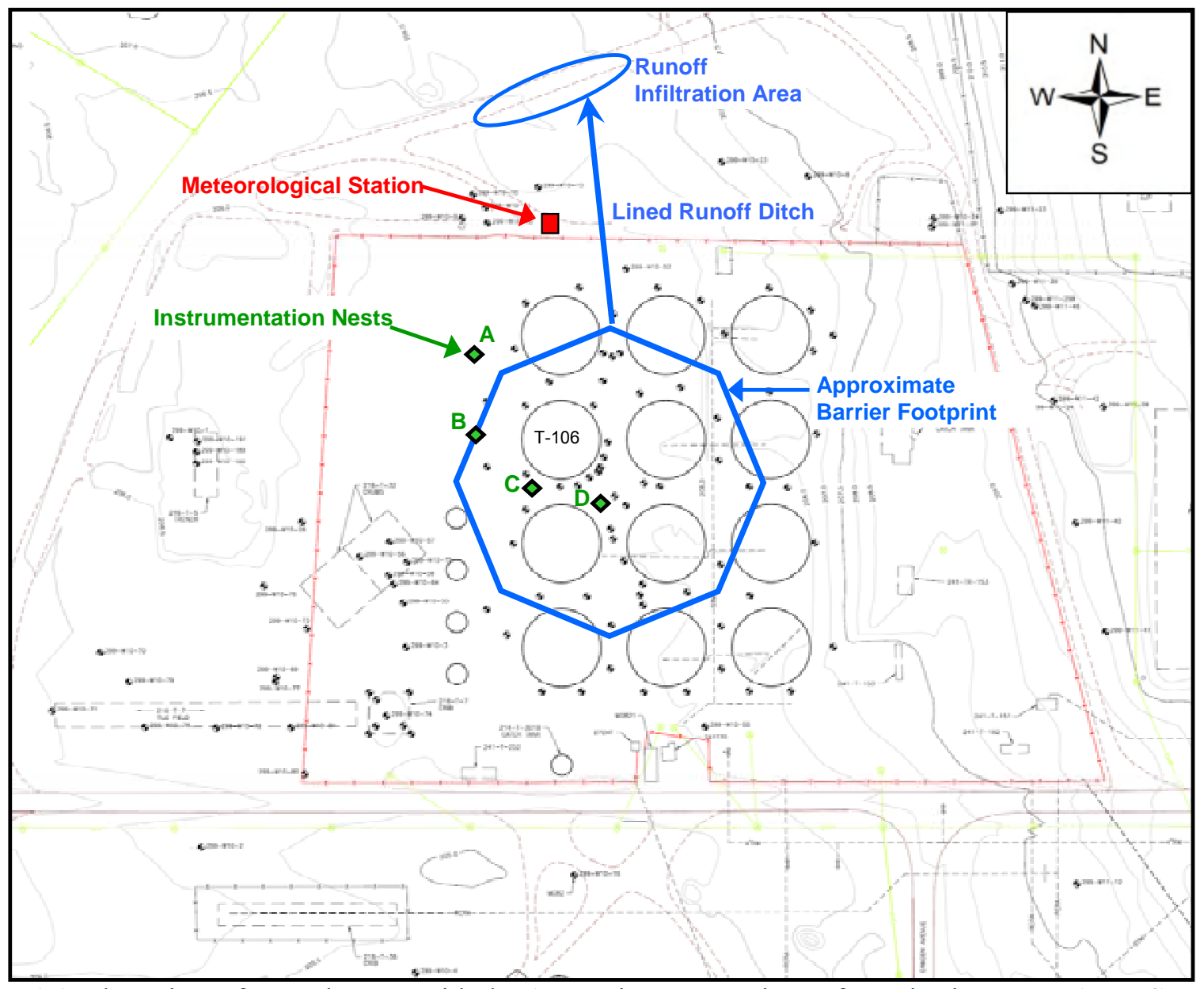

Figure 1.1. Plan View of T Tank Farm with the Approximate Locations of Monitoring Nests A, B, C, and D, Meteorological Station, and Approximate Interim Surface Barrier Boundary as Marked by the Octagon

\subsection{Surface Barrier Construction}

The construction of the T Farm interim surface barrier was started in October 2007 and completed in April 2008. The approximate interim surface barrier boundary is marked by the octagon in Figure 1.1. Approximately 1-foot-thick compacted soil was added to the original ground surface before the surface 
barrier was emplaced. Above the compacted soil is a 1/4-inch-thick poly-urea as the impermeable interim barrier. The barrier dips slightly to the north so that the rainwater on it can run off it along a lined runoff ditch to a runoff infiltration area.

\subsection{Recommendations from FY07 Report}

Based on the instrument performance and data obtained, the following recommendations were given in the FY07 Report (Zhang et al. 2008):

- Calibrate the neutron probes (NP) for the access tube used to quantify soil-water content. For the neutron-probe measurements, the original data were recorded as neutron counts per 16 seconds at each location of measurement. By calibrating the NP, the measured neutron counts can be converted into actual soil-water contents. This provides the added advantages that the soil-water contents can be compared with the capacitance probe (CP)-measured water contents, and the water storage in the soil profile can be calculated.

- Move the $60-\mathrm{cm}$-depth sensor of the CP in Nest A down by one scale $(10 \mathrm{~cm})$ so that the measurements are not affected by the sealing bentonite.

- Measure the soil-water retention and the unsaturated hydraulic conductivities of the T Tank Farm backfill materials between 0 and $10 \mathrm{~m}(0$ to $33 \mathrm{ft}) \mathrm{bgs}$ so that the Heat-Dissipation Unit (HDU) measurements can be used to estimate soil-water flux.

- Do not use the water-flux meters installed in the T Tank Farm to estimate the natural recharge rate due to the higher-than-expected silt content.

Based on the above recommendations, the calibration of the NP was planned; the 60 -cm-depth sensor of the CP in Nest A was moved down by one scale $(10 \mathrm{~cm})$; and the water-flux meters installed in the T Tank Farm are not used to estimate the natural recharge rate. However, the measurement of the soil-water retention and the unsaturated hydraulic conductivities of the T Tank Farm backfill materials between 0 and $10 \mathrm{~m}$ ( 0 to $33 \mathrm{ft})$ bgs was not conducted.

\subsection{Objective and Scope}

The objective of the report is to present the data collected from the four subsurface instrument nests (Figure 1.1) through FY08 in accordance with the T Tank Farm Interim Surface Barrier Demonstration Vadose Zone Monitoring Plan (Zhang et al. 2007), which will be referred to as the Monitoring Plan hereafter. The data collected from different instrument nests are compared. Nests A and B were installed in FY06, as described in the Monitoring Plan. Nests C and D were installed in FY07, as described in the FY07 Report. Data from all nests will be used to evaluate the impacts of the interim surface barrier on sub-surface moisture conditions. Chapter 2 of this report summarizes the monitoring instruments, pertinent calibration information, instrument installation methods, and data-analysis methodology. Chapter 3 summarizes the functionality of the monitoring system. Chapter 4 presents the monitoring results of the primary variables, i.e., the soil-water content measured by the $\mathrm{CP}$, the normalized neutral counts by the NP, and the soil-water-pressure head by the HDU. Chapter 5 summarizes instrument functionality and results of the measured soil-water conditions and presents recommendations for future monitoring activities. 



\subsection{The Vadose Zone Monitoring System}

Soil-moisture conditions were monitored using an array of solar-powered instrument nests and neutronprobe access tubes located beneath and outside of the interim barrier. The principal variables monitored for this purpose are soil-water content $(\theta)$, soil-water pressure $(\psi)$, and soil-water flux. The reasons for selecting these variables were given in Section 3.1 of the Monitoring Plan. Briefly, each variable reflects one aspect of the soil-moisture regime and their variation is different under different conditions. The measurement of three different variables also serves as a redundancy of monitoring. Based on the FY07 monitoring results and the recommendation from the FY07 Report, the drain gauges have not been used to monitor soil water flux in since FY08. Secondary variables monitored include soil temperature and meteorological conditions, including precipitation and air temperature. The measured precipitation will be used to estimate the total volume of water intercepted by the surface barrier after construction is complete. Soil temperature is used to correct the temperature impact on $\theta$ and $\psi$, and along with air temperature, to assess system functionality.

To fulfill the purpose of monitoring surface-barrier impacts on the subsurface water regime, multiple instrument nests were installed both under the interim surface barrier and outside of the surface barrier, as described in Section 5.1 of the Monitoring Plan. Nest A is placed in the area outside the barrier footprint and serves as a control, providing subsurface conditions outside the influence of the surface barrier. Nest B provides subsurface measurements to assess surface-barrier edge effects. Nests $C$ and $D$ are used to assess changes in soil-moisture conditions beneath the interim surface barrier. Spatial variability of soil properties and measurement error were considered and were minimized by one of more of the following: 1) using measurements of different types (i.e., $\theta$, and $\psi$ ), 2) taking multiple measurements in the vertical direction (e.g., $\theta$ and $\psi$ ), 3) duplicating instrument nests (e.g., Nests $\mathrm{C}$ and D), 4) measuring the same variable with more than one method (e.g., $\theta$ is measured using CPs and NPs), and 5) measuring the variation with time at desired frequency (for all the variables).

The Monitoring Plan presented the criteria used to select the various measurement methods, the principles of selected methods (Section 3.0), part of the instrument calibrations (Section 4.0), instrument layout and installation of Nests A and B (Section 5.0), and measurement procedures and frequencies (Section 6.1). In FY06, instrument Nests A and B were installed; in FY07, instrument Nests C and D were installed; in FY08, the interim surface barrier was constructed. The instrument layout and installation of Nests $\mathrm{C}$ and B were presented in the FY07 Report (Section 2.2). For convenience for the readers and completeness, this section summarizes the monitoring instruments, pertinent calibration information, instrument installation methods, and data-analysis methodology.

\subsection{Monitoring Instruments and Calibration}

Monitoring instruments were chosen based on several considerations. Primary considerations used to select instrumentation are that the instrumentation is amenable to the prescribed installation method (hydraulic hammer) and restrictions of working within the T Tank farm. Additional criteria considered are described in Table 3.1 of the Monitoring Plan. Table 2.1 lists the instruments selected for use in FY08 and the variables monitored by each instrument. Figure 2.1 shows monitoring components, instrumentation, and a data-collection and management flow diagram. In the following sections, each instrument is briefly described, and supporting calibration information is provided. 


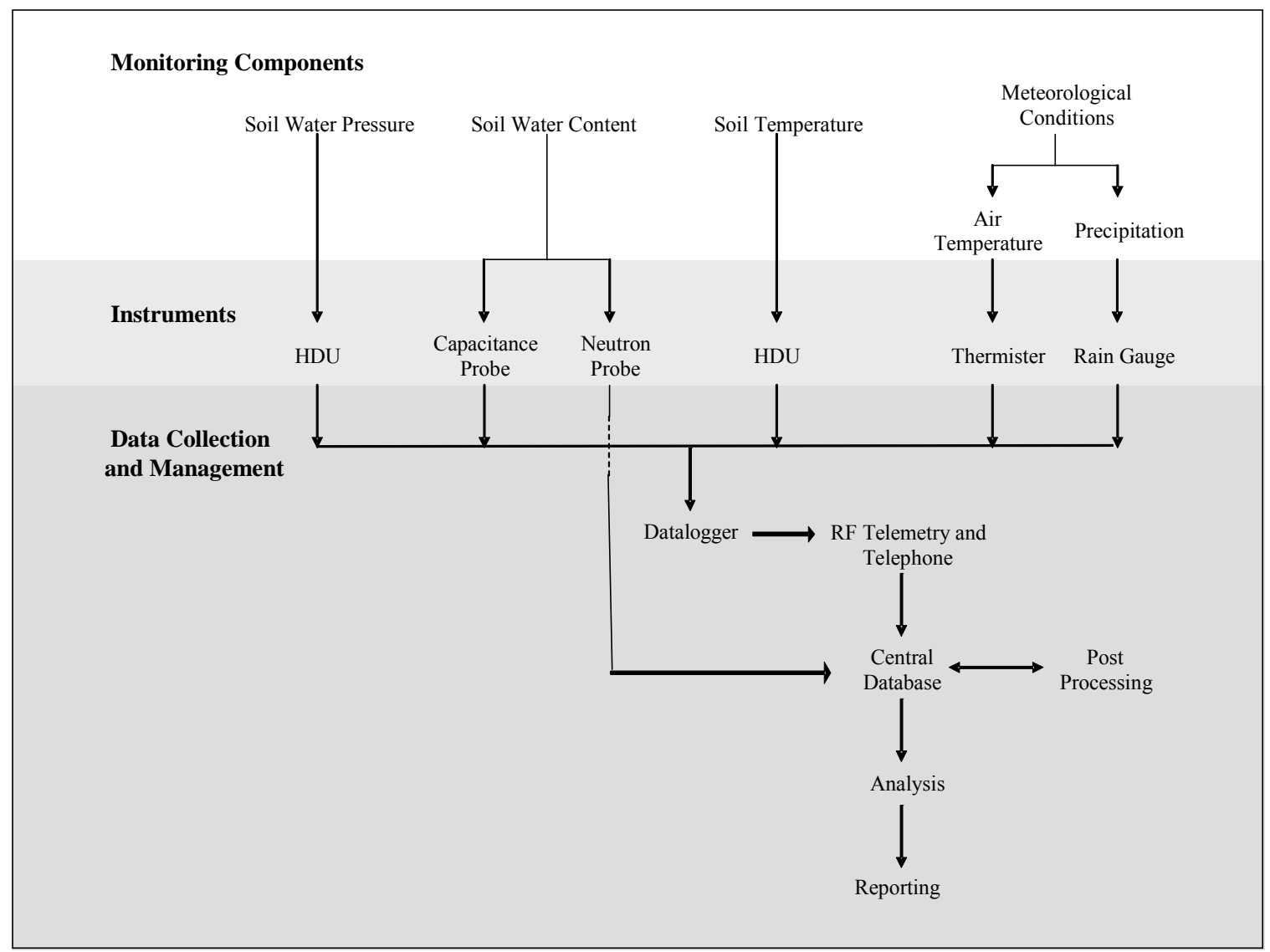

Figure 2.1. Vadose Zone Monitoring Components, Instrumentation, and Data-Collection and Management Flow Diagram for the T Farm Interim Surface Barrier Demonstration Project

Table 2.1. Instruments Selected for Interim Surface Barrier Monitoring and the Monitored Variables

\begin{tabular}{|c|c|c|c|c||}
\hline \hline Instrument & Manufacturer & Model & $\begin{array}{c}\text { Variable } \\
\text { Monitored }\end{array}$ & $\begin{array}{c}\text { Measurement } \\
\text { Precision }\end{array}$ \\
\hline Neutron Probe & $\begin{array}{c}\text { Campbell Pacific } \\
\text { Nuclear }\end{array}$ & $\begin{array}{c}\text { 503DR } \\
\text { Hydroprobe }\end{array}$ & $\begin{array}{c}\text { Soil Moisture } \\
\text { Content }\end{array}$ & $\pm 0.016 \mathrm{~m}^{3} \mathrm{~m}^{-3}$ \\
\hline Capacitance Probe & Sentek & EnviroSMART & $\begin{array}{c}\text { Soil Moisture } \\
\text { Content }\end{array}$ & $\pm 0.01 \mathrm{~m}^{3} \mathrm{~m}^{-3}$ \\
\hline $\begin{array}{c}\text { Heat Dissipation } \\
\text { Unit }\end{array}$ & $\begin{array}{c}\text { Campbell } \\
\text { Scientific, Inc. }\end{array}$ & 229-L & $\begin{array}{c}\text { Soil-Water Pressure, } \\
\text { Soil Temperature }\end{array}$ & $\pm 20 \%$ \\
$\pm 0.25^{\circ} \mathrm{C}$ \\
\hline $\begin{array}{c}\text { Precipitation } \\
\text { Sensor }\end{array}$ & Texas Electronics & TE525WS & Precipitation & $\pm 1 \%$ \\
\hline Thermistor & $\begin{array}{c}\text { Campbell } \\
\text { Scientific, Inc. }\end{array}$ & 109-L & Air Temperature & $\pm 0.1^{\circ} \mathrm{C}$ \\
\hline \hline
\end{tabular}

\subsubsection{Neutron Probe}

Neutron thermalization, as a method to measure soil-water content, uses a radioactive source of fast neutrons (mean energy of $5 \mathrm{MeV})$ and a detector of slow neutrons $(\sim 0.025 \mathrm{eV})$. High-energy neutrons emitted from the source are either slowed through repeated collisions with the nuclei of atoms in the soil (scattering) or are absorbed by those nuclei. The most common elements in soil (Al, Si, and $\mathrm{O}$ ) scatter neutrons with little energy loss. If the neutron hits a hydrogen $(\mathrm{H})$ atom, its energy is reduced on average 
by about half because the mass of the $\mathrm{H}$ nucleus is the same as that of the neutron. The concentration of thermal neutrons changes mainly with the $\mathrm{H}$ content of the surrounding material, while changes in $\mathrm{H}$ content occur mainly because of changes in soil-water content. Therefore, the concentration of thermal neutrons surrounding a neutron source placed in the soil can be related to the soil volumetric water content. Neutron-probe monitoring of the T Farm interim surface barrier uses a 503DR hydroprobe manufactured by CPN International, Inc. (Martinez, California), which was described in detail in Section 3.3.1 of the Monitoring Plan. The 2.5-inch-OD, 0.375-inch-thick 4140 carbon steel casings are used for NP access.

\subsubsection{Capacitance Probe}

The $\mathrm{CP}$ is an electromagnetic method used to measure the volumetric soil-water content $\left(\theta_{\mathrm{v}}\right)$ of the surrounding soil. The capacitance method uses the soil surrounding the electrodes as part of a capacitor in which the dipoles of water in the soil become polarized in response to the frequency of an imposed electric field. Hence, oscillation frequency is a function of soil-water content. The CP used for the T Farm interim surface barrier monitoring is the EnviroSMART probe (Sentek Pty Ltd, Stepney, Australia), which was described in detail in Section 3.3.2 of the Monitoring Plan.

Two components exist as part of the EnviroSMART CP calibration: 1) a normalization process to minimize instrumental-dependent readings and 2) a calibration process to relate the soil-water content with the normalized frequency. For cylindrical sensors, a normalized frequency $\left(\mathrm{S}_{\mathrm{f}}\right)$ is calculated by incorporating the raw-frequency reading in soil $(\mathrm{F})$ with frequency readings in air $\left(\mathrm{F}_{\mathrm{a}}\right)$ and in water $\left(\mathrm{F}_{\mathrm{w}}\right)$ (Paltineanu and Starr 1997):

$$
S_{f}=\frac{F_{a}-F}{F_{a}-F_{w}}
$$

Table 2.2 presents the water and open-air measurement output for each sensor. The water measurements were taken with the sensors inside the water-tight access tube that was placed in a 10-inch-diameter cylindrical water vessel. The measurements for the 15 sensors listed in the left half of Table 2.2 were the same as those in Table 4.1 of the Monitoring Plan, while the 10 sensors in the right half were new values obtained in FY07.

The CP calibration documentation (Sentek Pty Ltd. 2001) provides a default calibration developed using sand, loam, and clay-loam soils. This calibration was developed by performing nonlinear regression on frequency data for paired volumetric moisture content and normalized frequency:

$$
\theta=\left(\frac{S_{f}-c}{a}\right)^{1 / b}
$$

where $\mathrm{a}=0.1957, \mathrm{~b}=0.4040$, and $\mathrm{c}=0.02852$. The general calibration can also be used in gravelly soils (e.g., the T Tank Farm soils) because capacitance probes are relatively insensitive to gravel content (Baumhardt et al. 2000). 
Table 2.2. Capacitance Sensor Frequency Readings in Air and Water. Values are used to normalize capacitance sensor output using Eq. (2.1).

\begin{tabular}{||c|c|c|c|c|c||}
\hline \multirow{2}{*}{ Sensor Serial \# } & \multicolumn{2}{|c|}{ Frequency } & & \multicolumn{2}{|c||}{ Frequency } \\
\cline { 2 - 3 } \cline { 6 - 6 } & Air & Water & Sensor Serial \# & Air & Water \\
\hline AP06-303 & 37584 & 28503 & FE06-451 & 35956 & 27169 \\
\hline AP06-304 & 37170 & 28219 & FE06-452 & 36556 & 27383 \\
\hline AP06-305 & 37522 & 28657 & FE06-453 & 36275 & 27152 \\
\hline AP06-309 & 37728 & 28863 & FE06-454 & 36451 & 27641 \\
\hline AP06-310 & 37583 & 28413 & FE06-455 & 36713 & 27817 \\
\hline FE06-371 & 37448 & 28395 & FE06-456 & 37535 & 27134 \\
\hline FE06-372 & 37048 & 28148 & FE06-457 & 36751 & 27148 \\
\hline FE06-373 & 37323 & 28227 & FE06-458 & 36225 & 27622 \\
\hline FE06-374 & 37720 & 28468 & FE06-459 & 38346 & 28328 \\
\hline FE06-375 & 37180 & 27835 & FE06-460 & 37643 & 27621 \\
\hline FE06-376 & 37162 & 28246 & & & \\
\hline FE06-377 & 37468 & 28374 & & & \\
\hline FE06-378 & 37545 & 28517 & & & \\
\hline FE06-379 & 37359 & 28270 & & & \\
\hline FE06-380 & 37381 & 28456 & & & \\
\hline \hline
\end{tabular}

\subsubsection{Heat-Dissipation Unit}

An HDU indirectly measures the soil matric potential $(\psi)$ by measuring the thermal conductivity of the reference matrix, which is part of an HDU and is made of porous ceramics. HDU measurement and calibration are independent of soil texture because the heat pulse is restricted to the ceramic. It is also independent of salinity because the method is independent of electrical conductivity. HDUs have the added benefit of also measuring soil temperature.

HDUs consist of a heater and a temperature sensor in a porous ceramic. The temperature rise measured by the temperature sensor at time $t$ represents the heat that is not dissipated at this time. The time dependence of temperature, $\mathrm{T}$, in a line heat source buried in an infinite medium can be approximated by the method of Shiozawa and Campbell (1990):

$$
\Delta T=T-T_{0}=\frac{q}{4 \pi k} \ln \left(t-t_{0}\right)
$$

where $\mathrm{T}$ and $\mathrm{T}_{0}$ are the temperatures $\left({ }^{\circ} \mathrm{C}\right)$ at time $\mathrm{t}$ and $\mathrm{t}_{0}$, respectively, $\mathrm{q}$ is the heat input, and $\Delta \mathrm{T}$ is temperature rise. The HDU used for the T Farm interim surface barrier monitoring is the model 229-L HDU manufactured by Campbell Scientific, Inc. (Logan, Utah), which was described in detail in Section 3.4 in the Monitoring Plan.

Similar to the CP, there are two elements to the HDU calibration: 1) a normalization procedure to remove variation between the HDU sensors and 2) a calibration procedure to develop the relationship between soil-water pressure head and the normalized temperature rise measured by the HDU. The normalization procedure of Flint et al. (2002) was used to calculate the normalized temperature rise $\left(\mathrm{S}_{\Delta \mathrm{T}}\right)$, according to: 


$$
S_{\Delta T}=\frac{\Delta T_{d}-\Delta T}{\Delta T_{d}-\Delta T_{w}}
$$

where subscripts " $d$ " and " $w$ " denote the temperature rises for a dry and water-saturated ceramic matrix, respectively. The HDU temperature-rise measurement under dry conditions $\left(\Delta T_{d}\right)$ was made after the HDU had been placed over oven-dried desiccant in a sealed container for a length of time (approximately 24 hours). For the HDU temperature-rise measurement under water-saturated conditions $\left(\Delta T_{w}\right)$, the sensor was submerged in water for 24 to 48 hours and then removed before the HDU measurement. All readings were taken with a constant line-heat source current of $50 \mathrm{~mA}$ and measurement times of $1 \mathrm{~s}$ and $30 \mathrm{~s}$ after HDU heating was initiated. Details of sensor normalization and calibration are given in Section 4.3 of the Monitoring Plan.

Using the normalized HDU temperature rise, $\mathrm{S}_{\Delta \mathrm{T}}$, and tensiometer-measured matric potential, $\psi(\mathrm{m}$ of water), under steady-state soil conditions, a calibration was developed (Eq. 4.2 in the Monitoring Plan):

$$
\psi=12.388 \times S_{\Delta T}^{2}-3.9697 \times S_{\Delta T}-6.2548, \mathrm{r}^{2}=0.9689
$$

\subsubsection{Precipitation Sensor}

Monitoring precipitation directly at the T Tank Farm is useful in determining the total amount of meteoric water and the amount of water intercepted by the surface barrier. Localized thunderstorms that occasionally occur at Hanford produce spatially variable short-term, high-energy precipitation events. The possibility of such events requires that a meteorological monitoring station be located at the T Tank Farm to document potential localized precipitation events.

The rain gauge installed at the $\mathrm{T}$ Tank Farm for this purpose is a tipping-spoon type rain gauge, model TE525WS, manufactured by Texas Electronics (Dallas, Texas). Power requirements needed for a heated rain gauge necessitated an unheated rain gauge because there is no available $\mathrm{AC}$ power. As such, the rain gauge may not accurately measure precipitation during periods of snowfall. Given the proximity of the Hanford Meteorological Station (HMS) and the uniformity of snowfall across the Hanford Site, it was concluded that snowfall measured by the HMS will approximately describe the snowfall at the T Farm. The rain-gauge tipping spoon is factory calibrated to an equivalent depth of water of $0.254 \mathrm{~mm}$ per tip.

\subsubsection{Thermistor}

A thermistor is a resistor that relies on the change in its resistance with changing temperature to measure temperature. Two different Campbell Scientific, Inc. models of thermistors are used for interim surface barrier monitoring, the Model 107 and the Model 109. The Model 107 temperature probe is used as a reference temperature probe and is located within the enclosure boxes housing the dataloggers that control the instruments inside the T Tank Farm. The Model 107 temperature probe is described by a fifth-order polynomial equation relating thermistor resistance, $\mathrm{R}_{\mathrm{s}}(\mathrm{Ohms})$, to temperature, $\mathrm{T}\left({ }^{\circ} \mathrm{C}\right)$ by $(\mathrm{Campbell}$ Scientific Inc., 2004), 


$$
T=C_{0}+C_{1} R_{s}+C_{2} R_{s}^{2}+C_{3} R_{s}^{3}+C_{4} R_{s}^{4}+C_{5} R_{s}^{5}
$$

where $\mathrm{C}_{0}=-53.4601$

$\mathrm{C}_{1}=90.807$

$\mathrm{C}_{2}=-83.257$

$\mathrm{C}_{3}=52.283$

$\mathrm{C}_{4}=-16.723$

$\mathrm{C}_{5}=2.211$

The Model 109 temperature probe is used as part of the meteorological station. This temperature sensor relates thermistor resistance to temperature $\left({ }^{\circ} \mathrm{C}\right)$ using the relationship (Campbell Scientific Inc., 2004),

$$
T=\left\{\frac{1}{A+B \ln (R s)+C[\ln (R s)]^{3}}\right\}-273.15
$$

where $\mathrm{A}=1.129241 \times 10^{-3}, \mathrm{~B}=2.341077 \times 10^{-4}$, and $\mathrm{C}=8.775468 \times 10^{-8}$.

\subsection{Monitoring Nests and Installation}

This section describes the location and composition of the instrument nests and summarizes the installation procedure.

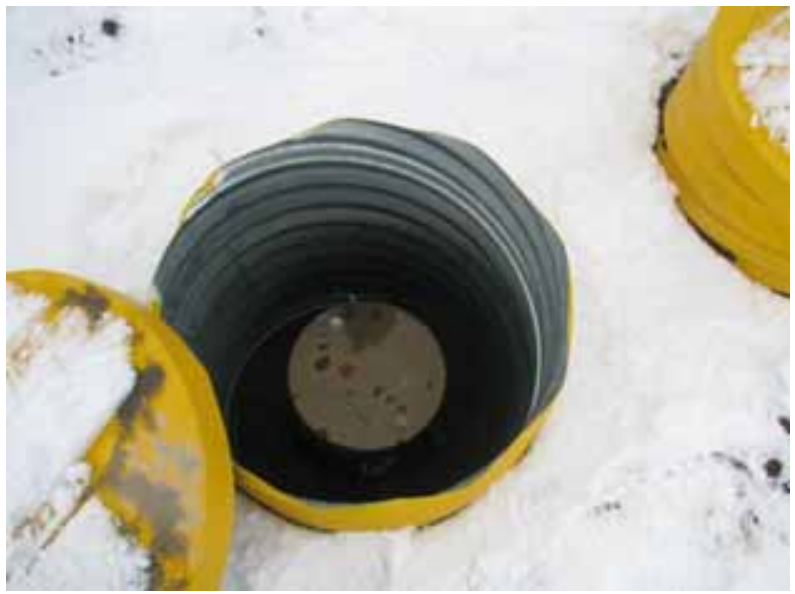

Figure 2.2. Typical Instrument Surface Completion Showing Outer 24-In.-Diameter Corrugated Metal Pipe Sleeving and Inner Steel Casing (Nest A; photo taken in the winter 2008; snow can be seen on the ground)

\section{Monitoring-Nest Locations and Design}

Figure 1.1 provides a plan view of instrument nest locations and the planned footprint of the interim surface barrier. In accordance with the Monitoring Plan, four subsurface monitoring instrument nests were located both under and outside of the surface barrier (i.e., A, B, C, and D; denoted as 1, 2, 3, and 4, respectively, in CH2M HILL 2006, 2007). Each nest includes a neutron access tube, a CP with five sensors, and four HDUs. Nest A is placed in the area outside the barrier footprint and serves as a control, providing subsurface conditions outside the influence of the surface-barrier. It is approximately $10 \mathrm{~m}$ away from the closest edge of the surface barrier, which is a sufficient distance to prevent measurable 
impacts from the surface barrier. Nest B is placed at the western edge of the surface barrier, but beneath the barrier. Nest B provides subsurface measurements to assess surface-barrier edge effects. (Although Nest A and B also contain drain gauges, according to the FY07 recommendation, they were not used to measure soil-water flux). The monitoring of Nests A and B was initiated on September 29, 2006, to provide baseline conditions before installing the interim surface barrier. Nests $\mathrm{C}$ and $\mathrm{D}$ were placed in the area covered by the barrier and monitoring was initiated on May 3, 2008. Nest $\mathrm{C}$ was placed between tanks T-106 and T-109 at a distance of approximately $4.0 \mathrm{~m}$ from the nearest tank wall of T-106. Nest D was placed near the center of the surface barrier, between tanks T-105, T-106, T-108, and T-109. The nearest tank, T-109, is about $4 \mathrm{~m}$ from Nest D. Nests C and D are used to assess changes in soil-moisture conditions beneath the interim surface barrier at locations where subsurface hydraulic conditions are anticipated to exhibit the greatest change (McMahon 2007). Table 2.3 provides the surface coordinates of each instrument head using the Washington Coordinate System, NAD83(91) datum and the Hanford Coordinate System. For Nests B, C and D, additional sleeving was installed around each instrument head consisting of 24-in.-diameter corrugated metal pipe (Figure 2.2). The sleeving was added to accommodate fill material placed at these locations during construction of the interim surface barrier (CH2M HILL 2007).

All instrument nests lie within backfill soil that surrounds the tanks, except for the lower part of the neutron access tubes, which extend into the undisturbed Hanford formation below the tanks. Table 2.4 summarizes the vertical placement of instruments or the measurement points. The sensor serial numbers and/or sensor numbers for the capacitance and HDU sensors are listed in the Table 2.5 and 2.6 in the FY07 Report, respectively. The adjacent instruments in a nest were kept $1 \mathrm{~m}$ apart except that the distance between the neutron-probe access tube and the CP access tube in Nest D was $1.6 \mathrm{~m}$.

Each instrument nest within the tank farm was designed to have a dedicated datalogger adjacent to the instrument nest. A CR10X Campbell Scientific datalogger is used for instrument Nests A and B and the meteorological station, and a CR1000 Campbell Scientific datalogger is planned for instrument Nests C and D.

The datalogger and peripherals are powered by a 12-volt rechargeable battery, which is charged by a solar panel attached to the tripod. The battery is placed within the enclosure. Data from the datalogger are transmitted remotely by a $900-\mathrm{MHz}$ spread spectrum radio to a receiving computer located outside of the tank farm. 
Table 2.3. Vadose Zone Monitoring Borehole Coordinates and Associated Installed Instruments (CH2M HILL 2006, 2007)

\begin{tabular}{|c|c|c|c|c|c|c|}
\hline \multirow[b]{2}{*}{$\begin{array}{c}\text { Instrument } \\
\text { Nest }^{(a)}\end{array}$} & \multirow[b]{2}{*}{$\begin{array}{c}\text { Well } \\
\text { Number }\end{array}$} & \multirow[b]{2}{*}{ Instrument } & \multicolumn{2}{|c|}{$\begin{array}{c}\text { Washington } \\
\text { Coordinates }^{(\mathbf{b})}\end{array}$} & \multicolumn{2}{|c|}{$\begin{array}{c}\text { Hanford } \\
\text { Coordinates }^{(\mathrm{c})}\end{array}$} \\
\hline & & & $\begin{array}{c}\text { Northing } \\
\text { (m) }\end{array}$ & $\begin{array}{c}\text { Easting } \\
(\mathrm{m})\end{array}$ & $\begin{array}{c}\text { Northing } \\
\text { (ft) }\end{array}$ & $\begin{array}{c}\text { Easting } \\
\text { (ft) }\end{array}$ \\
\hline \multirow{4}{*}{ Nest A } & C5306 & Drain Gauge & 136762.16 & 566752.82 & 43640.53 & -75915.61 \\
\hline & C5307 & Neutron Access Tube & 136761.16 & 566752.82 & 43637.25 & -75915.61 \\
\hline & C5309 & HDUs & 136760.16 & 566751.82 & 43633.97 & -75918.89 \\
\hline & C5310 & Capacitance Probe & 136761.16 & 566751.82 & 43637.25 & -75918.89 \\
\hline \multirow{4}{*}{ Nest B } & C5311 & Drain Gauge & 136739.59 & 566753.47 & 43566.49 & -75913.49 \\
\hline & C5312 & Neutron Access Tube & 136738.59 & 566753.47 & 43563.20 & -75913.49 \\
\hline & C5314 & HDUs & 136737.59 & 566752.47 & 43559.92 & -75916.78 \\
\hline & C5315 & Capacitance Probe & 136738.59 & 566752.47 & 43563.20 & -75916.78 \\
\hline \multirow{3}{*}{ Nest C } & C5696 & Neutron Access Tube & 136720.98 & 566768.77 & 43505.16 & -75863.34 \\
\hline & C5697 & Capacitance Probe & 136720.93 & 566767.76 & 43505.16 & -75866.63 \\
\hline & C5698 & HDUs & 136720.91 & 566766.76 & 43505.16 & -75869.90 \\
\hline \multirow{3}{*}{ Nest D } & C5699 & Neutron Access Tube & 136714.87 & 566789.75 & 43485.23 & -75794.55 \\
\hline & C5700 & Capacitance Probe & 136714.85 & 566788.13 & 43485.23 & -75799.83 \\
\hline & C5701 & HDUs & 136714.89 & 566787.11 & 43485.23 & -75803.11 \\
\hline \multicolumn{7}{|c|}{$\begin{array}{l}\text { (a) Nests A, B, C, and D were referred to as Nests 1, 2, 3, and 4, respectively, in CH2M HILL }(2006,2007) \text {. } \\
\text { (b) Washington Coordinate System, NAD83(91) datum. } \\
\text { (c) Coordinates for Nests A and B were from CH2M HILL (2006) and those for Nests C and D from CH2M } \\
\text { HILL (2007). }\end{array}$} \\
\hline
\end{tabular}

Table 2.4. Instrument Vertical Placement

\begin{tabular}{|c|c|c|l||}
\hline Methods & Nest & $\begin{array}{c}\text { No. of Sensors/ } \\
\text { Measurement Points }\end{array}$ & $\begin{array}{c}\text { Depth of Sensors/ } \\
\text { Measurement Points }\end{array}$ \\
\hline Capacitance Probe & A, B, C, D & 5 & $0.6,0.9,1.3,1.8$, and $2.3 \mathrm{~m}$ \\
\hline Neutron Probe & A, B, C, D & 50 & $\begin{array}{l}\text { From } 1 \text { to } 50 \mathrm{ft} \text { bgs at } 1-\mathrm{ft} \\
\text { interval }\end{array}$ \\
\hline HDU & A, B, C, D & 4 & $1,2,5$, and 9 or $10^{(\mathrm{a})} \mathrm{m}$ \\
\hline (a) $10 \mathrm{~m}$ for Nests A, B, and D and $9 \mathrm{~m}$ for Nest C. \\
\hline
\end{tabular}

\section{Instrument Installation}

The instruments were installed following the procedures and methods described in Section 5.3 of the Monitoring Plan. Instruments were placed in an open borehole created by pounding a cone-tipped hollow drive shaft (Figure 2.3) into the ground using a hydraulic hammer (Figure 2.4). Installation diagrams for Nests A and B are provided in Section 5.3 of the Monitoring Plan. Installation diagrams for Nests C and $\mathrm{D}$ are given in Section 2.2.2 of the FY07 Report. 


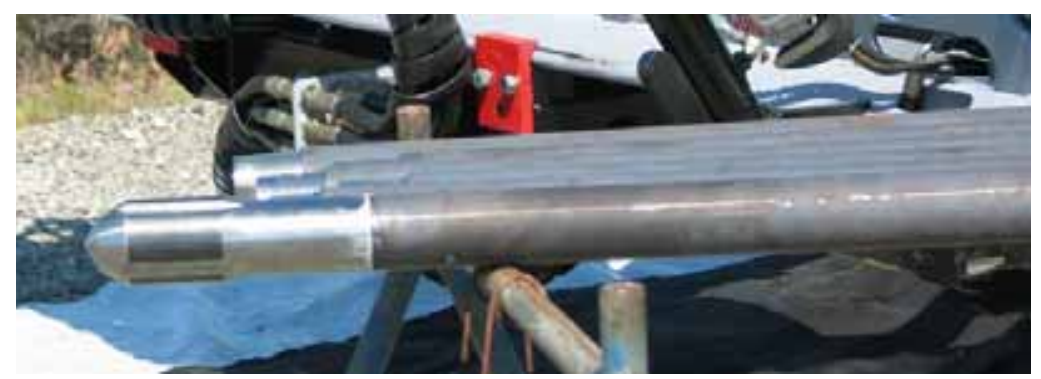

Figure 2.3. Cone-Tipped Drive Shaft Used in Conjunction with a Hydraulic Hammer for Creating Boreholes (Photo taken in the summer of 2006)

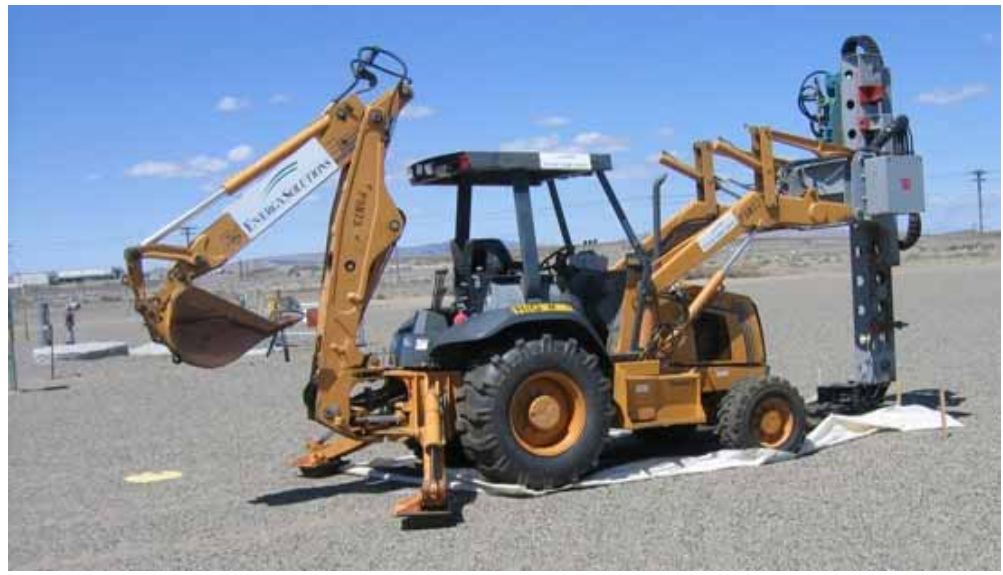

Figure 2.4. Hydraulic Hammer Used to Install Instruments in the T Tank Farm (Photo taken in the summer of 2006)

\subsection{Monitoring Frequency}

The monitoring approach uses the instrument nests and meteorological station presented in the previous section to document vadose zone response to the placement of an interim surface barrier in the T Tank Farm. Table 6.1 in the Monitoring Plan summarizes the six variables monitored, the monitoring methods, and the monitoring frequency and is repeated in Table 2.5 below. In FY08, the actual monitoring frequency was the same or better (more frequent) than the planned frequency (Table 2.5).

Table 2.5. Data-Collection Method ${ }^{(\mathrm{a})}$ and Approximate Frequency Under Normal Working Conditions

\begin{tabular}{||l|l|l|l||}
\hline \multicolumn{1}{|c|}{ Monitoring Variable } & Monitoring Method & $\begin{array}{l}\text { Planned Monitoring } \\
\text { Frequency }\end{array}$ & $\begin{array}{c}\text { Actual Monitoring } \\
\text { Frequency }\end{array}$ \\
\hline Soil-water content & $\begin{array}{l}\text { Neutron Moisture } \\
\text { Probe }\end{array}$ & Quarterly & Quarterly \\
\hline Soil-water content & Capacitance Probe & Every 6 hours & Hourly \\
\hline Soil-water pressure & Heat Dissipation Unit & Every 6 hours & Every 6 hours \\
\hline Soil temperature & Heat Dissipation Unit & Every 6 hours & Every 6 hours \\
\hline Air temperature & Thermistor & Hourly & Every 15 minutes \\
\hline Precipitation & Rain Gauge & Hourly & Every 15 minutes \\
\hline (a) All measurements except the neutron probe are controlled by dataloggers and taken automatically.
\end{tabular}

Neutron-moisture-probe measurements are performed manually at 1-foot intervals to the depths of the access tubes following the neutron-probe-measurement procedure documented in CH2M HILL (Ross 
2007). The dataloggers control and store the measurement data of moisture content from capacitance sensors, soil-water pressure and soil temperature from HDUs, precipitation from the rain gauge, and air temperature from the thermistor.

\subsection{Water Use During Barrier Construction}

For the purpose of dust control and soil compaction, water was sprinkled on the ground surface where the surface barrier was to be emplaced. The amount of water and the sprinkling dates are given in Appendix A. In total, 104,000 gallons of water were applied by a 4000-gallon truck. All of the water was sprinkled between October 24 and November 16, 2007, except the last truckload of water was sprinkled on March 15,2008 . The sprinkled water was equivalent to a cumulative of $50-\mathrm{mm}$ precipitation assuming that the barrier is a 300-ft-diameter circle and the sprinkled water was applied to an area 1.2 times the area of the barrier. Due to the relatively low temperature during this period, it is expected that a significant amount of the sprinkled water infiltrated into the soil. As will be shown in the results section, the sprinkled water created a pulse of high water content and high pressure head in the soil.

\subsection{Data-Analysis Methodology}

The methodology described in Sections 6.2 and 6.3 of the Monitoring Plan provided a general guidance for data analysis. To reduce the amount of data, daily-average values of each variable were calculated for further analyses. Instrument performance was evaluated by examining measurements against the instrument-performance indicators listed in Table 6.2 of the Monitoring Plan. Instrument functionality was assessed by examining the battery voltages and soil temperature. Additionally, the measured precipitation and air temperature at T Tank Farm were compared with those from the HMS. The following sections describe the details of removing anomalous data, the methodology to correct the temperature impacts on the CPs and the HDUs, and method to calculate the normalized neutron counts.

\subsubsection{Removal and Correction of Anomalous Data}

The causes for anomalous data generally were (but are not limited to) interruptions of the system due to checking and/or other operations. When water was sprinkled on ground surface for dust control and compaction, some of the water entered into the $\mathrm{CP}$ access tube in Nest $\mathrm{A}$ and caused the probe to malfunction. Hence, this probe was either not functional or reported anomalous data after January 31, 2008. When the problem was identified, in May 2008, the damaged probe (referred to as CP-a1) in Nest A was replaced with a spare capacitance probe (referred to as $\mathrm{CP}-\mathrm{a} 2$ ), which was again damaged by the water at the bottom of the access tube. While waiting for a new $\mathrm{CP}$ on order, a probe (referred to as CPa3) was assembled with undamaged sensors of CP-a1 and CP-a2 and was normalized in the vessel provided by the probe distributor, i.e., Campbell Scientific, Inc. CP-a3 was installed in the field in August 2008. It was found that the results from CP-a3 were significantly different from those from CPa1. This difference was due to the use of different normalization vessel. Also, the $0.9-\mathrm{m}$ depth CP sensor in Nest D showed noisy data. Therefore, any data from the CP in Nest A after January 31 and the data from the 0.9-m depth $\mathrm{CP}$ sensor Nest $\mathrm{D}$ were not considered in this report.

In addition to the winter precipitation, the sprinkled water made the soil much wetter than it would be under normal conditions. Consequently, the HDUs at the 1-m and 2-m depths showed pressure-head values higher than the upper measurement limit, i.e., $-1 \mathrm{~m} \mathrm{H}_{2} \mathrm{O}$ height. Some values were even greater than the pressure head at saturation (i.e., zero). Considering that it is improbable for the soil to be fully saturated, the pressure head greater than zero were reported as zero. 
The sensors in Nests C and D were hooked up for logging on May 3, 2008. It was found out that the 5-m and 9-m-depth HDUs in Nest C were misconnected to each other's ports. This misconnection was corrected on August 16, 2008. The data for the two sensors before this date were corrected.

In the deep vadose zone, the soil-water conditions are generally stable, and no significant annual change should occur if no extreme event happens. Hence, the pattern of the neutron logging profile from the same location should be very similar among different logging events. Two types of error, i.e., incorrect logging depth or incorrect counts (typos), may happen during a neutron logging because the operation and data recording were manual. Four obvious typos (e.g., the NP counts were off by 1000) in the data were corrected after comparing a value with those logged before and/or after these dates at the same location. Six observations of the Nest B logging on April 9, 2008, were suspicious and the logging depths for most data points were off by 1 or $2 \mathrm{ft}$. Hence Nest B was re-logged on May 25, 2008 and confirmed the neutron logging for Nest B on April 9, 2008 was incorrect.

\subsubsection{Temperature-Correction on HDU Measurements}

The HDU-measured soil-water pressure was based on the calibration curves for $20^{\circ} \mathrm{C}$. Because the thermal conductivity of the HDUs is temperature dependent, the measurements taken at different reference temperatures need to be corrected to the reference temperature. The correction equation of Flint et al. (2002) was used to correct for temperature effects for HDUs calibrated at $20^{\circ} \mathrm{C}$ :

$$
\begin{gathered}
S_{\Delta T}^{*}=S_{\Delta T}-S(T-20) \\
S=c_{0}+c_{1} S_{\Delta T}+c_{2} S_{\Delta T}^{2}+c_{3} S_{\Delta T}^{3}+c_{4} S_{\Delta T}^{4}+c_{5} S_{\Delta T}^{5}
\end{gathered}
$$

where $\mathrm{S}_{\Delta \mathrm{T}}{ }^{*}$ is the corrected $\mathrm{S}_{\Delta \mathrm{T}}$

$\mathrm{S}$ is an intermediate variable

$\mathrm{T}$ is the field temperature

$\mathrm{c}_{0}=0.0013$

$\mathrm{c}_{1}=0.011$

$\mathrm{c}_{2}=0.0203$

$c_{3}=-0.0747$

$\mathrm{c}_{4}=0.0559$

$c_{5}=-0.0133$

\subsubsection{Temperature-Correction on Capacitance-Probe Measurements}

Generally, there is a positive relationship between the capacitance sensor measurement and the soil temperature due to the temperature effects on the dielectric properties of water and air. Assuming that the factory calibration was conducted at $20^{\circ} \mathrm{C}$, the correction equation under any soil temperature condition was

$$
\theta^{*}=\theta-b(T-20)
$$

where $\theta^{*}$ and $\theta$ are the volumetric water contents with and without temperature correction, respectively, $\mathrm{T}$ $\left({ }^{\circ} \mathrm{C}\right)$ is soil temperature, and $\mathrm{b}$ is a coefficient of temperature impact on measurement. Evett et al. (2006) reported an average value of $b=0.0011 \mathrm{~m}^{3} \mathrm{~m}^{-3}{ }^{\circ} \mathrm{C}^{-1}$ for the EnviroSCAN CP, which is similar to the EnviroSMART probe used in the T Tank Farm and made by the same manufacturer. Hence, this average $b$ value was used to calibrate the temperature impacts on the capacitance sensors. 
Each CP contains five sensors residing at different depths. However, there were no soil-temperature measurements corresponding to each sensor. Hence, the HDU-measured soil temperature at 1- and 2-m depths was linearly interpolated or extrapolated to estimate soil temperatures at the remaining depths. In the future, sufficient temperature sensors should be installed at the depths corresponding to the depths of the $\mathrm{CP}$ sensors so that temperatures will not be approximated by interpolation or extrapolation as described above.

\subsubsection{Normalized Neutron Counts}

For the neutron-probe measurements, the original data were recorded as neutron counts $(\mathrm{N})$ per 16 seconds at each location of measurement. A standard count $\left(\mathrm{N}_{\mathrm{s}}\right)$ was also recorded before each logging practice. Four logging episodes were conducted using neutron probe H-38068291. The probe was not calibrated to the steel neutron access tube (2.5-inch-OD, 0.375-inch-thick 4140 carbon steel), and hence the actual soil-water content could not be determined. As a result, the neutron counts were normalized by the standard count $\mathrm{N}_{\mathrm{n}}=\mathrm{N} / \mathrm{N}_{\mathrm{s}}$, and the $\mathrm{N}_{\mathrm{n}}$ values are reported.

\subsection{Quality Assurance}

To verify the quality of the project, a stand-alone project management plan (PMP) was prepared and approved by the product line manager. A quality assurance plan (QAP) was also prepared. This project was conducted in accordance with the PMP and QAP. 


\subsection{Functionality of the Monitoring System}

The functionality of the monitoring system is evaluated in this section. The battery voltage is examined because most instruments require a minimum of $12 \mathrm{~V}$ to remain in normal operation. The functionality of the instrument nests and meteorological station was assessed by comparing the measured air temperature and precipitation at the T Tank Farm with those measured at the HMS, which is $1.7 \mathrm{kms}$ from the T Tank Farm. Soil-temperature behavior was examined to assess the functionality of the HDUs. The functionality of the CPs and HDUs when used for pressure head measurements are also briefly summarized while the monitoring results are presented in Section 4.0.

\subsection{Battery Voltage}

Rechargeable batteries were used for the instrument nests and the meteorological station. Each battery was recharged by a connected solar panel. Battery voltage greater than $12 \mathrm{~V}$ is required to provide sufficient power to the instrument. The variations in battery voltages are plotted in Figure 3.1. The lowest battery voltage occurred in November 2007 when solar energy was least available. However, for all five batteries, the minimum voltage was no less than $12.6 \mathrm{~V}$, which indicates sufficient power to the instruments.

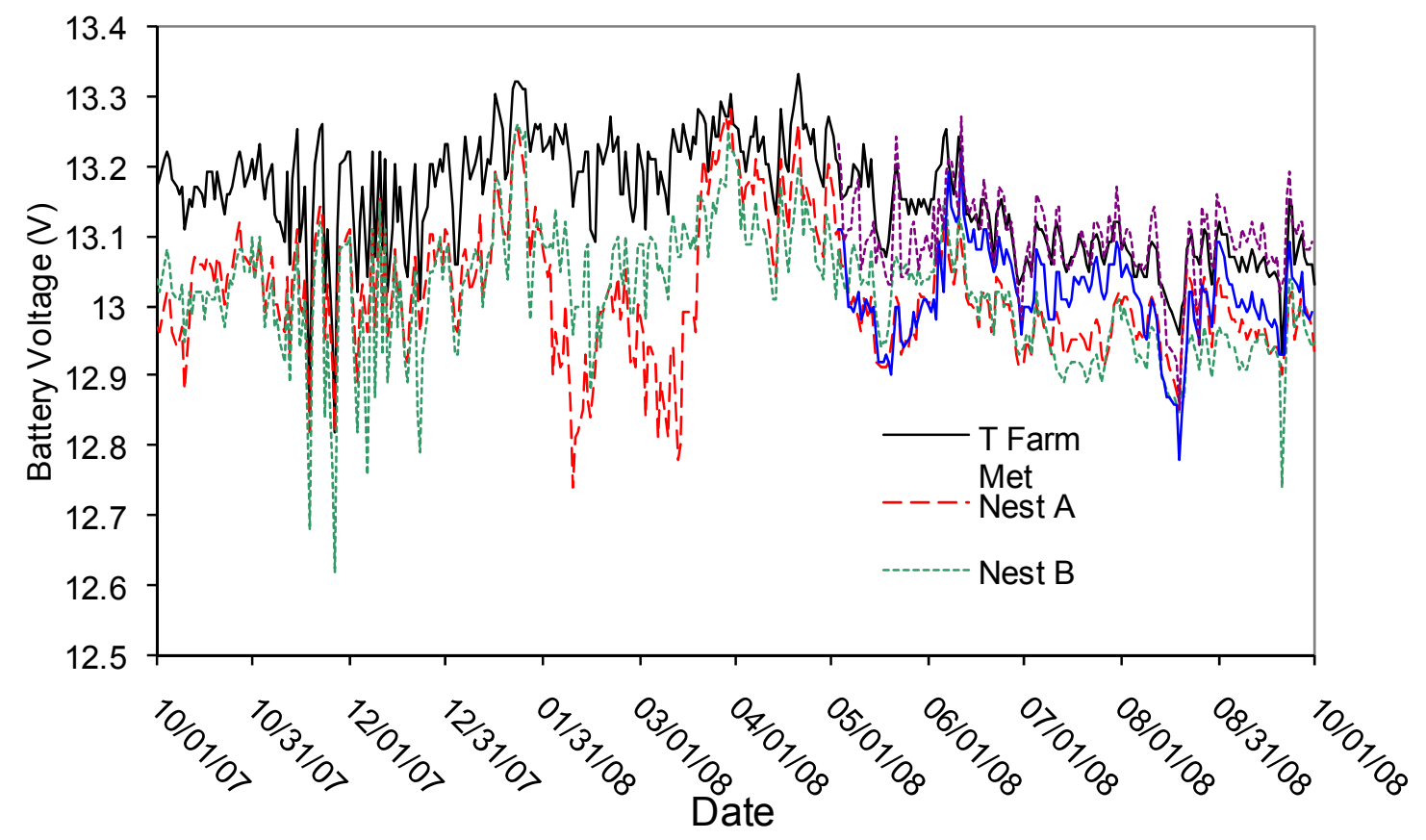

Figure 3.1. Daily Average Battery Voltage

\subsection{Air Temperature}

The daily average air temperature measured at the meteorological station located outside of the fence of $\mathrm{T}$ Tank Farm and the air temperature from the HMS are plotted in Figure 3.2. Also plotted are the reference temperatures of the dataloggers in the instrument nests. The temperature measurements from the different locations were very consistent. Between all locations, the difference in daily average temperature was within about $\pm 3^{\circ} \mathrm{C}$. The FY08 annual average air temperatures were $11.5^{\circ} \mathrm{C}$ at $\mathrm{HMS}$, $12.1^{\circ} \mathrm{C}$ at the T Farm meteorological station, $11.8^{\circ} \mathrm{C}$ at the enclosure of Nest A, and $12.1{ }^{\circ} \mathrm{C}$ at the enclosure of Nest B. The measurements at the T Tank Farm were about $0.3 \sim 0.6^{\circ} \mathrm{C}$ higher than those at 
HMS. This difference is consistent with that in FY07 $\left(0.3 \sim 0.6^{\circ} \mathrm{C}\right)$. The air temperatures from the sensors in Nests $\mathrm{C}$ and $\mathrm{D}$ were consistent with those of A and B. These indicate that the datalogger for each of the instrument Nests were functioning properly.

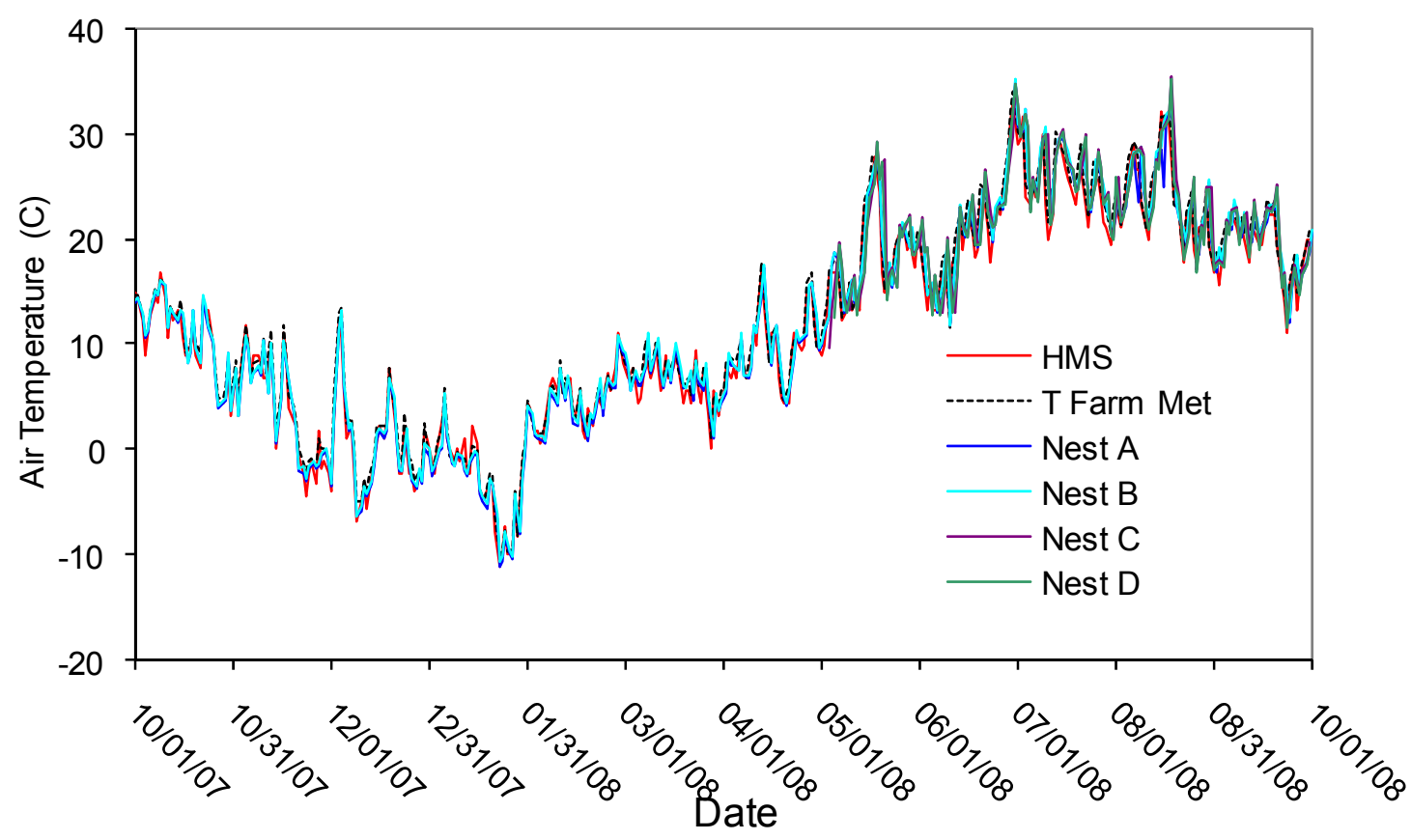

Figure 3.2. Daily Average Air Temperature

\subsection{Precipitation}

The FY08 cumulative precipitation measured outside of the fence of the T Tank Farm and that from the HMS are plotted in Figure 3.3. The cumulative precipitation at the T Tank Farm without correction was $49.8 \mathrm{~mm}(36.0 \%)$ lower than that at the HMS (Figure 3.3a). A recalibration of the rain gauge outside of the fence of the T Farm showed the water volume of the tipping spoon varied by $20.5 \%$ from an equivalency of $0.254 \mathrm{~mm}$ to $0.306 \mathrm{~mm}$ precipitation. After correcting this variation, the cumulative precipitation at the T Farm was $31.6 \mathrm{~mm}(22.8 \%$ ) lower than that at the HMS (Figure 3.3b). There are a couple of possible reasons for this difference. 1) The rain gauge in the T Tank Farm is not heated and hence the precipitation as snow cannot be measured. This seemed to significantly affect the precipitation measurement in January 2008 (32.5 mm in HMS and $16.8 \mathrm{~mm}$ in T Tank Farm). 2) It was also found that some debris (e.g., leaves) deposited within the rain gauge. This debris might have prevent some of the rain water entering into the tipping and the water eventually was lost by evaporation. The debris might have affected the precipitation measurement after August 8,2008. The rain gauge was recalibrated and debris cleared up on October 23, 2008. Hence, the spoon volume drifted off with time and the debris could also have caused the underestimation of the precipitation. Hence, for the winter months with significant snow, the precipitation in the HMS may be used. Routine maintenance of the rain gauge should also be taken. 

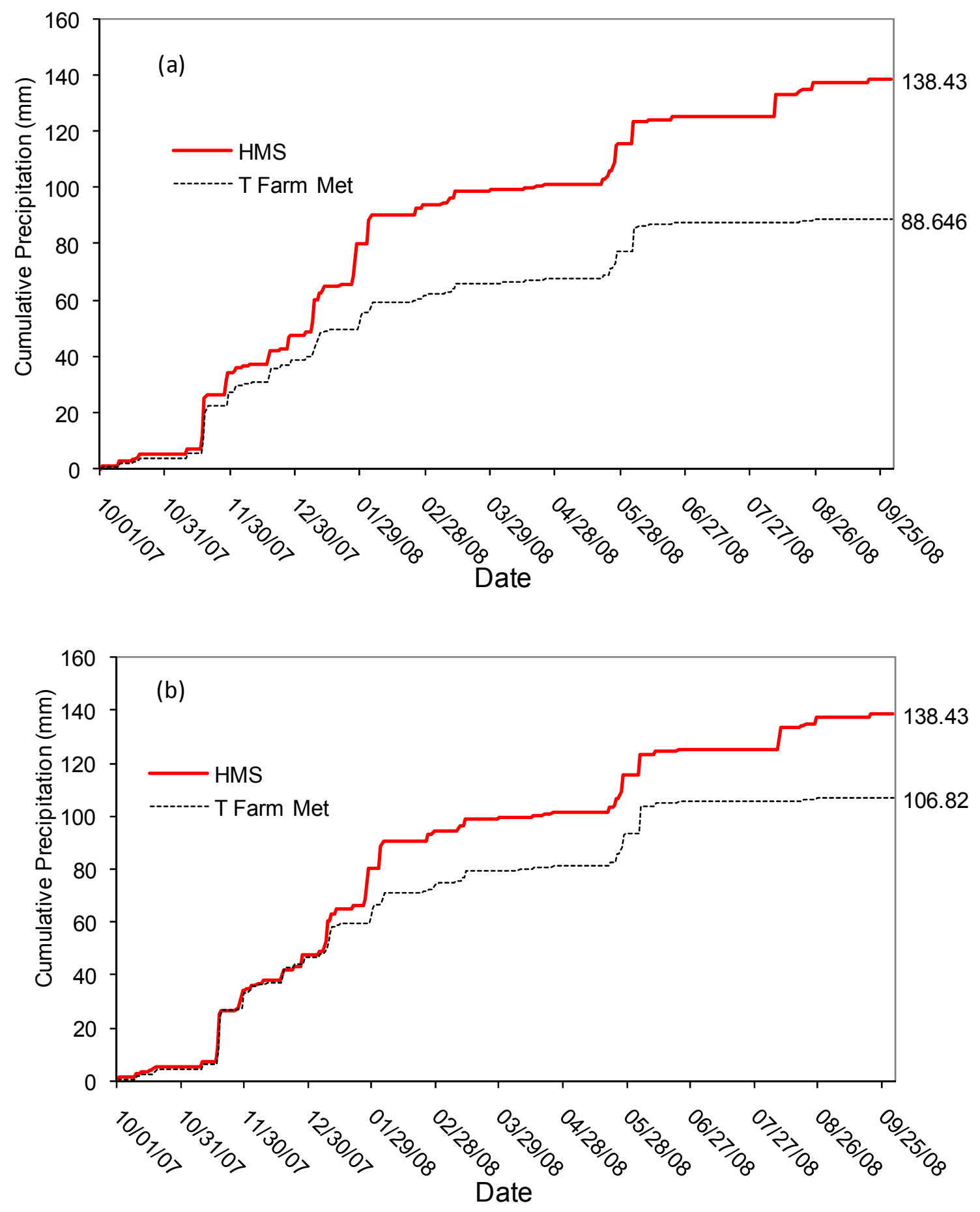

Figure 3.3. FY08 Cumulative Precipitation at the T Tank Farm and Hanford Meteorological Station a) before and b) after tipping volume correction.

\subsection{Soil Temperature}

Complete data sets from October 2007 through September 2008 were obtained for Nests A and B. Nests $\mathrm{C}$ and D started logging on May 2008 after the surface barrier construction was completed. Figure 3.4 
shows the daily average soil temperatures $(\mathrm{T})$ measured by the HDUs for the four instrument nests. The HDU-measured FY08 average $\left(\mathrm{T}_{\text {avg }}\right)$, minimum $\left(\mathrm{T}_{\min }\right)$, and maximum $\left(\mathrm{T}_{\max }\right) \mathrm{T}$ and the standard deviation of $\mathrm{T}$ for Nests A and B are summarized in Table 3.1.

Nest A resides outside of the barrier footprint (see Figure 1.1). The soil temperature varied seasonally with a lag of phase relative to the variation of air temperature. The soil temperature at the 1-m depth decreased to the minimum $\left(2.5^{\circ} \mathrm{C}\right)$ in late January to early February, after which the soil temperature started to increase and reached the maximum $\left(29.3^{\circ} \mathrm{C}\right)$ in mid-August, with an annual average of $15.8^{\circ} \mathrm{C}$. The soil temperature at the $2-\mathrm{m}$ depth decreased to the minimum $\left(6.9^{\circ} \mathrm{C}\right)$ in mid-February before beginning to increase to the maximum $\left(25.2^{\circ} \mathrm{C}\right)$ in late August, with an annual average of $16.0^{\circ} \mathrm{C}$. The soil temperature at the 5-m depth reached its minimum $\left(14.1^{\circ} \mathrm{C}\right)$ in early April and the maximum $(19.5$ ${ }^{\circ} \mathrm{C}$ ) late October, with an annual average of $16.6^{\circ} \mathrm{C}$. The soil temperature at the $10-\mathrm{m}$ depth was stable at $16.9 \pm 0.5^{\circ} \mathrm{C}$. These results are very similar to those of Nest A in FY07 with a deviation generally within $\pm 0.5^{\circ} \mathrm{C}$.

Nest B resides near the edge but under the surface barrier (see Figure 1.1). Generally, the soil-temperature variation in Nest B is similar to that of Nest A. However, the magnitude of soil-temperature variation at the 1-m and 2-m depths were smaller than those of Nest A. At 1-m depth, $\mathrm{T}_{\min }$ was $3.3{ }^{\circ} \mathrm{C}$ higher, $\mathrm{T}_{\max }$ $5.3{ }^{\circ} \mathrm{C}$ lower, and $\mathrm{T}_{\text {avg }} 1.3{ }^{\circ} \mathrm{C}$ lower for Nest B than those for Nest A. At $5-\mathrm{m}$ and $10-\mathrm{m} \mathrm{depths,} \mathrm{the}$ temperature differences between the two Nests were no more than $\pm 0.2^{\circ} \mathrm{C}$.

For the reason of comparison of soil temperature among soil nests, the temperature statistics for all the instrument nests after May 4, 2008, are listed in Table 3.2 and the average $\mathrm{T}$ is also shown in Figure 3.5. At 1-m and 2-m depths, soil temperature of Nests B, C, and D in the summer of 2008 were very similar (varied by no more than $\pm 0.2^{\circ} \mathrm{C}$ ) due to the impact of the surface barrier. At 5-m and 10-m depths, temperature different between the Nests were no more than $\pm 0.4^{\circ} \mathrm{C}$.

These results indicate that the HDUs were functioning properly when used to measure soil temperature and the communication between HDUs and the dataloggers did not have any problem. However, this does not mean that the correct measurement of soil water pressure head were obtained with the HDUs.

\subsection{Soil-Water Pressure Head}

According to the HDU specification (Campbell Scientific, Inc. 2006), the upper-limit of HDU-measured $\psi$ is $-1 \mathrm{~m} \mathrm{H}_{2} \mathrm{O}$ height. Theoretically, the HDU should report a constant value of $-1 \mathrm{~m}$ for the $\psi$ values $>-1$ $\mathrm{m}$. Some $\psi$ values measured by HDUs were greater than $-1 \mathrm{~m}$ but not constant. This indicates that these HDUs were still responding to the variation of soil-water pressure. Possible explanations are: a) the actual upper limit of ceramic of the HDUs may be higher than $-1 \mathrm{~m}$; b) some uncertainty from the calibration equation; and c) the ceramic was partly damaged causing a different measurement under the same soilwater pressure condition (the damage may happen during installation). Because the HDUs, once buried underground, are unlikely to be checked further by being dug out, it is suggested that the upper limit of the HDUs be examined before any future deployments or a different installation method be used so that the sensors are maintainable.

\subsection{CP-Measured Soil-Water Content}

All the CPs were functioning properly except the Nest A CP after January 31, 2008 (see Section 2.5.1 for details). The 0.9-m depth CP in Nest D showed noisy data before August 23, 2008. 

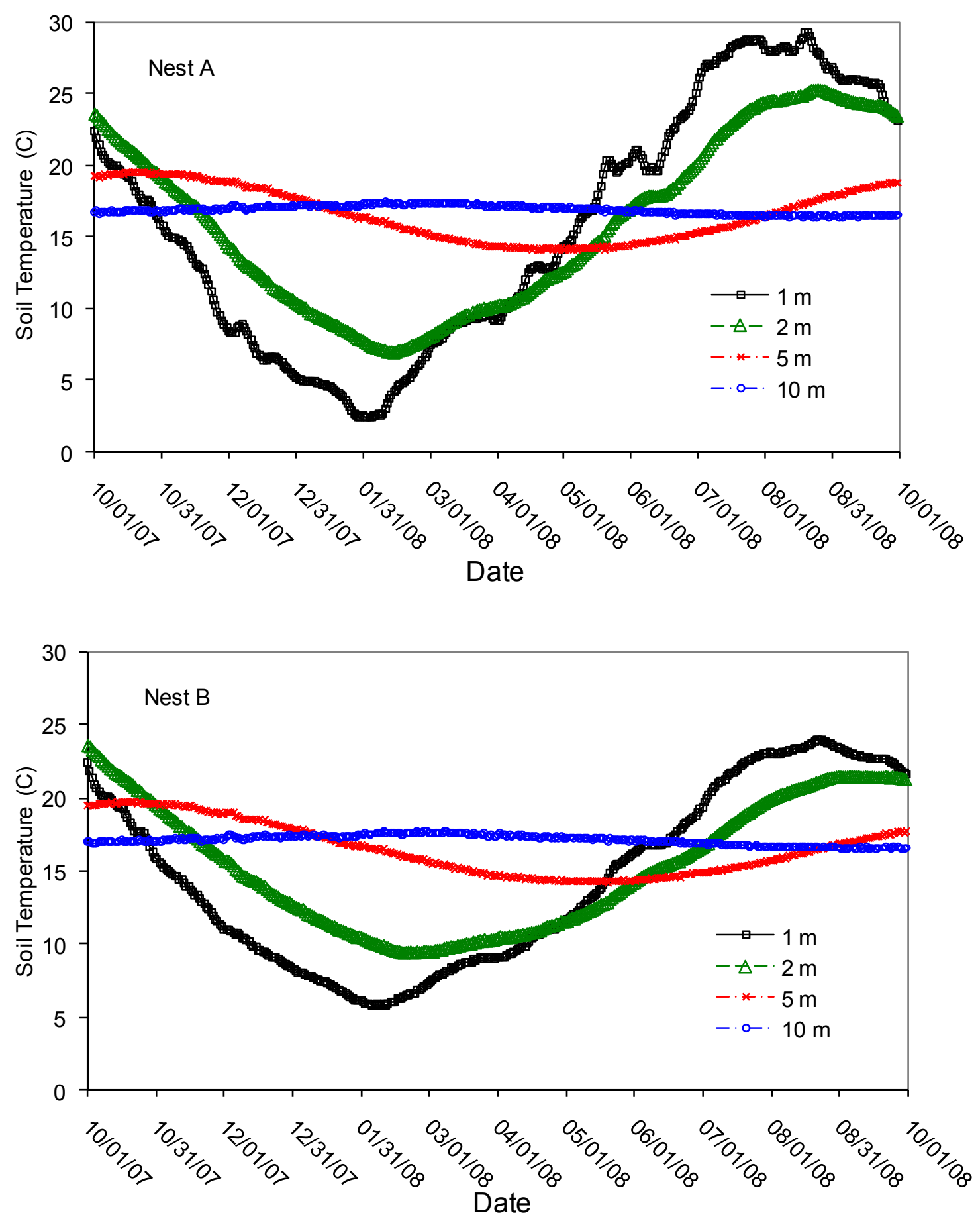

Figure 3.4. Daily Average Soil Temperature at Different Depths Measured Using the HDUs (the HDUs in Nests C and D started logging on May 4, 2008) 

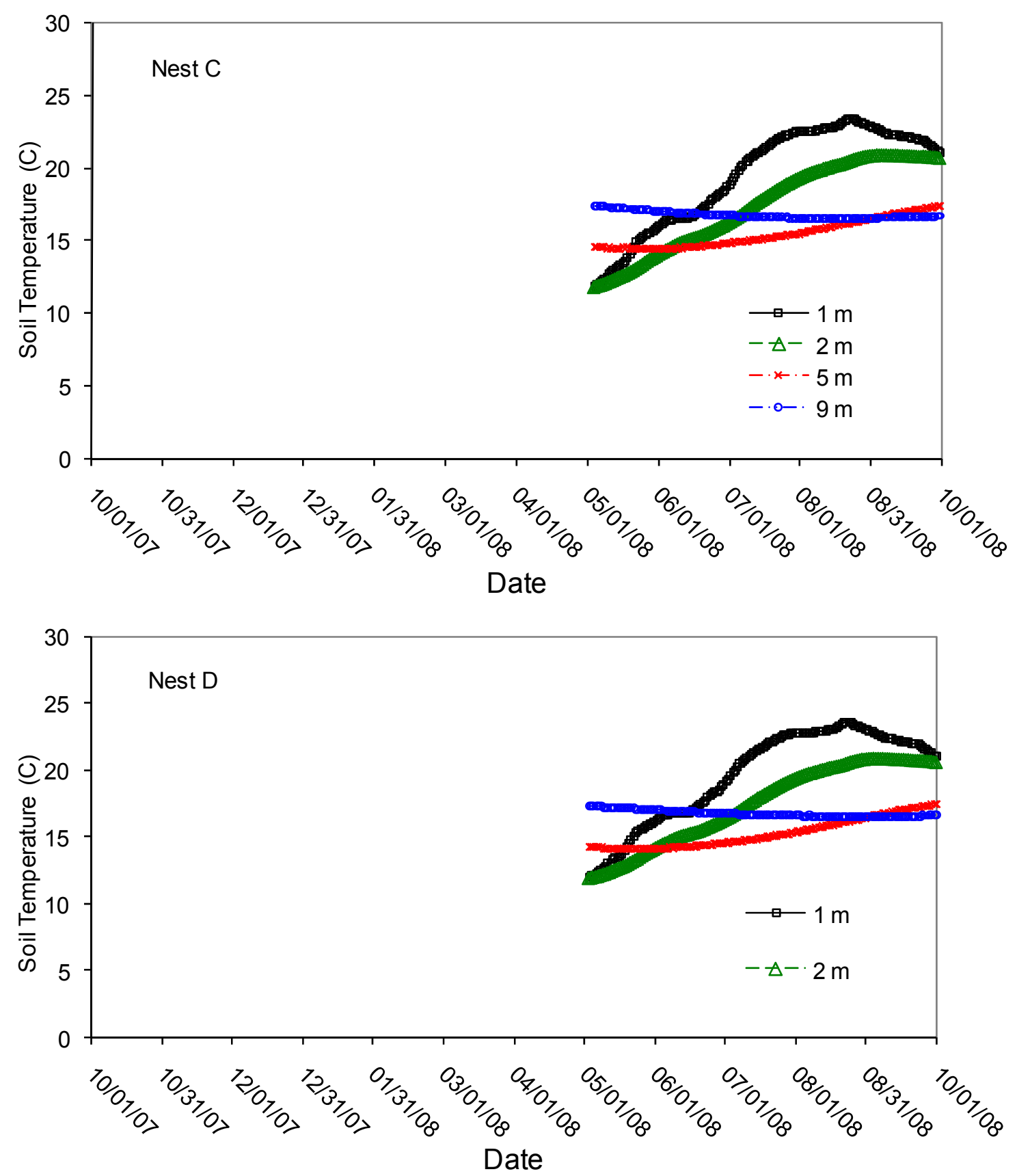

Figure 3.4. Daily Average Soil Temperature at Different Depths Measured Using the HDUs (the HDUs in Nests C and D started logging on May 4, 2008) (Cont.) 
Table 3.1. The FY08 Annual HDU-Measured Average $\left(\mathrm{T}_{\text {avg }}\right)$, Minimum $\left(\mathrm{T}_{\min }\right)$, Maximum $\left(\mathrm{T}_{\max }\right)$, and Standard Deviation $\left(\mathrm{T}_{\text {std }}\right)$ of Soil Temperature for Nests A and B

\begin{tabular}{||c|c|l|l|l|l||}
\hline Nest & $\begin{array}{c}\text { Depth } \\
(\mathbf{m})\end{array}$ & $\begin{array}{c}\mathbf{T}_{\text {avg }} \\
\left({ }^{\circ} \mathbf{C}\right)\end{array}$ & $\begin{array}{c}\mathbf{T}_{\text {min }} \\
\left({ }^{\circ} \mathbf{C}\right)\end{array}$ & $\begin{array}{c}\mathbf{T}_{\max } \\
\left({ }^{\circ} \mathbf{C}\right)\end{array}$ & $\begin{array}{c}\mathbf{T}_{\text {std }} \\
\left({ }^{\circ} \mathbf{C}\right)\end{array}$ \\
\hline \multirow{4}{*}{ A } & 1 & 15.8 & 2.5 & 29.3 & 8.5 \\
\cline { 2 - 6 } & 2 & 16.0 & 6.9 & 25.2 & 6.1 \\
\cline { 2 - 6 } & 5 & 16.6 & 14.1 & 19.5 & 1.9 \\
\cline { 2 - 6 } & 10 & 16.9 & 16.4 & 17.5 & 0.3 \\
\hline \multirow{4}{*}{ B } & 1 & 14.5 & 5.8 & 24.0 & 6.1 \\
\cline { 2 - 6 } & 2 & 15.3 & 9.4 & 23.6 & 4.4 \\
\cline { 2 - 6 } & 5 & 16.6 & 14.2 & 19.8 & 1.8 \\
\cline { 2 - 6 } & 10 & 17.2 & 16.5 & 17.8 & 0.3 \\
\hline \hline
\end{tabular}

Table 3.2. The HDU-Measured Average $\left(\mathrm{T}_{\mathrm{avg}}\right)$, Minimum $\left(\mathrm{T}_{\min }\right)$, Maximum $\left(\mathrm{T}_{\max }\right)$, and Standard Deviation ( $\left.\mathrm{T}_{\text {std }}\right)$ of Soil Temperature for All Nests Since May 4, 2008 (the day Nests C and D started logging)

\begin{tabular}{||c|l|l|l|l|l||}
\hline $\begin{array}{c}\text { Depth } \\
(\mathbf{m})\end{array}$ & Nest & $\begin{array}{c}\mathbf{T}_{\text {avg }} \\
\left({ }^{\circ} \mathbf{C}\right)\end{array}$ & $\begin{array}{c}\mathbf{T}_{\min } \\
\left({ }^{\circ} \mathbf{C}\right)\end{array}$ & $\begin{array}{c}\mathbf{T}_{\max } \\
\left({ }^{\circ} \mathbf{C}\right)\end{array}$ & $\begin{array}{c}\mathbf{T}_{\text {std }} \\
\left({ }^{\circ} \mathbf{C}\right)\end{array}$ \\
\hline \multirow{4}{*}{1} & $\mathrm{~A}$ & 24.3 & 14.5 & 29.3 & 4.1 \\
\cline { 2 - 6 } & $\mathrm{B}$ & 19.9 & 11.9 & 24.0 & 3.7 \\
\cline { 2 - 6 } & $\mathrm{C}$ & 19.5 & 11.9 & 23.4 & 3.5 \\
\cline { 2 - 6 } & $\mathrm{D}$ & 19.7 & 12.0 & 23.6 & 3.5 \\
\hline \multirow{4}{*}{2} & $\mathrm{~A}$ & 21.0 & 12.8 & 25.2 & 3.9 \\
\cline { 2 - 6 } & $\mathrm{B}$ & 17.8 & 11.7 & 21.5 & 3.3 \\
\cline { 2 - 6 } & $\mathrm{C}$ & 17.4 & 11.8 & 20.9 & 3.1 \\
\cline { 2 - 6 } & $\mathrm{D}$ & 17.4 & 11.8 & 20.9 & 3.1 \\
\hline \multirow{4}{*}{5} & $\mathrm{~A}$ & 16.1 & 14.1 & 18.8 & 1.6 \\
\cline { 2 - 6 } & $\mathrm{B}$ & 15.6 & 14.2 & 17.8 & 1.1 \\
\cline { 2 - 6 } & $\mathrm{C}$ & 15.4 & 14.4 & 17.4 & 1.0 \\
\cline { 2 - 6 } & $\mathrm{D}$ & 15.3 & 14.2 & 17.4 & 1.0 \\
\hline \multirow{3}{*}{10} & $\mathrm{~A}$ & 16.6 & 16.4 & 17.1 & 0.2 \\
\cline { 2 - 6 } & $\mathrm{B}$ & 16.8 & 16.5 & 17.3 & 0.2 \\
\cline { 2 - 6 } & $\mathrm{C}$ & 16.7 & 16.4 & 17.4 & 0.3 \\
\cline { 2 - 6 } & $\mathrm{D}$ & 16.7 & 16.4 & 17.3 & 0.2 \\
\hline \multirow{3}{*}{} & & & & & \\
\hline
\end{tabular}




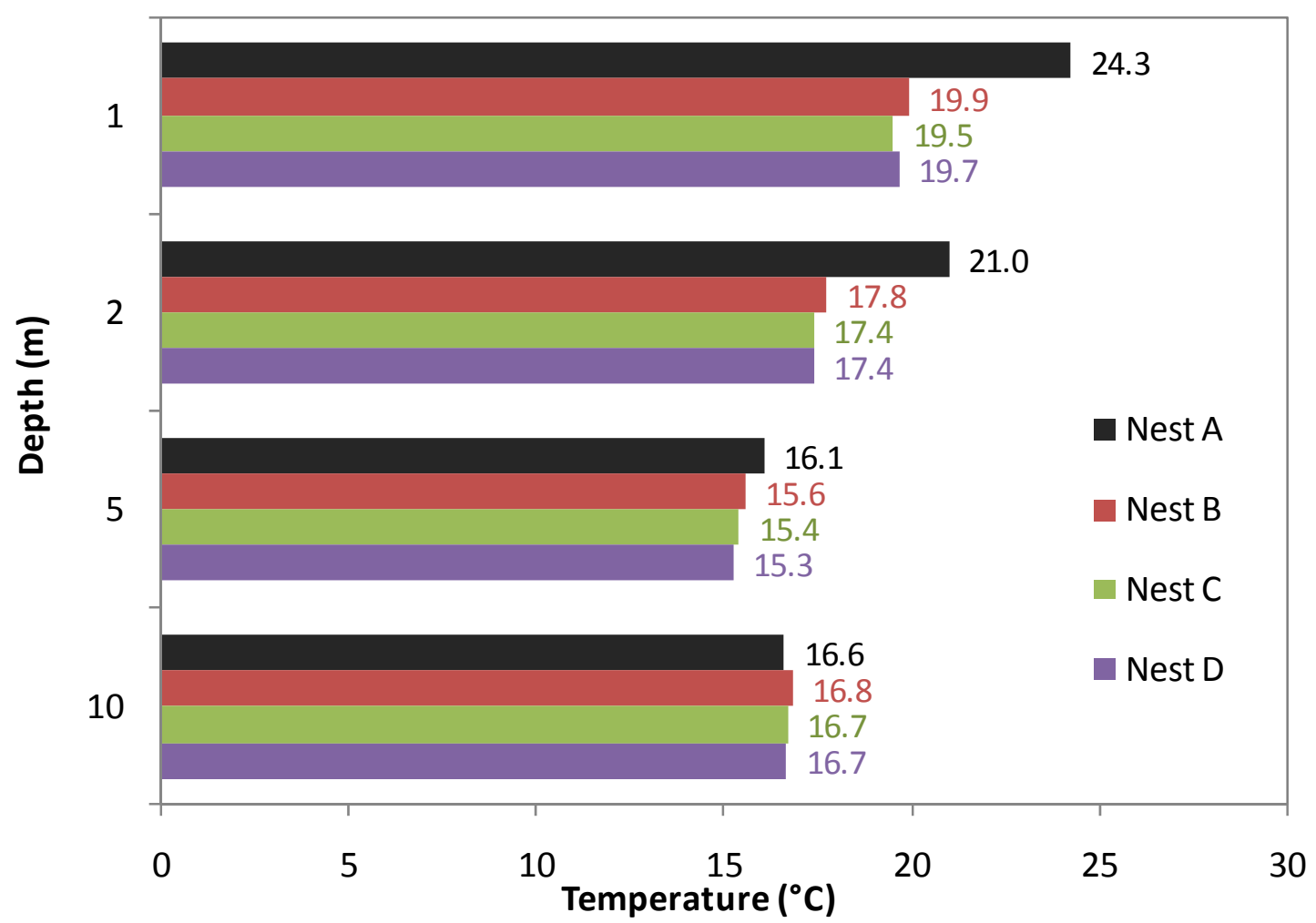

Figure 3.5. Average Soil Temperature at Different Depths Measured Using the HDUs Since May 4, 2008, the time the HDUs in Nests C and D started logging. 


\subsection{Monitoring Results}

In FY08, the interim surface barrier was constructed in the T Tank Farm and completed by April 2008. Equipment in Nests C and D was hooked up on May 3, 2008, for data logging. This section summarizes the water contents from the capacitance probes, the pressure head from the heat-dissipation-units and neutron-counts ratio from the NP. For better understanding of the seasonal variation of soil-water conditions, the FY08 climate conditions are reported as well.

\subsection{Climate Conditions}

Although the air temperature and precipitation were measured in the T Tank Farm, their purposes are to examine system functionality and detect any possible uneven distribution of precipitation. Hence, the data from the Hanford meteorological station are used here to describe the climate conditions.

Figure 4.1 shows the monthly precipitation in FY08 and the multi-year average values (from 1947 to 2007). ${ }^{(1)}$ The total precipitation in FY08 was $138.4 \mathrm{~mm}$, which was $19.9 \%$ less than the 61 -year average value of $172.7 \mathrm{~mm}$. FY08 winter (November-March) and summer (October, April-September) precipitations were $7.8 \%$ and $37.1 \%$ less the multi-year average values, respectively. Hence, FY08 had an average winter but a dry summer in regard to precipitation. Figure 4.2 shows the monthly air temperature in FY08 and the 63-year average values (from 1945 to 2007) ${ }^{(2)}$. The FY08 annual mean air temperature was $11.5^{\circ} \mathrm{C}$, which was $0.4^{\circ} \mathrm{C}$ less than the 63 -year average value.

In addition to natural precipitation, about $50 \mathrm{~mm}$ of water was sprinkled to the ground surface for dust control and soil compaction during a 3-week period before barrier construction.

\subsection{Soil-Water Content}

This section summarizes the results of soil-water content measured with the CPs and the normalized neutron counts by the NP.

\subsubsection{Capacitance-Probe Measurements}

The soil water dynamic is shown by the temporal variation of the soil-water content and soil-water content profiles on selected dates. A quantitative description is given by the annual average, minimum, and maximum values. As mentioned in Section 2.5.1, the data from the CP in Nest A after January 31, 2008, was discarded due to the malfunction caused by the water spray at ground surface during the surface barrier construction. The CP has been repaired in November 2008. The sensors in Nests C and D started logging on May 3, 2008.

Figure 4.3 shows the temporal variation of the soil-water content $(\theta)$ measured by the CPs for the four instrument nests. According to the data from Nest B, the soil-water content was increasing since late November 2007 and reached the maximum in late February 2008, followed by a slight decrease. At the 0.6-m depth, there were two fast increases in soil water content in late November and mid-February, respectively. These increases were also observed at the $0.9-\mathrm{m}$ depth. As will be shown later, these increases were also observed by the HDUs. The two fast increases corresponding to large infiltration events, one due to the sprinkled water from late October to mid-November and the other due to natural precipitation in the winter. At the 1.3-m depth and deeper, the soil-water contents were relatively stable

(1) Available at http://hms.pnl.gov/totprcp.htm. Verified in January 2009.

$\left({ }^{2}\right)$ Available at http://hms.pnl.gov/monmean.htm. Verified in January 2009. 
during FY08. For Nests C and D, the soil water content at all depths showed a slight decreasing trend from May to September, 2008.

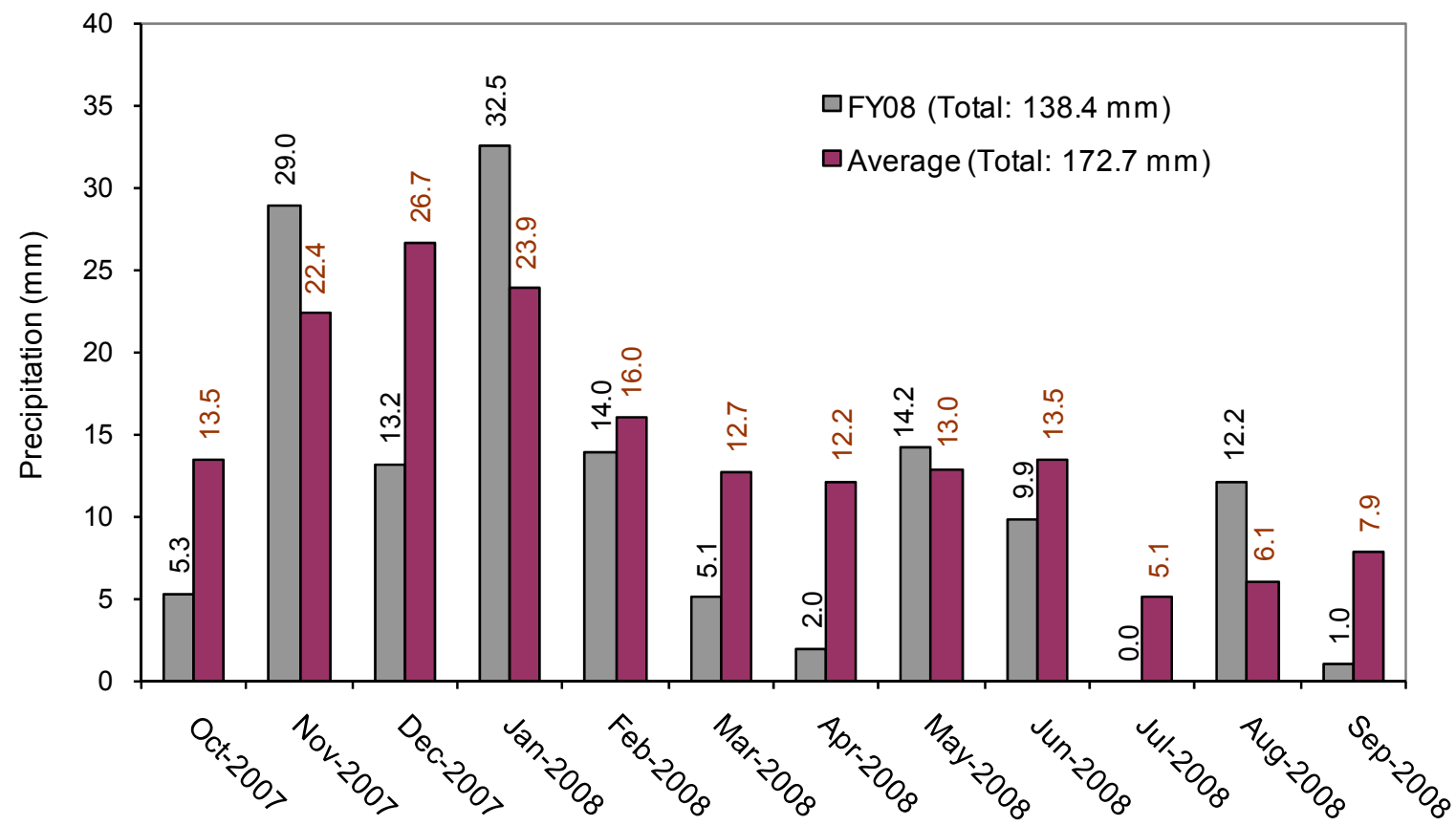

Figure 4.1. Monthly Precipitation (mm) in Hanford

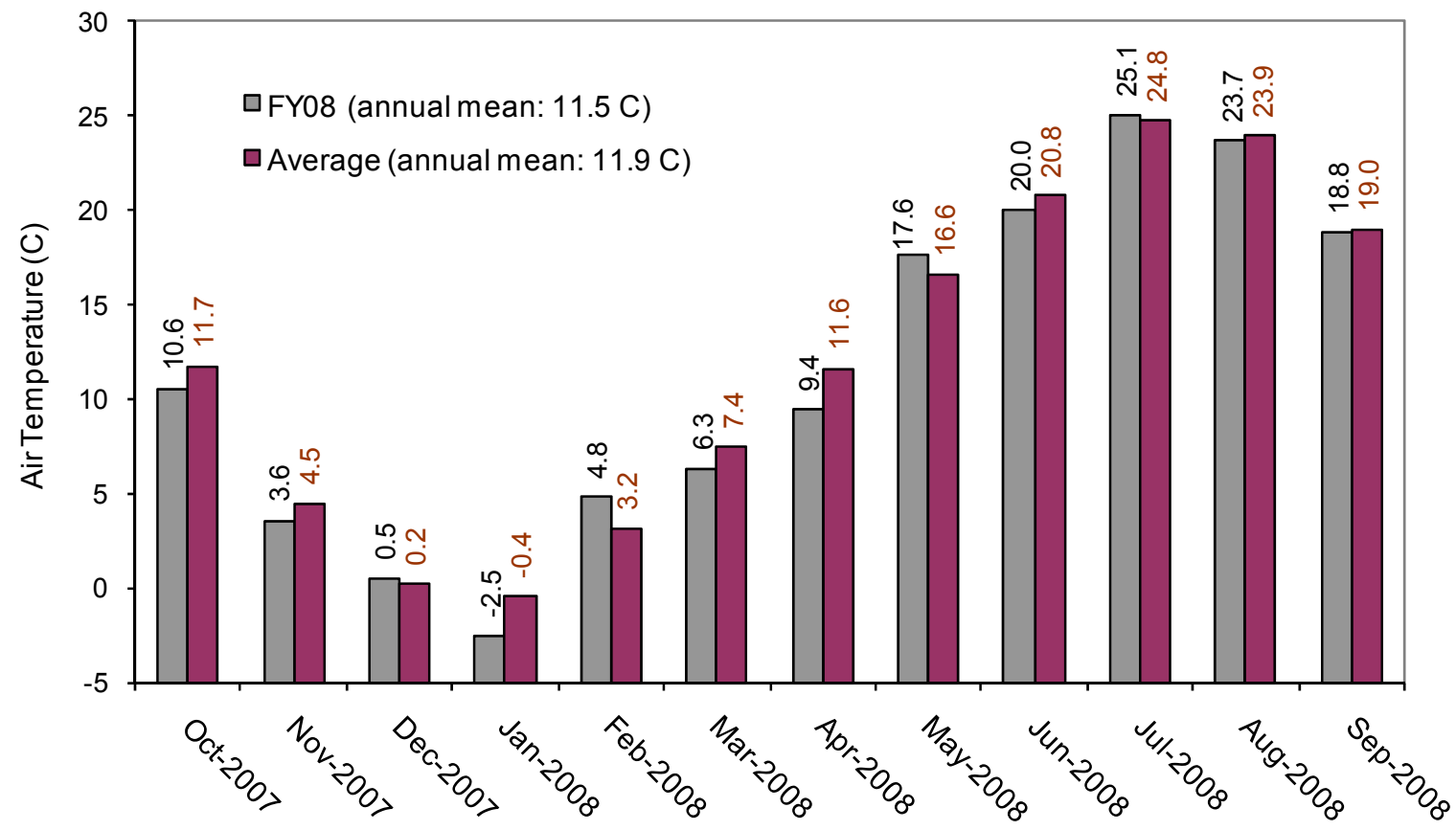

Figure 4.2. Monthly Air Temperature $\left({ }^{\circ} \mathrm{C}\right)$ in Hanford 

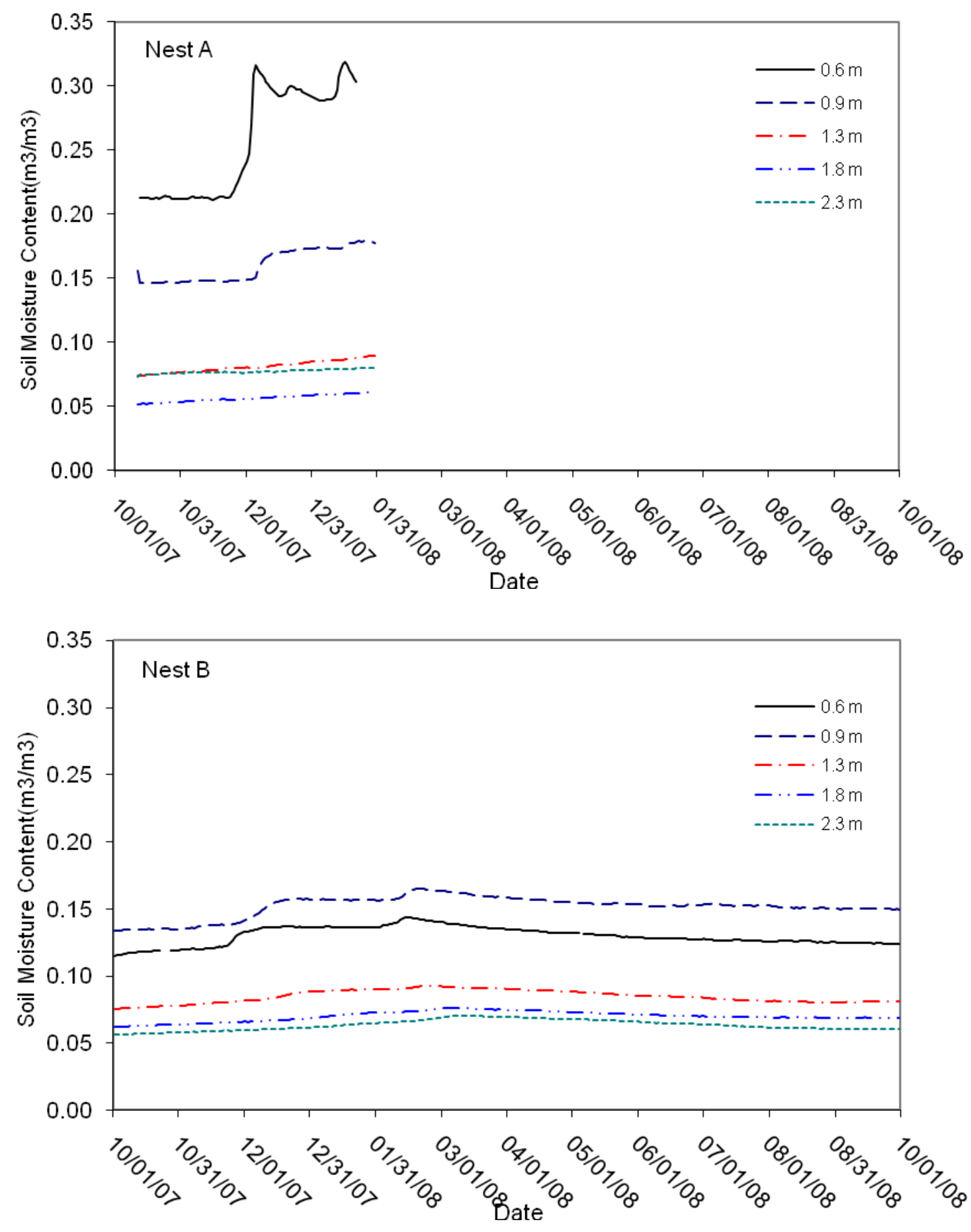

Figure 4.3. Daily Average Soil-Water Content at Five Depths Measured Using the CPs (the sensors in Nests C and D started logging on May 4, 2008; the data of the 0.9 -m-depth sensor in Nest D were noisy and not shown) 

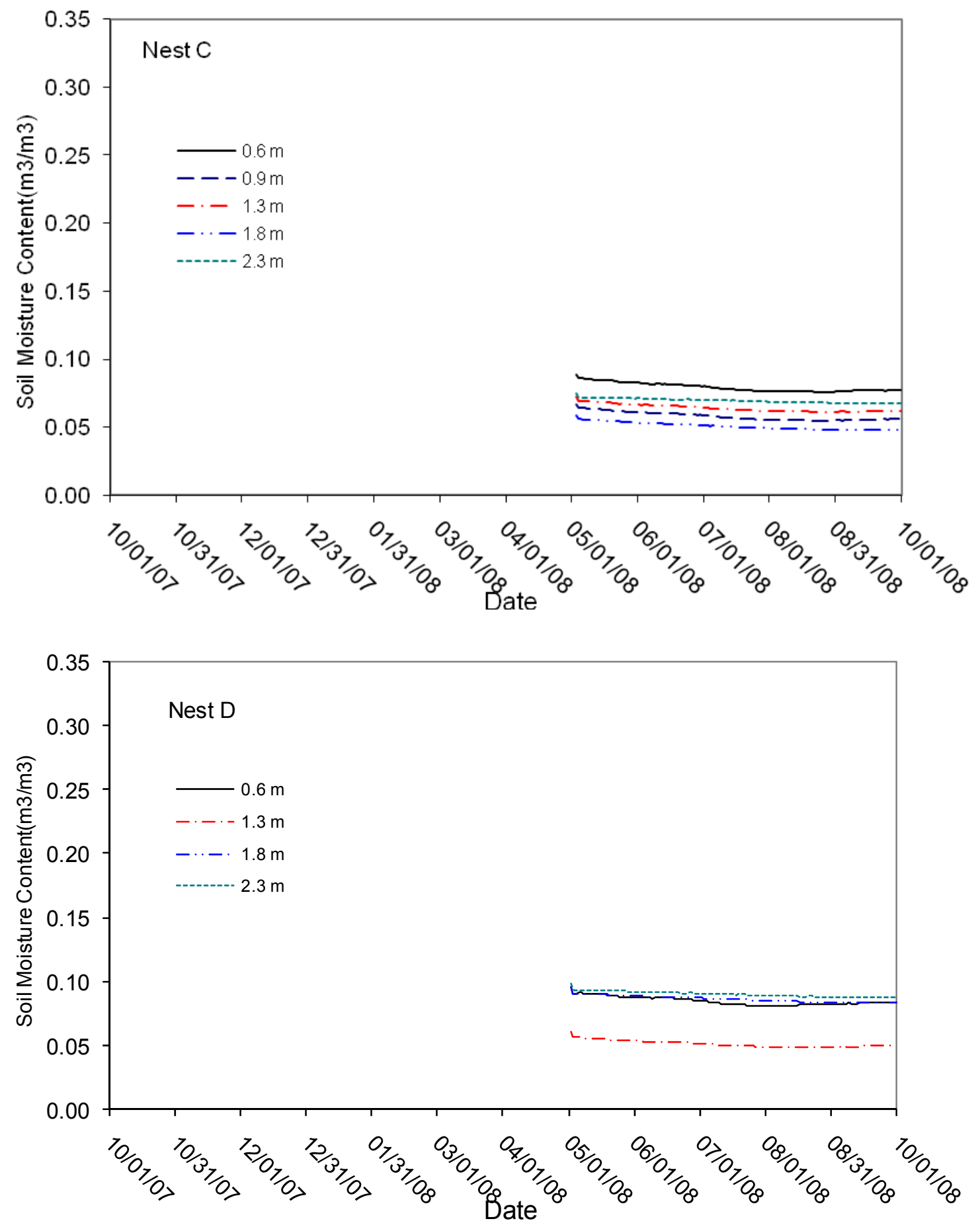

Figure 4.3. Daily Average Soil-Water Content at Five Depths Measured Using the CPs (the sensors in Nests C and D started logging on May 4, 2008; the data of the 0.9-m-depth sensor in Nest D were noisy and not shown) (Cont.) 

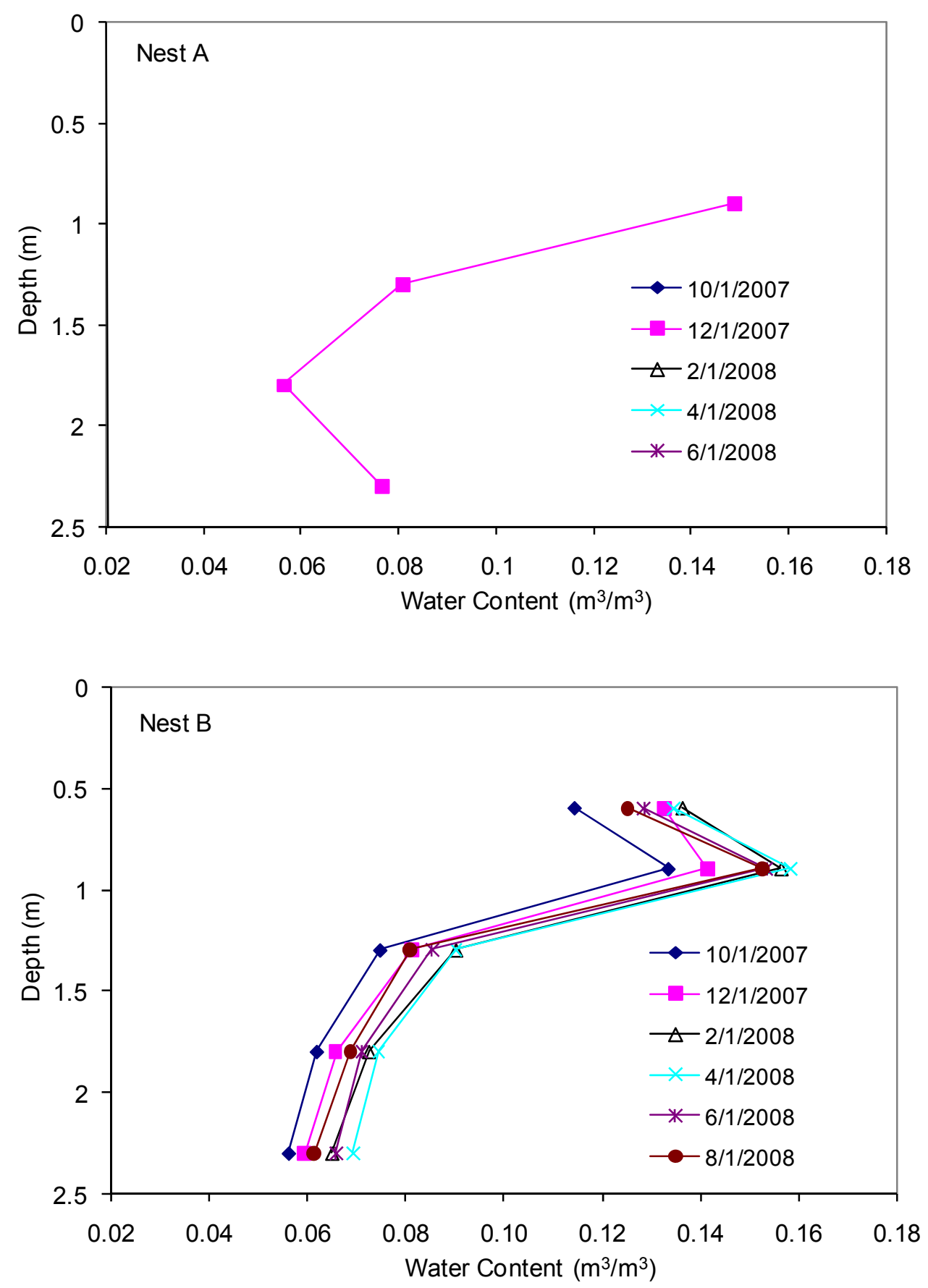

Figure 4.4. Soil-Water Content Profiles on Selected Dates for CPs (The CP in Nest A was not functional after January 31, 2008; the sensors in Nests C and D started logging on May 4, 2008) 

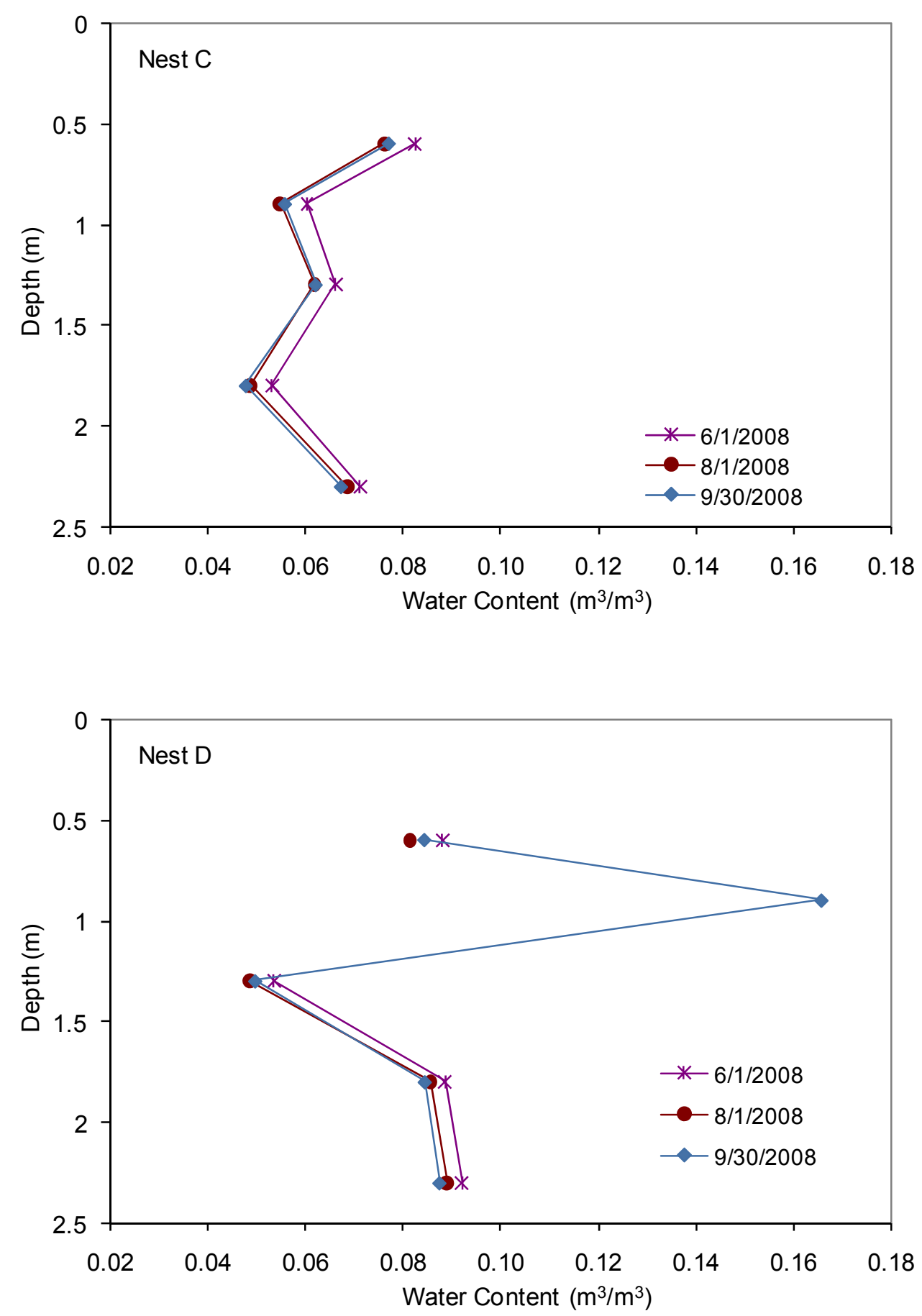

Figure 4.4. Soil-Water Content Profiles on Selected Dates for CPs (The CP in Nest A was not functional after January 31, 2008; the sensors in Nests C and D started logging on May 4, 2008) (Cont.) 
Table 4.1. The FY09 Average $\left(\theta_{\text {avg }}\right)$, Minimum $\left(\theta_{\min }\right)$ and Maximum $\left(\theta_{\max }\right)$ and Standard Deviation $\left(\theta_{\text {std }}\right)$ of Soil-Water Content for Nests A and B

\begin{tabular}{||c|c|c|c|c|c|c|}
\hline \multirow{3}{*}{ Nest } & \multirow{2}{*}{ Item } & \multicolumn{5}{|c|}{ Depth } \\
\cline { 3 - 7 } & & $0.6 \mathrm{~m}+$ & $0.9 \mathrm{~m}$ & $1.3 \mathrm{~m}$ & $1.8 \mathrm{~m}$ & $2.3 \mathrm{~m}$ \\
\hline \multirow{3}{*}{ Nest A $^{\dagger}$} & $\theta_{\text {avg }}$ & 0.257 & 0.160 & 0.081 & 0.057 & 0.077 \\
\cline { 2 - 7 } & $\theta_{\min }$ & 0.211 & 0.147 & 0.074 & 0.052 & 0.073 \\
\cline { 2 - 7 } & $\theta_{\max }$ & 0.319 & 0.179 & 0.090 & 0.061 & 0.080 \\
\cline { 2 - 7 } & $\theta_{\text {std }}$ & 0.0427 & 0.0129 & 0.0044 & 0.0027 & 0.0015 \\
\hline \multirow{3}{*}{ Nest B } & $\theta_{\text {avg }}$ & 0.130 & 0.152 & 0.085 & 0.070 & 0.063 \\
\cline { 2 - 7 } & $\theta_{\min }$ & 0.115 & 0.134 & 0.075 & 0.062 & 0.056 \\
\cline { 2 - 7 } & $\theta_{\max }$ & 0.144 & 0.165 & 0.093 & 0.076 & 0.070 \\
\cline { 2 - 7 } & $\theta_{\text {std }}$ & 0.0068 & 0.0081 & 0.0049 & 0.0035 & 0.0039 \\
\hline
\end{tabular}

$\dagger$ The data were available from Oct. 1, 2007 to Jan. 30, 2008, after which the probe was not functional.

+tThe measurements from this sensor were exceptionally high due to possible impact of sealing bentonite.

Table 4.2. The Average $\left(\theta_{\text {avg }}\right)$, Minimum $\left(\theta_{\min }\right)$ and Maximum $\left(\theta_{\max }\right)$ and Standard Deviation $\left(\theta_{\text {std }}\right)$ of SoilWater Content for All Nests After May 4, 2008

\begin{tabular}{|c|c|c|c|c|c|c|}
\hline \multirow{2}{*}{ Nest } & \multirow{2}{*}{ Item } & \multicolumn{5}{|c|}{ Depth } \\
\hline & & $0.6 \mathrm{~m}$ & $0.9 \mathrm{~m}$ & $1.3 \mathrm{~m}$ & $1.8 \mathrm{~m}$ & $2.3 \mathrm{~m}$ \\
\hline \multirow{4}{*}{ Nest $\mathrm{A}^{\dagger}$} & $\theta_{\mathrm{avg}}$ & - & - & - & - & - \\
\hline & $\theta_{\min }$ & - & - & - & - & - \\
\hline & $\theta_{\max }$ & - & - & - & - & - \\
\hline & $\theta_{\text {std }}$ & - & - & - & - & - \\
\hline \multirow{4}{*}{ Nest B } & $\theta_{\text {avg }}$ & 0.127 & 0.152 & 0.083 & 0.070 & 0.063 \\
\hline & $\theta_{\min }$ & 0.124 & 0.150 & 0.080 & 0.069 & 0.060 \\
\hline & $\theta_{\max }$ & 0.132 & 0.155 & 0.088 & 0.073 & 0.068 \\
\hline & $\theta_{\text {std }}$ & 0.0021 & 0.0014 & 0.0025 & 0.0012 & 0.0024 \\
\hline \multirow{4}{*}{ Nest C } & $\theta_{\text {avg }}$ & 0.079 & 0.058 & 0.064 & 0.051 & 0.070 \\
\hline & $\theta_{\min }$ & 0.076 & 0.054 & 0.061 & 0.048 & 0.068 \\
\hline & $\theta_{\max }$ & 0.089 & 0.067 & 0.072 & 0.059 & 0.075 \\
\hline & $\theta_{\text {std }}$ & 0.0033 & 0.0031 & 0.0026 & 0.0026 & 0.0015 \\
\hline \multirow{4}{*}{ Nest D } & $\theta_{\text {avg }}$ & 0.085 & 0.165 & 0.051 & 0.087 & 0.090 \\
\hline & $\theta_{\min }$ & 0.082 & 0.164 & 0.048 & 0.084 & 0.087 \\
\hline & $\theta_{\max }$ & 0.097 & 0.169 & 0.062 & 0.096 & 0.099 \\
\hline & $\theta_{\text {std }}$ & 0.0033 & 0.0012 & 0.0027 & 0.0023 & 0.0022 \\
\hline
\end{tabular}

$\dagger$ The CP in Nest A was not functioning correctly during this period 
Table 4.3. Water content changes from May 4 to September 30, 2008

\begin{tabular}{||c|c|c|c|c|c||}
\hline \multirow{2}{*}{ Nest } & \multicolumn{5}{|c||}{ Depth (m) } \\
\cline { 2 - 6 } & 0.6 & 0.9 & 1.3 & 1.8 & 2.3 \\
\hline $\mathrm{A}^{\dagger}$ & - & - & - & - & - \\
\hline $\mathrm{B}$ & -0.0079 & -0.0047 & -0.0071 & -0.0038 & -0.0070 \\
\hline $\mathrm{C}$ & -0.0087 & -0.0079 & -0.0068 & -0.0079 & -0.0045 \\
\hline $\mathrm{D}$ & -0.0072 & $-\mathrm{H}$ & -0.0069 & -0.0062 & -0.0063 \\
\hline
\end{tabular}

† The CP in Nest A was not functioning correctly during this period

tt The CP in Nest D was not functioning correctly until August 23, 2008.

The soil-water dynamics are also shown by the soil-water content profiles for Nests A and B on selected dates (Figure 4.4). For Nest B, the soil profile was the driest at the beginning of FY08. The soil water contents became higher as shown by the curves on December 1, 2006. From then on, there was more precipitation infiltrated into the soil, and the soil profile was wettest between February and April, 2008. After that, the soil started losing water and gradually became drier. From June 1 to August 1, 2008, there was little change in soil-water conditions.

The statistics of soil water content (i.e., average, minimum, and maximum and the standard deviation of $\theta$ ) for Nests A and B are summarized in Table 4.1. The standard deviation of $\theta$ in Nest B was between 0.0039 and $0.0068 \mathrm{~m}^{3} \mathrm{~m}^{-3}$. To compare the soil water conditions from different instrument nests, the statistics of $\theta$ between May 4 and Sept. 30, 2008 are summarized in Table 4.2. Generally, the variation of $\theta$ for Nests B, C and D were very small. The STD of $\theta$ were no more than $0.0033 \mathrm{~m}^{3} \mathrm{~m}^{-3}$. The water content changes from May 4 to September 30, 2008, are summarized in Table 4.3. The soil became dryer at all the depths for all the nests.

\subsubsection{Neutron-Probe Measurements}

Four neutron loggings were carried out for Nests A, C and D on the same dates. For Nest B, the logging in January could not be done due to the raised ground surface elevation during the surface barrier construction (the neutron access tube in Nest B was not extended tall enough. An extension was added later). The normalized neutron counts are shown in Figure 4.5. The depth-averaged normalized neutron counts are summarized in Table 4.4 to Table 4.7. For all the instrument nests, the soil was wetting from October 2007 to April 2008 but was drying up from April to July 2008. 

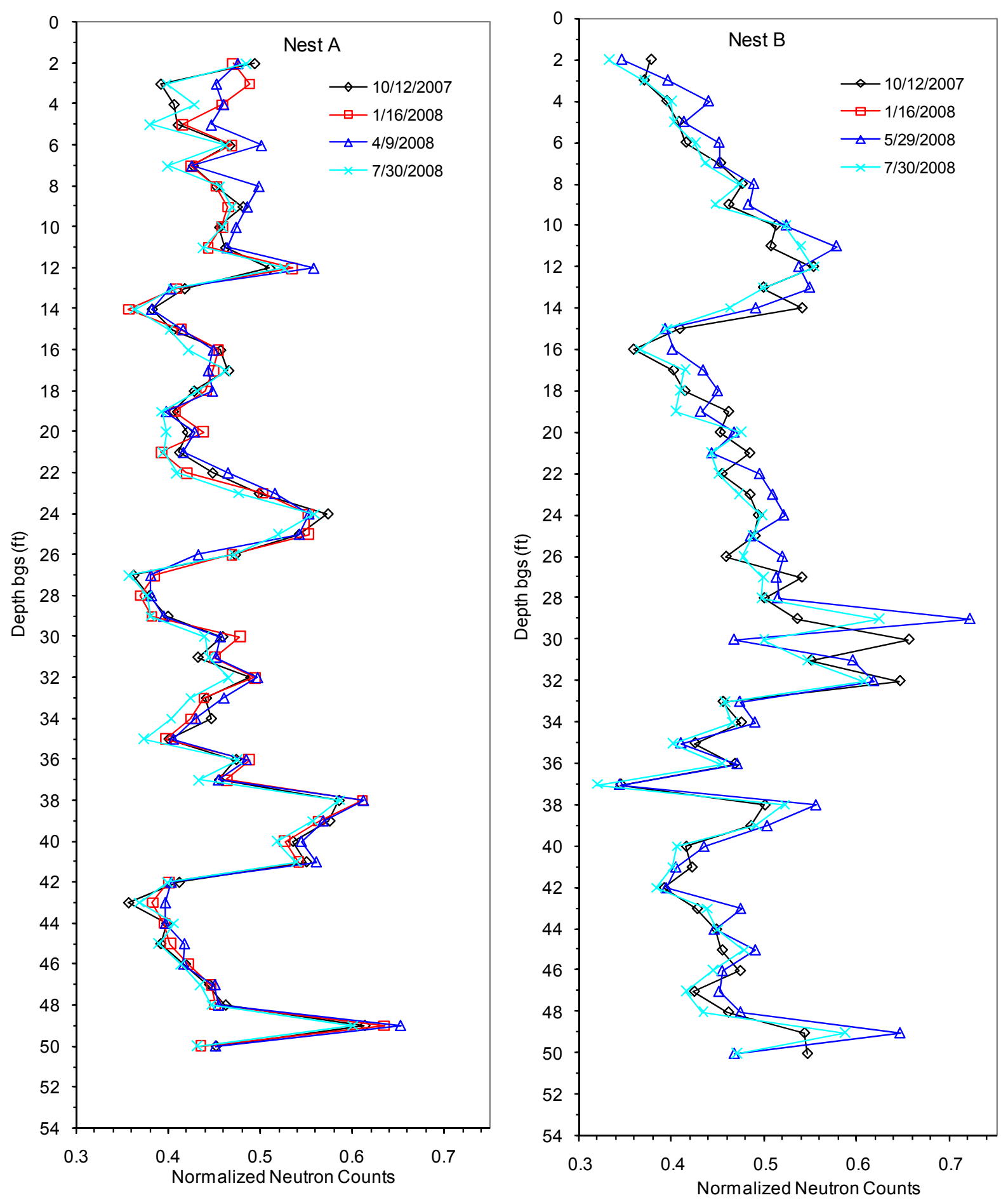

Figure 4.5. Normalized Neutron Counts Measured Using Neutron Probes at Different Depths (The depth bgs was relative to the ground surface before barrier construction. For Nest B, the logging in January could not be done due to the raised ground surface elevation during the surface barrier construction) 

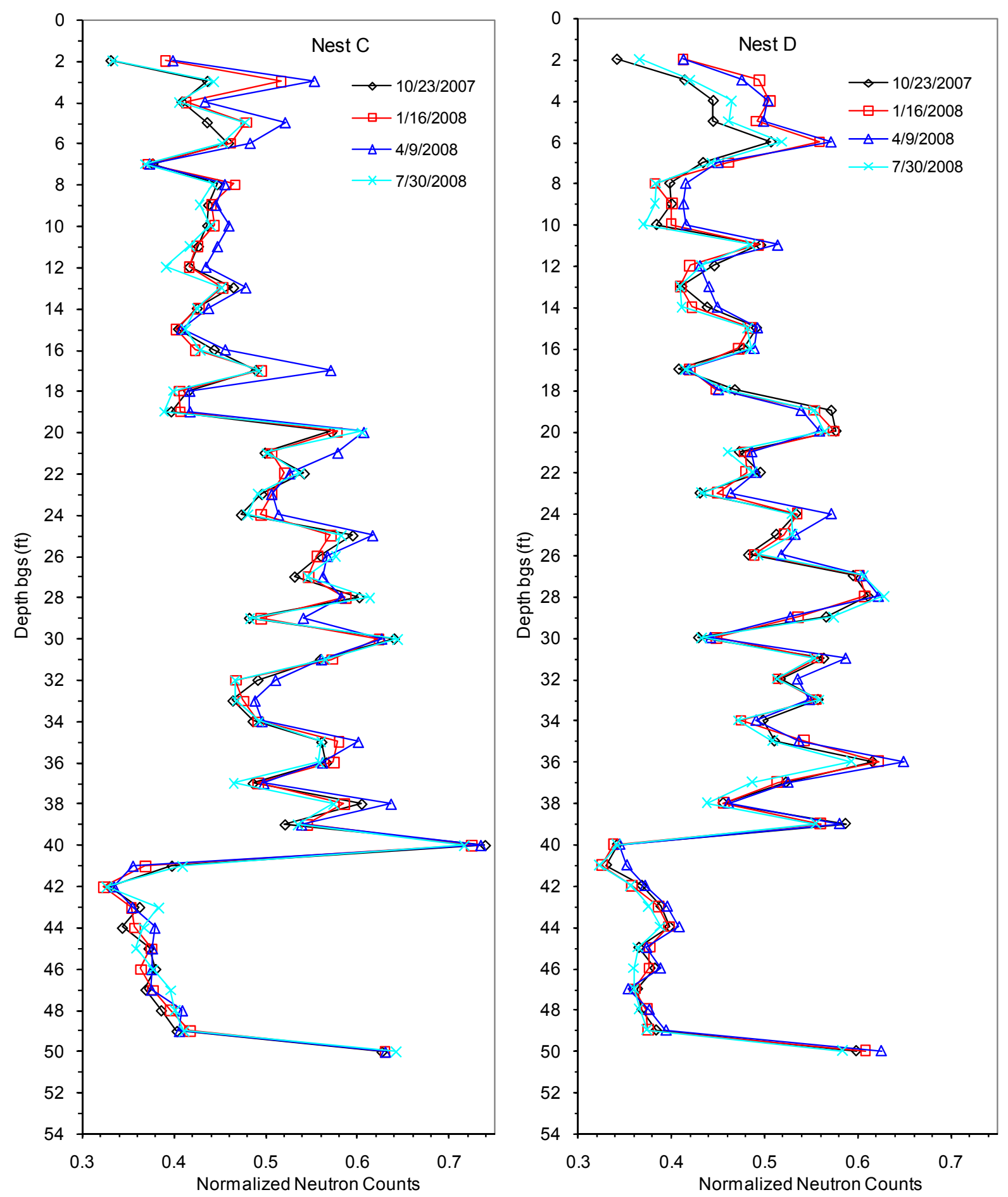

Figure 4.5. Normalized Neutron Counts Measured Using Neutron Probes at Different Depths (Cont.) 
Table 4.4. The Depth-Averaged Normalized Neutron Counts for Nest A

\begin{tabular}{|c|c|c|c|c|}
\hline Depth & $10 / 12 / 2007$ & $1 / 16 / 2008$ & $4 / 9 / 2008$ & $7 / 30 / 2008$ \\
\hline $2-3 \mathrm{ft}(0.61-0.91 \mathrm{~m})$ & 0.442 & 0.479 & 0.464 & 0.442 \\
\hline $4-6 \mathrm{ft}(1.22-1.83 \mathrm{~m})$ & 0.427 & 0.448 & 0.469 & 0.423 \\
\hline $7-10 \mathrm{ft}(2.13-3.05 \mathrm{~m})$ & 0.454 & 0.450 & 0.471 & 0.446 \\
\hline $11-20 \mathrm{ft}(3.35-6.10 \mathrm{~m})$ & 0.435 & 0.435 & 0.439 & 0.424 \\
\hline $21-30 \mathrm{ft}(6.40-9.14 \mathrm{~m})$ & 0.454 & 0.450 & 0.454 & 0.438 \\
\hline $31-40 \mathrm{ft}(9.45-12.19 \mathrm{~m})$ & 0.483 & 0.486 & 0.491 & 0.468 \\
\hline $41-50 \mathrm{ft}(12.50-15.24 \mathrm{~m})$ & 0.450 & 0.451 & 0.460 & 0.443 \\
\hline $2-50 \mathrm{ft}(0.61-15.24 \mathrm{~m})$ & 0.453 & 0.456 & 0.462 & 0.442 \\
\hline
\end{tabular}

Table 4.5. The Depth-Averaged Normalized Neutron Counts for Nest B

\begin{tabular}{|c|c|c|c|c||}
\hline Depth & $10 / 12 / 2007$ & $1 / 16 / 2008$ & $5 / 29 / 2008$ & $7 / 30 / 2008$ \\
\hline 2-3 ft (0.61-0.91 m) & 0.373 & - & 0.371 & 0.351 \\
\hline 4-6 ft (1.22-1.83 m) & 0.405 & - & 0.435 & 0.408 \\
\hline $7-10 \mathrm{ft}(2.13-3.05 \mathrm{~m})$ & 0.475 & - & 0.486 & 0.469 \\
\hline $11-20 \mathrm{ft}(3.35-6.10 \mathrm{~m})$ & 0.459 & - & 0.473 & 0.451 \\
\hline $21-30 \mathrm{ft}(6.40-9.14 \mathrm{~m})$ & 0.509 & - & 0.519 & 0.494 \\
\hline $31-40 \mathrm{ft}(9.45-12.19 \mathrm{~m})$ & 0.476 & - & 0.489 & 0.466 \\
\hline $41-50 \mathrm{ft}(12.50-15.24 \mathrm{~m})$ & 0.458 & - & 0.470 & 0.449 \\
\hline $2-50 \mathrm{ft}(0.61-15.24 \mathrm{~m})$ & 0.467 & - & 0.480 & 0.457 \\
\hline
\end{tabular}

Table 4.6. The Depth-Averaged Normalized Neutron Counts for Nest C

\begin{tabular}{||c|c|c|c|c||}
\hline Depth $^{\dagger}$ & $10 / 23 / 2007$ & $1 / 16 / 2008$ & $4 / 9 / 2008$ & $7 / 30 / 2008$ \\
\hline 2-3 ft (0.61-0.91 m) & 0.384 & 0.454 & 0.476 & 0.389 \\
\hline 4-6 ft (1.22-1.83 m) & 0.435 & 0.451 & 0.480 & 0.445 \\
\hline $7-10 \mathrm{ft}(2.13-3.05 \mathrm{~m})$ & 0.424 & 0.431 & 0.434 & 0.420 \\
\hline $11-20 \mathrm{ft}(3.35-6.10 \mathrm{~m})$ & 0.446 & 0.443 & 0.468 & 0.442 \\
\hline $21-30 \mathrm{ft}(6.40-9.14 \mathrm{~m})$ & 0.542 & 0.541 & 0.562 & 0.545 \\
\hline $31-40 \mathrm{ft}(9.45-12.19 \mathrm{~m})$ & 0.548 & 0.551 & 0.563 & 0.540 \\
\hline $41-50 \mathrm{ft}(12.50-15.24 \mathrm{~m})$ & 0.397 & 0.396 & 0.400 & 0.407 \\
\hline 2-50 ft (0.61-15.24 m) & 0.471 & 0.475 & 0.491 & 0.472 \\
\hline
\end{tabular}

† The depth for Nest $\mathrm{C}$ was relative to the ground surface before barrier construction 
Table 4.7. The Depth-Averaged Normalized Neutron Counts for Nest D

\begin{tabular}{|c|c|c|c|c|}
\hline Depth $^{\dagger}$ & $10 / 23 / 2007$ & $1 / 16 / 2008$ & $4 / 9 / 2008$ & $7 / 30 / 2008$ \\
\hline $2-3 \mathrm{ft}(0.61-0.91 \mathrm{~m})$ & 0.378 & 0.453 & 0.445 & 0.393 \\
\hline 4-6 ft $(1.22-1.83 \mathrm{~m})$ & 0.466 & 0.519 & 0.525 & 0.482 \\
\hline $7-10 \mathrm{ft}(2.13-3.05 \mathrm{~m})$ & 0.404 & 0.411 & 0.424 & 0.395 \\
\hline $11-20 \mathrm{ft}(3.35-6.10 \mathrm{~m})$ & 0.479 & 0.470 & 0.479 & 0.470 \\
\hline $21-30 \mathrm{ft}(6.40-9.14 \mathrm{~m})$ & 0.513 & 0.515 & 0.526 & 0.518 \\
\hline $31-40 \mathrm{ft}(9.45-12.19 \mathrm{~m})$ & 0.517 & 0.513 & 0.526 & 0.502 \\
\hline $41-50 \mathrm{ft}(12.50-15.24 \mathrm{~m})$ & 0.395 & 0.394 & 0.404 & 0.385 \\
\hline $2-50 \mathrm{ft}(0.61-15.24 \mathrm{~m})$ & 0.466 & 0.470 & 0.480 & 0.460 \\
\hline
\end{tabular}

† The depth for Nest $\mathrm{D}$ was relative to the ground surface before barrier construction

\subsection{Soil-Water-Pressure Head}

Figure 4.6 shows the soil-water pressure $(\psi)$ measured by the HDUs after temperature correction. Figure 4.7 shows soil-water-pressure head profiles on selected dates. Note that the logging of the sensors in Nests C and D did not start until May 4, 2008, when the surface barrier construction had completed. Based on the results from Nests A and B, the sensors at the $1.0-\mathrm{m}$ depth showed significant increase in soil-water pressures in late November and/or early December 2007, which indicate increased water content. As also indicated by the increased water content at $0.6-\mathrm{m}$ and $0.9-\mathrm{m}$ depth measured with CPs, this increase was likely caused by the sprinkling of water from late October to mid-November 2007. The maximum values of soil-water-pressure head occurred in February 2008 due to the winter precipitation. The sensors at the 2.0-m depth showed increased soil-water pressures from January to late February or early March 2008 before they started decreasing.

From May to September 2008, the soil water pressure head at 1-m and 2-m depths decreased for all the instrument nests primarily due to the drainage of soil water. During this period, the meteoric precipitation was very limited and might be evaporated completely due to summer high temperature. Comparing with the 1-m and 2-m depth pressure heads, the soil-water pressures at 5- and 10-m (9-m for Nest C) depths were more stable. 

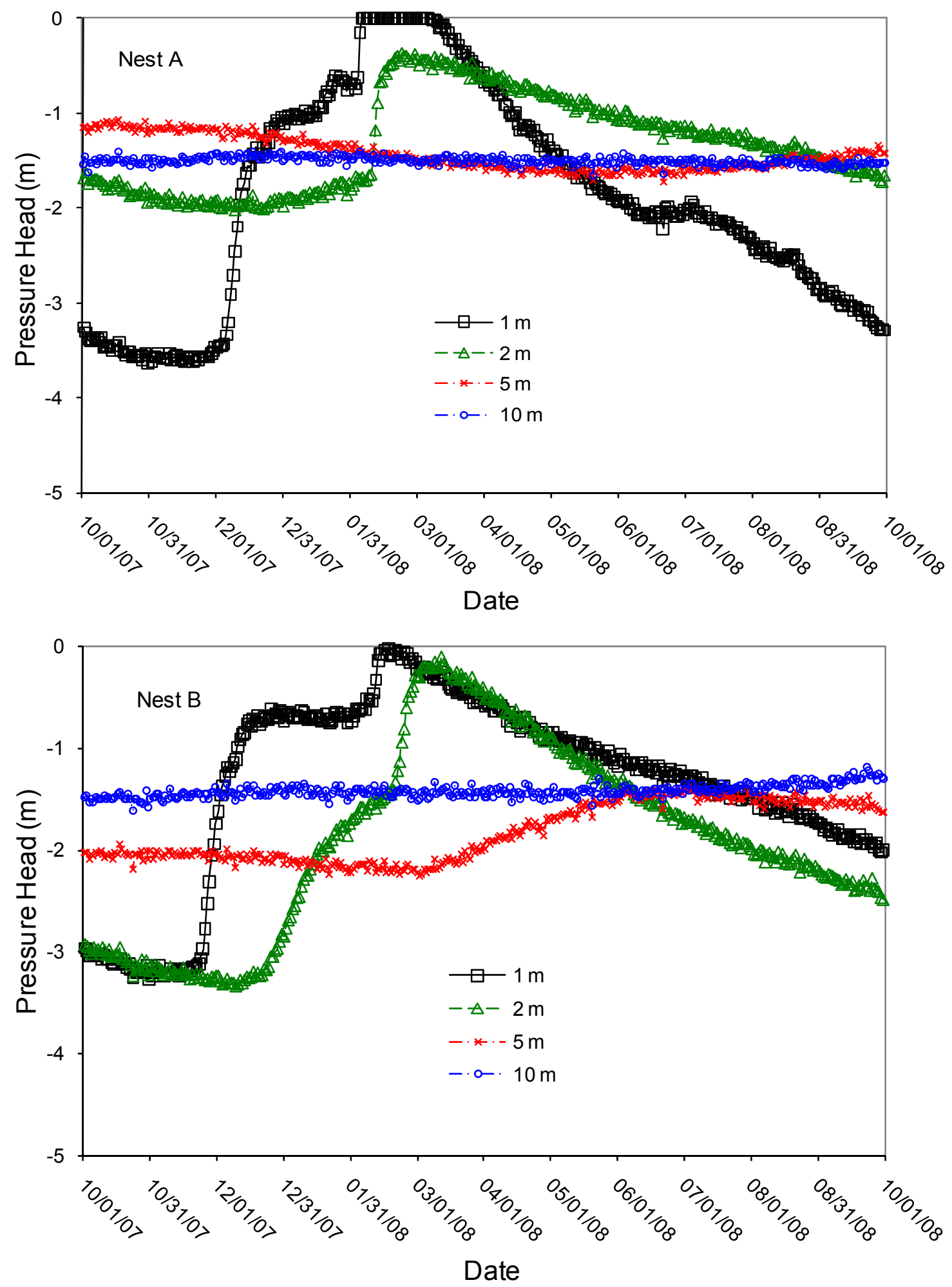

Figure 4.6. Daily Average Soil-Water Pressure at Different Depths Measured Using the HDUs (the sensors in Nests C and D started logging on May 4, 2008) 

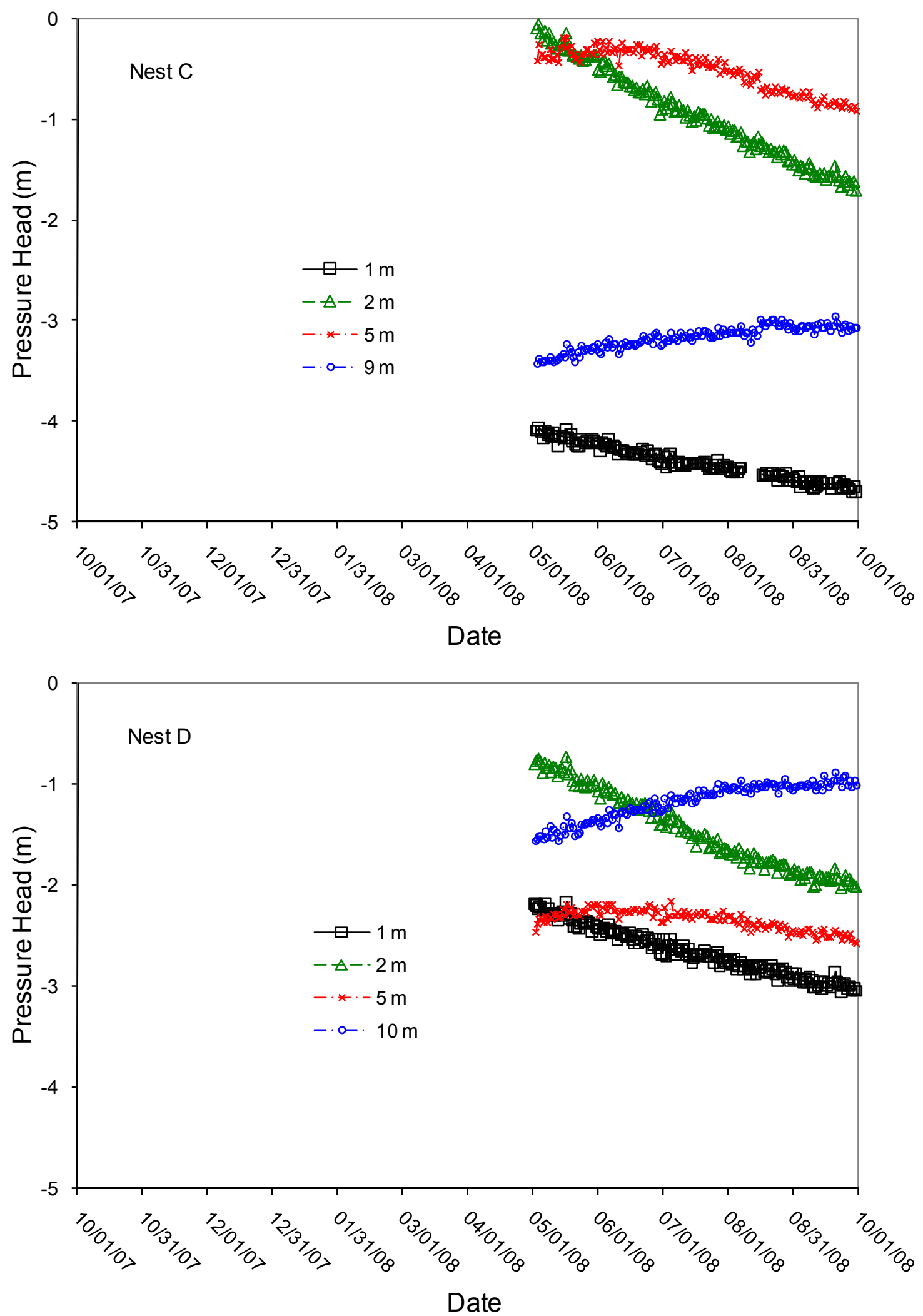

Figure 4.6. Daily Average Soil-Water Pressure at Different Depths Measured Using the HDUs (the sensors in Nests C and D started logging on May 4, 2008) (Cont.) 

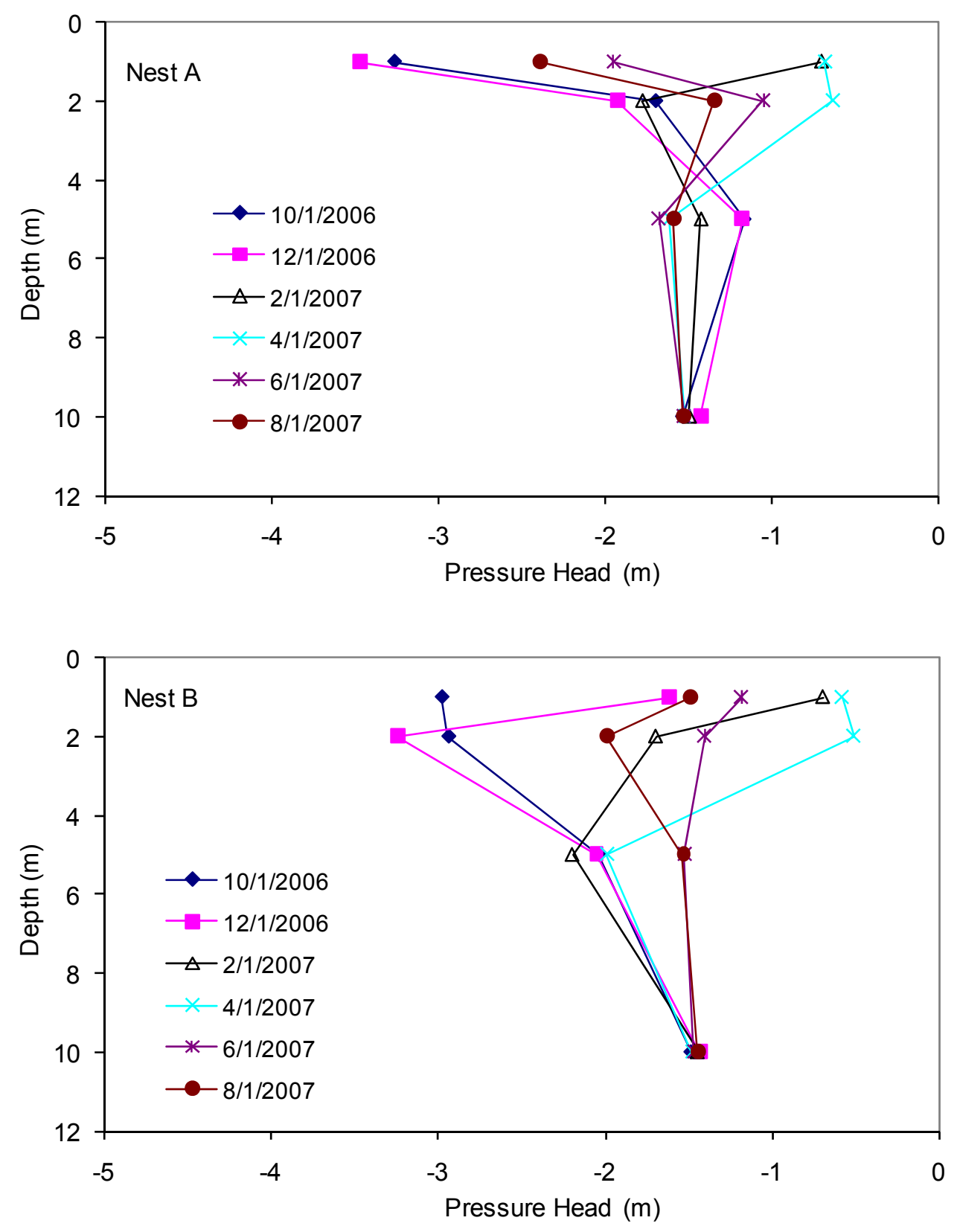

Figure 4.7. Soil-Water-Pressure Head Profiles on Selected Dates Using the HDUs (the sensors in Nests C and D started logging on May 4, 2008) 

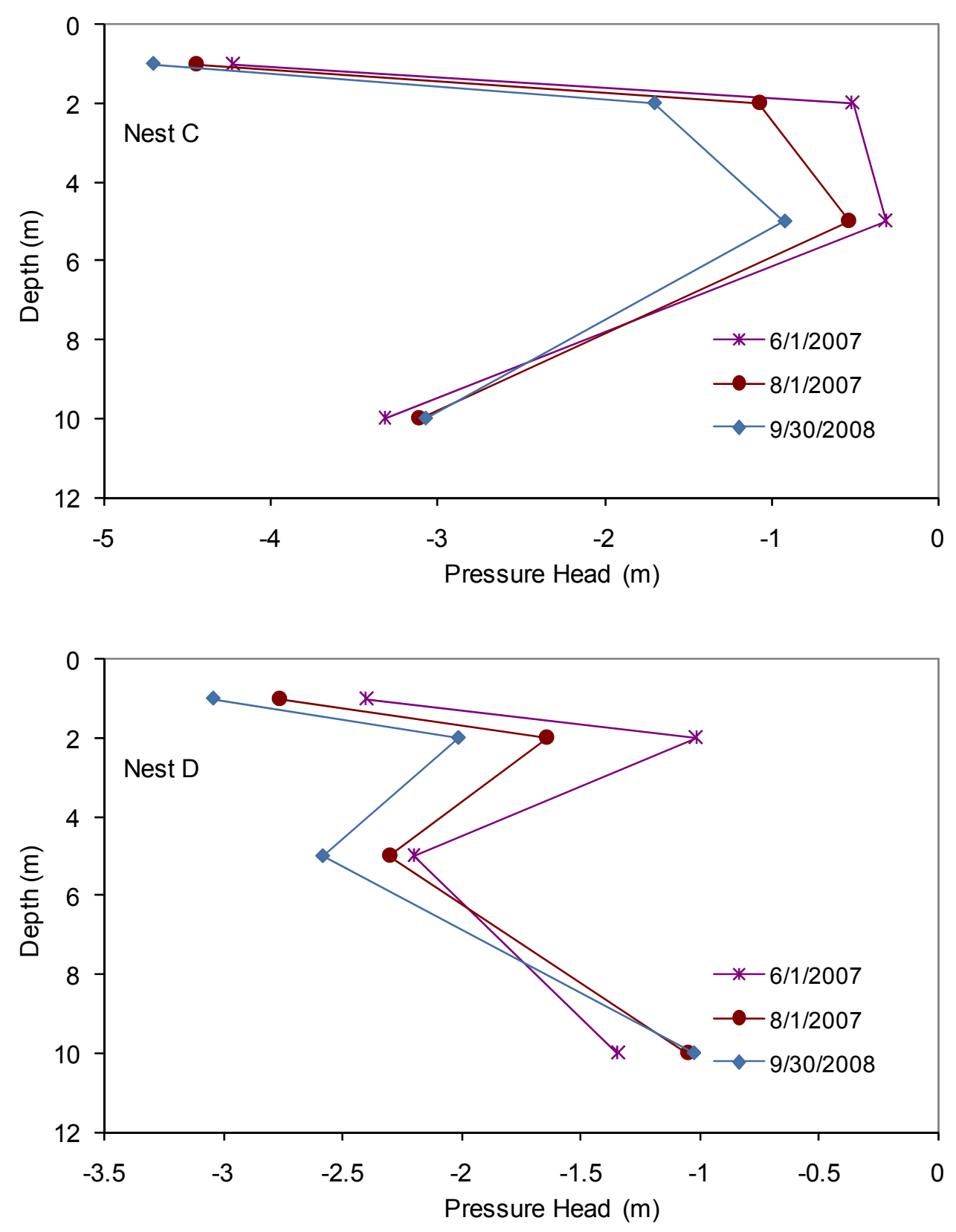

Figure 4.7. Soil-Water-Pressure Head Profiles on Selected Dates Using the HDUs (the sensors in Nests C and D started logging on May 4, 2008) (Cont.)

The HDU-measured annual average $\left(\psi_{\text {avg }}\right)$, minimum $\left(\psi_{\min }\right)$, and maximum $\left(\psi_{\max }\right)$ pressure head and the standard deviation of $\psi\left(\psi_{\text {std }}\right)$ for Nests A and B are summarized in Table 4.8. For Nest A, the standard deviations of $\psi$ were between 0.04 and $1.15 \mathrm{~m}$ water-height, with smaller variations in deeper soil. For Nest B, the standard deviations of $\psi$ were between 0.062 and $0.94 \mathrm{~m}$ water-height, with largest variations in the 1-m depth soil. 
Table 4.8. The HDU-Measured Average ( $\left.\psi_{\text {avg }}\right)$, Minimum $\left(\psi_{\min }\right)$, Maximum $\left(\psi_{\max }\right)$, and Standard Deviation $\left(\psi_{\text {std }}\right)$ of Soil-Water-Pressure Head for Nests A and B

\begin{tabular}{||c|c|c|c|c|c||}
\hline \multirow{2}{*}{ Nest } & \multirow{2}{*}{ Item } & \multicolumn{4}{|c||}{ Depth } \\
\cline { 3 - 6 } & & $1 \mathrm{~m}$ & $2 \mathrm{~m}$ & $5 \mathrm{~m}$ & $10 \mathrm{~m}$ \\
\hline \multirow{3}{*}{ Nest A } & $\psi_{\text {avg }}$ & -1.90 & -1.33 & -1.43 & -1.50 \\
\cline { 2 - 6 } & $\psi_{\min }$ & -3.64 & -2.03 & -1.73 & -1.65 \\
\cline { 2 - 6 } & $\psi_{\max }$ & 0.00 & -0.36 & -1.07 & -1.40 \\
\cline { 2 - 6 } & $\psi_{\text {std }}$ & 1.154 & 0.512 & 0.175 & 0.040 \\
\hline \multirow{3}{*}{ Nest B } & $\psi_{\text {avg }}$ & -1.35 & -1.90 & -1.84 & -1.43 \\
\cline { 2 - 6 } & $\psi_{\min }$ & -3.28 & -3.34 & -2.26 & -1.62 \\
\cline { 2 - 6 } & $\psi_{\max }$ & -0.02 & -0.10 & -1.39 & -1.19 \\
\cline { 2 - 6 } & $\psi_{\text {std }}$ & 0.904 & 0.944 & 0.286 & 0.062 \\
\hline
\end{tabular}

Table 4.9. The HDU-Measured Average ( $\left.\psi_{\text {avg }}\right)$, Minimum ( $\left.\psi_{\min }\right)$, Maximum ( $\left.\psi_{\max }\right)$, and Standard Deviation $\left(\psi_{\text {std }}\right)$ of Soil-Water-Pressure Head for All Nests After May 4, 2008

\begin{tabular}{||c|c|c|c|c|c||}
\hline \multirow{3}{*}{ Nest } & \multirow{2}{*}{ Item } & \multicolumn{4}{|c||}{ Depth } \\
\cline { 3 - 6 } & & $1 \mathrm{~m}$ & $2 \mathrm{~m}$ & $5 \mathrm{~m}$ & $10 \mathrm{~m}^{\dagger}$ \\
\hline \multirow{4}{*}{ Nest A } & $\psi_{\text {avg }}$ & -2.31 & -1.25 & -1.56 & -1.52 \\
\cline { 2 - 6 } & $\psi_{\min }$ & -3.29 & -1.73 & -1.73 & -1.65 \\
\cline { 2 - 6 } & $\psi_{\max }$ & -1.43 & -0.81 & -1.34 & -1.41 \\
\cline { 2 - 6 } & $\psi_{\text {std }}$ & 0.485 & 0.232 & 0.081 & 0.035 \\
\hline \multirow{4}{*}{ Nest B } & $\psi_{\text {avg }}$ & -1.43 & -1.80 & -1.52 & -1.39 \\
\cline { 2 - 6 } & $\psi_{\min }$ & -2.03 & -2.49 & -1.71 & -1.57 \\
\cline { 2 - 6 } & $\psi_{\max }$ & -0.90 & -0.96 & -1.39 & -1.19 \\
\cline { 2 - 6 } & $\psi_{\text {std }}$ & 0.312 & 0.423 & 0.068 & 0.063 \\
\hline & $\psi_{\text {avg }}$ & -4.40 & -0.95 & -0.51 & -3.16 \\
\cline { 2 - 6 } & $\psi_{\min }$ & -4.70 & -1.70 & -0.92 & -3.42 \\
\cline { 2 - 6 } & $\psi_{\max }$ & -4.06 & -0.06 & -0.19 & -2.95 \\
\cline { 2 - 6 } & $\psi_{\text {std }}$ & 0.173 & 0.455 & 0.210 & 0.112 \\
\hline & $\psi_{\text {avg }}$ & -2.66 & -1.45 & -2.35 & -1.18 \\
\cline { 2 - 6 } & $\psi_{\min }$ & -3.05 & -2.02 & -2.58 & -1.56 \\
\cline { 2 - 6 } & $\psi_{\max }$ & -2.16 & -0.73 & -2.16 & -0.89 \\
\cline { 2 - 6 } & $\psi_{\text {std }}$ & 0.240 & 0.385 & 0.099 & 0.178 \\
\hline \multirow{5}{*}{ Nest D } & & & & \\
\hline \hline
\end{tabular}

† $9 \mathrm{~m}$ for Nest C. 
The HDU-measured $\psi_{\text {avg }}, \psi_{\min }, \psi_{\max }$ and $\psi_{\text {std }}$ from May 4 to Sept. 30, 2008, for all the four instrument nests are summarized in Table 4.9. Generally, the actual pressure head values among different nests are not comparable due to the spatial heterogeneity of soil. However, the temporal variation relative to the mean at 1-m and 2-m depths were different between Nest A, which was outside of the barrier footprint, and Nests B, C and D, which were below the barrier. At the 1-m depth, $\psi_{\text {std }}$ was the largest for Nest A; at the 2-m depth, $\psi_{\text {std }}$ was the smallest for Nest A. At the 5-m and 10-m depth, there is no systematic differences.

Table 4.10 summarizes the soil-water-pressure head changes from May 4 to September 30, 2008. At 1-m and 2-m depths, the pressure head in all the instrument nests decreased by 0.6 to $1.8 \mathrm{~m}$. This was due to the effects of drainage to deeper soil (for all the nests) and/or evaporation to the atmosphere (for Nest A). The pressure-head changes at 5-m and 10-m depths were relatively small.

Table 4.10. Soil-water-pressure head changes from May 4 to September 30, 2008

\begin{tabular}{||c|c|c|c|c||}
\hline \multirow{2}{*}{ Nest } & \multicolumn{4}{|c||}{ Depth $(\mathrm{m})$} \\
\cline { 2 - 5 } & 1 & 2 & 5 & 10 \\
\hline A & -1.84 & -0.82 & 0.22 & -0.02 \\
\hline B & -1.09 & -1.50 & 0.08 & 0.18 \\
\hline C & -0.60 & -1.55 & -0.57 & 0.33 \\
\hline D & -0.81 & -1.26 & -0.24 & 0.50 \\
\hline
\end{tabular}

\subsection{Effects of Surface Barrier on Soil Water Condition}

The construction of the surface barrier was completed in April 2008. The barrier is impermeable to any liquid or gas and there should be no exchange of water between the atmosphere and the soil beneath the barrier. Hence, it was expected that the soil water contents and pressure head beneath the surface barrier (Nests B, C and D) would decrease gradually. During the period from May to September 2008, the water content measurements from the capacitance probes, neutron count ratio (as an indication of soil water content) from the NP, and the soil-water pressure head measurements from the HDUs showed that the soil beneath the barrier within 0 to $2 \mathrm{~m}$ depth was drying. This confirms that the antecedent soil water was draining out from the soil. There were no significant changes of soil water condition in the soil below $2 \mathrm{~m}$ due to the draining water from the soil above. It is mentioned that the soil outside of the barrier footprint (Nest A) was also drying during the same period of time. However, the causes for this drying-up is twofold: the drainage to deeper soil and the evaporation to the atmosphere.

It is pointed out that measurements from Nests $\mathrm{C}$ and $\mathrm{D}$ can represent only the local soil water conditions. If further confirmation of the performance of the barrier is needed, a surface survey with a geophysical instrument (e.g., the ground-penetrating radar) may be conducted to map the soil water condition beneath the whole surface barrier.

\subsection{Instrument Performance}

The instrument performance is assessed against the indicators given in Table 6.2 of the Monitoring Plan and is given in Table 4.11. The performances of all instruments except three of the HDUs were within the ranges of the performance. However, although 8 of the 16 HDUs reported values larger (wetter) than the upper bound of the performance indicators $(-1 \mathrm{~m})$, this does not necessarily indicate the malfunction of 
the instruments but very wet soil conditions (wetter than $-1 \mathrm{~m}$ pressure head) and/or the uncertainty of the HDU calibration curve [Eq. (2.5)]. However, as mentioned before, the 5-m depth HDU in Nest $\mathrm{C}$ seemed to give consistent high pressure head values larger than $-1 \mathrm{~m}$. There is a possibility that this HDU did not perform correctly. This will be further investigated.

Table 4.11. Instrument Performance

\begin{tabular}{|c|c|c|c|}
\hline Monitoring Method & Monitoring Component & $\begin{array}{l}\text { Performance } \\
\text { Indicator }\end{array}$ & $\begin{array}{c}\text { Within the Indicated } \\
\text { Range? }\end{array}$ \\
\hline \multirow{2}{*}{ Neutron Moisture Probe } & \multirow{2}{*}{ Soil-Water Content $(\theta)$} & $0.75 \leq \mathrm{SDR} \leq 1.25$ & Yes \\
\hline & & $S C= \pm 0.98 \times \sqrt{P S C}$ & Yes \\
\hline Capacitance Probe & Soil-Water Content $(\theta)$ & $0 \leq \theta_{\mathrm{v}} \leq \theta_{\mathrm{s}}$ & Yes \\
\hline Heat Dissipation Unit & Soil-Water Pressure $(\psi)$ & $-100 \mathrm{~m} \leq \psi \leq-1 \mathrm{~m}$ & Yes and $\mathrm{No}^{(\mathrm{a})}$ \\
\hline Heat Dissipation Unit & Soil Temperature $\left(\mathrm{T}_{\text {soil }}\right)$ & $0^{\circ} \mathrm{C} \leq \mathrm{T}_{\text {soil }} \leq 30^{\circ} \mathrm{C}$ & Yes \\
\hline Rain Gauge & Precipitation $(\mathrm{P})$ & $\begin{array}{l}\text { Annual value is within } \\
\pm 50 \% \\
\text { HMS measured } \mathrm{P}\end{array}$ & Yes \\
\hline Thermister & Air Temperature $\left(\mathrm{T}_{\text {air }}\right)$ & $\begin{array}{l}\text { Annual average is } \\
\text { within } \pm 5 \% \quad \mathrm{HMS} \mathrm{T}_{\text {air }}\end{array}$ & Yes \\
\hline \multicolumn{4}{|c|}{$\begin{array}{l}\text { SDR }- \text { standard deviation ratio of neutron count } \\
\text { SC - standard count } \\
\text { PSC - previous standard count } \\
\text { (a) Most pressure-head measurements were within the indicated range, while some values were larger than }-1 \mathrm{~m} \text { as } \\
\text { shown in Figure 4.6. }\end{array}$} \\
\hline
\end{tabular}





\subsection{Summary and Recommendations}

This section summarizes instrument functionality and results of measured soil-water conditions. It also presents recommendations for future monitoring activities.

\subsection{System Functionality}

During FY08, the battery voltage at the meteorological station and instrument Nests A and B all remained above $12.5 \mathrm{~V}$, denoting that the battery voltages were sufficient for the stations to remain functional. The air temperature at the T Tank Farm meteorological station and that measured at the HMS were very similar, supporting the functionality of the temperature sensor. The soil temperature as measured by the HDUs produced typical trends with depth and compared similarly to soil-temperature data in FY07 and indicated the normal function of the HDU sensors when they were used to measure soil temperature. The good agreement of air temperature, precipitation, and soil-temperature measurements indicates normal functionality of the vadose zone monitoring system.

Cumulative precipitation measured at the T Tank Farm was less than that measured at the HMS. All the $\mathrm{CP}$ sensors were functional except the CP in Nest A and the 0.9-m-depth sensor in Nest D. The capacitance in Nest A was not functioning after January 31, 2008. The 0.9-m depth CP sensor showed noisy data before August 23, 2008. All the HDUs were functional but some pressure-head values measured by HDUs were greater than the upper measurement-limit.

\subsection{Soil Water Conditions}

Similar to FY07, under natural conditions, the soil is recharged during the winter period (October-March) and discharged during the summer period (April-September). Soil water conditions above about $2 \mathrm{~m}$ depth from all three types of measurements (i.e., CP, NP and HDU) showed relatively large variation during the seasonal wetting-drying cycle. For the soil below $2 \mathrm{~m}$ depth, the seasonal variation of soil water content was relatively small.

The construction of the surface barrier was completed in April 2008. During the period from May to September 2008, the soil-water conditions from three types of measurements showed that the soil beneath the barrier within 0 to $2 \mathrm{~m}$ depth became dryer. This confirms that the antecedent soil water was draining out from the soil.

\subsection{Lessons Learned}

The following lessons learned from the T Tank Farm monitoring experience are useful for any future instrument deployment and vadose zone monitoring. We have learned that the risers above the CPs need water-tight lids so that no water can enter into the CP access tubes; consistent procedures need to be used for CP-sensor normalization; it better to install sufficient temperature sensors at the depths corresponding to the depths of the CP sensors; HDUs need to be installed in a way that they can be repaired or replaced if problems happen; the upper bounds of the HDUs need to be measured before they are installed; the rain gauge requires regular maintenance. 


\subsection{Recommendations}

Based on the instrument performance and data obtained, we recommend completing neutron probe calibration so that the neutron logging can be converted to soil water content. 


\subsection{References}

Atlantic-Richfield Hanford Company (ARHCO). 1973. 241-T-106 Tank leak investigation. ARH_2874, Atlantic-Richfield Hanford Company, Richland, WA.

Baumhardt RL, RJ Lascano, and SR Evett. 2000. "Soil material, temperature, and salinity effects on calibration of multisensor capacitance probes." Soil Sci. Soc. Am. J. 64:1940-1946.

Campbell Scientific, Inc. 2004. Model 107 Temperature Probe Instruction Manual. Logan, UT.

Campbell Scientific, Inc. 2006. Water Matric Potential Sensor Models 229, CE4, CE8. Logan, UT.

CH2M HILL. 2006. 241-T Tank Farm Vadose Zone Instrumentation. CH2M HILL Engineering Change Notice, ECN-723963 R1, CH2M HILL Hanford Group, Inc., Richland, WA.

CH2M HILL. 2007. 241-T Tank Farm Vadose Zone Instrumentation. CH2M HILL Engineering Change Notice, ECN-724716 R2, CH2M HILL Hanford Group, Inc., Richland, WA.

Evett, SR JA Tolk, and TA Howell. 2006. "Soil profile water content determination: sensor accuracy, axial response, calibration, temperature dependence, and precision.” Vadose Zone Journal 5:894-907.

Flint AL, GS Campbell, KM Ellett, and C Calissendorff. 2002. "Calibration and temperature correction of heat dissipation matric potential sensors.” Soil Sci. Soc. Am. J. 66:1439-1445.

McMahon WJ. 2007. "Performance simulation of an interim surface barrier over the 242-T-106 Tank release.” In: AE Bauer, Design Analysis for T-Farm Interim Surface Barrier (TISB), Appendix A, RPP-33431 Rev. 0, CH2M HILL Hanford Group, Inc., Richland, WA.

Myers DA. 2005. Field Investigation Report for Waste Management Areas. RPR-23752, CH2M HILL Hanford Group, Richland, WA.

Paltineanu IC, and JL Starr. 1997. "Real-time soil water dynamics using multisensor capacitance probes: laboratory calibration." Soil Sci. Soc. Am. J. 61:1576-1585.

Ross L. 2007. Tank Farm Plant Operating Procedure - Operate Model 503DR Hydroprobe Neutron Moisture Detection. TO-320-022, B-8. CH2M HILL Hanford Group, Richland, WA.

Routson RC, WH Price, DJ Brown, and KR Fecht. 1979. High-level waste leakage from the 241-T-106 tank at Hanford. RHO-ST-14, Rockwell Hanford Operations, Richland, WA.

Sentek Pty Ltd. 2001. Calibration of the Sentek Pty Ltd Soil Moisture Sensors. Stepney, Australia.

Shiozawa S and GS Campbell. 1990. "Soil thermal conductivity.” Remote Sens. Rev. 5:301-310.

Zhang ZF, JM Keller, and CE Strickland. 2007. T Tank Farm Interim Surface Barrier Demonstration Vadose Zone Monitoring Plan. PNNL-16538, Pacific Northwest National Laboratory, Richland, WA. 
Zhang ZF, CE Strickland, JM Keller, CD Wittreich, and HA Sydnor. 2008. T Tank Farm Interim Surface Barrier Demonstration -Vadose Zone Monitoring FY07 Report. PNNL-17306, Pacific Northwest National Laboratory, Richland, WA. 


\section{Appendix A}

\section{Volume of Water Sprayed to Ground Surface}

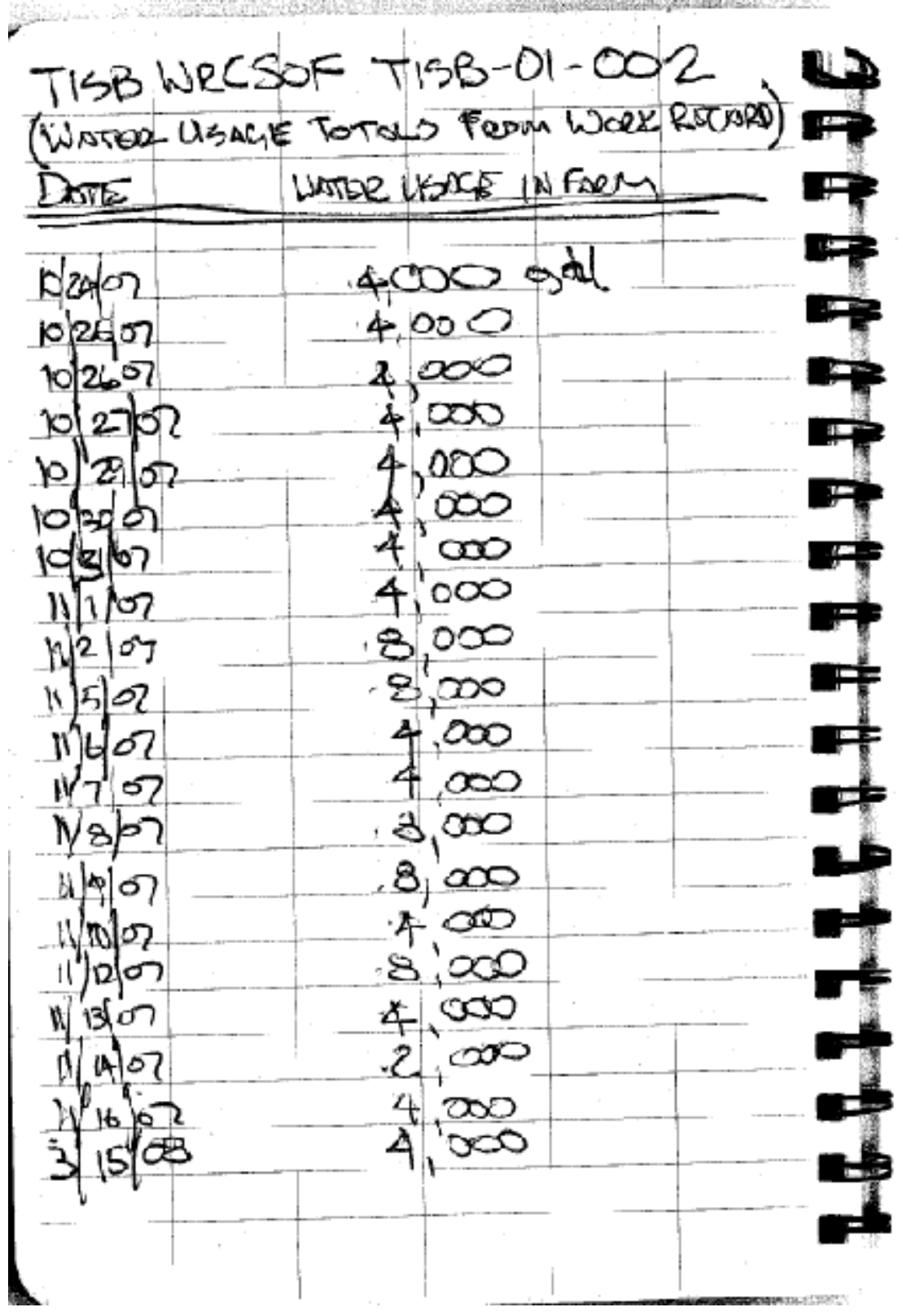





\section{Distribution}

No. of

Copies

\section{Local Distribution}

5 Pacific Northwest National Laboratory

ZF Zhang

CE Strickland

MJ Fayer

AL Ward

ML Rockhold
No. of

Copies

2 Washington River Protection Solutions Inc. JG Field

DL Parker

H6-03

H6-03

K9-33

K9-33

K9-33

K9-33

Distr.1 


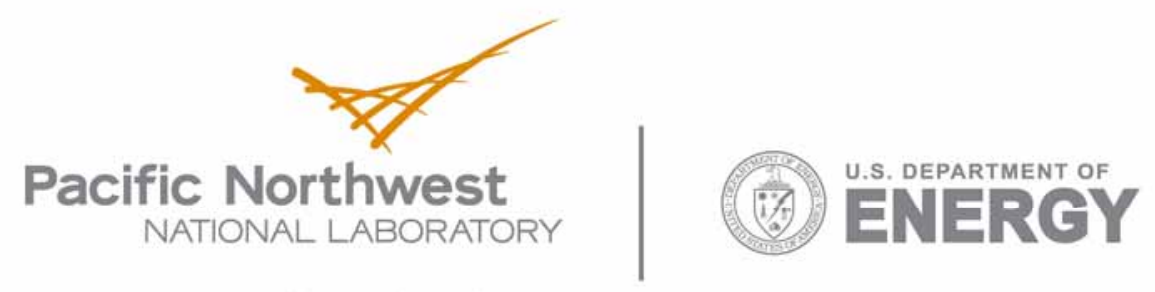

902 Battelle Boulevard

P.O. Box 999

Richland, WA 99352

1-888-375-PNNL (7665)

www.pnl.gov 